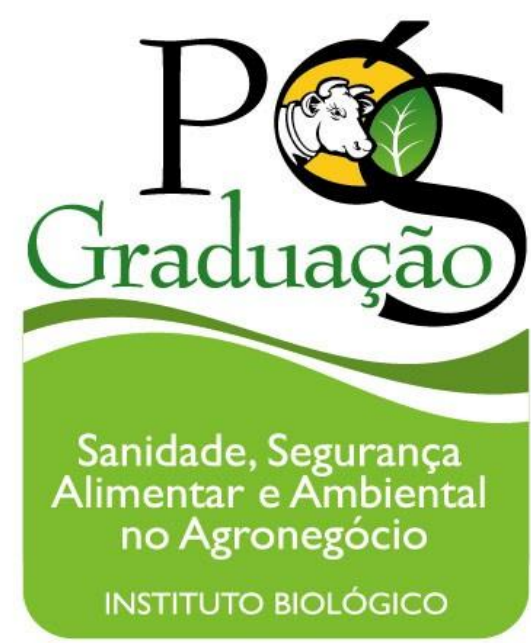

Caracterização da população de Phytophthora infestans (Mont) de

Bary em regiões produtoras de batata (Solanum tuberosum L.) no Brasil

\title{
Samantha Zanotta
}

Tese apresentada para a obtenção do título de Doutor em Sanidade, Segurança Alimentar e Ambiental no Agronegócio. Área de concentração: Segurança Alimentar e Sanidade no Agroecossistema

Área de Concentração: Sanidade, Segurança Alimentar e Ambiental no Agronegócio

Orientador (a): Prof (a). Dr (a). Ricardo Harakava

Co-orientador (a): Dr. Jesus Guerino, Töfoli 
Secretaria de Agricultura e Abastecimento do Estado de São Paulo Agência Paulista de Tecnologia dos Agronegócios

Instituto Biológico

Programa de Pós-Graduação em Sanidade, Segurança Alimentar e Ambiental no Agronegócio

Caracterização da população de Phytophthora infestans (Mont) de Bary em regiões produtoras de batata (Solanum tuberosum L.) no Brasil

\section{Samantha Zanotta}

Tese apresentada para a obtenção do título de Doutor em Sanidade, Segurança Alimentar e Ambiental no Agronegócio. Área de concentração: Segurança Alimentar e Sanidade no Agroecossistema 
Eu Samantha Zanotta, autorizo o Instituto Biológico (IB-APTA), da Secretaria de Agricultura e Abastecimento do Estado de São Paulo, a disponibilizar gratuitamente e sem ressarcimento dos direitos autorias, o presente trabalho acadêmico de minha autoria, no portal, biblioteca digital, catálogo eletrônico ou qualquer outra plataforma eletrônica do IB para fins de leitura, estudo, pesquisa e/ou impressã̃o pela Internet desde que citada a fonte.

Assinatura: Data

Dados Internaclonals de Catalogaçào na Publicaçăo (CIP) Secretarla de Agricultura $\theta$ Abastecimento do Estado de Săo Paulo Núcieo de Informaçăo $\theta$ Documentaçào - IB

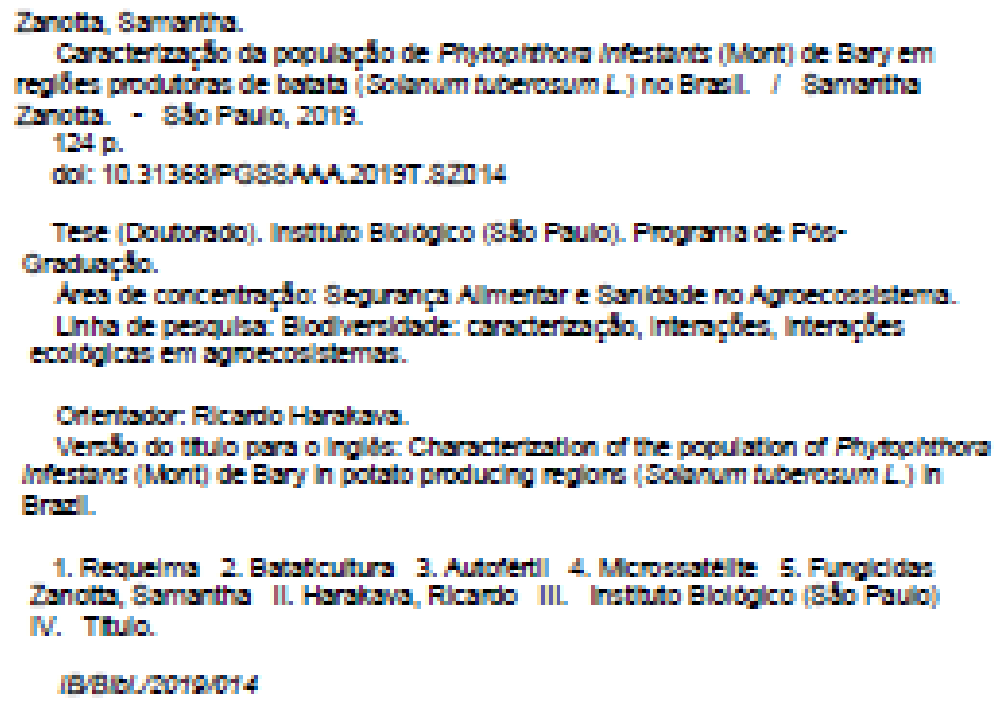

IBBEL/2018014 


\section{FOLHA DE APROVAÇÃO}

Nome: Samantha Zanotta

Título: Caracterização da população de Phytophthora infestans (Mont) de Bary em regiões produtoras de batata (Solanum tuberosum L.) no Brasil

Tese apresentada ao Programa de Pós-graduação em Sanidade, Segurança Alimentar e Ambiental no Agronegócio do Instituto Biológico, Agência Paulista de Tecnologia dos Agronegócios, da Secretaria de Agricultura e Abastecimento do Estado de São Paulo para a obtenção do título de Doutor em Sanidade, Segurança Alimentar e Ambiental no Agronegócio.

Aprovado em: 301712019

Banca Examinadora

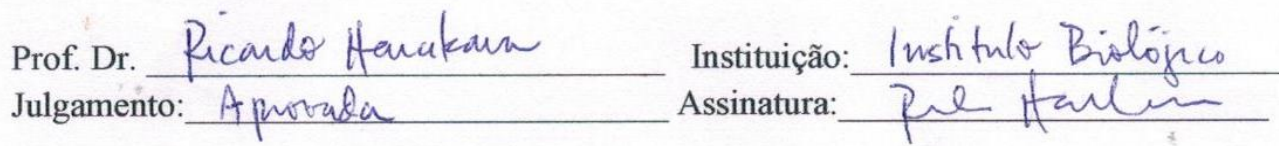

Prof. Dr. Flevia R.A. Patricio Instituição: Instítuty Biológico Julgamento: Aprovadr Assinatura:

Prof. Dr. EDUAR Do FEICh EEN BEREER Instituição Julgamento: APROVADA Assinatura:

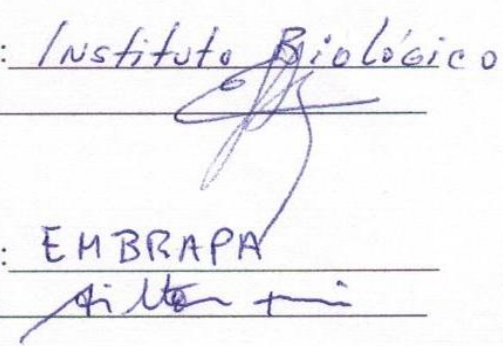

Prof. Dr. AILTON REIS Instituição: EM BRAPA Julgamento: APROV A \& A Assinatura:

Prof. Dr. LeONAndo Gires bOAUA Instituição: Julgamento: $P$ PROVADA Assinatura:

\section{UNAR}

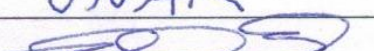


Aos meus pais Glória e Carlos, por tamanha dedicação a minha formação pessoal e profissional, pelo amor a mim dedicado e por me proporcionarem paz na alma e felicidade na vida.

Ao meu irmão Brunno, por todo amor e apoio incondicional.

Ao meu sobrinho Enrico, que trouxe muito mais alegria e me fez conhecer um amor que antes eu não sabia que podia existir.

\section{DEDICO}




\section{AGRADECIMENTOS}

Primeiramente e acima de tudo agradeço a Deus, por ter me dado a oportunidade de concretizar este trabalho mesmo com todos os desafios.

Aos meus pais, Carlos e Glória, por sempre me proverem de ensinamentos para a vida e para todas as questões em meus momentos mais difíceis, sem que, para isso, exigissem nada em troca. Pelo amor incondicional, orações, confiança, apoio e exemplo de vida a seguir.

Ao meu irmão, Brunno, pela atenção e carinho dedicado a minha pessoa, tanto nos momentos comemorativos como nos tumultuados. Sempre desenvolveu a função de irmão mais velho, aquele que protege, ampara e, às vezes, briga. Tenho uma admiração imensa por você!

Ao meu sobrinho Enrico Bassoi Zanotta, que mesmo pequeno, e sem saber, me trouxe força e o maior e melhor apoio, num momento tão importante da minha vida. A Titia te ama demais!

Ao Dr. Ricardo Harakava, por me aceitar como orientada nessa aventura e desafio que foi esse doutorado. Pelas oportunidades de aprendizado que foram e continuarão a ser de valor inestimável para a continuidade da minha carreira como cientista, pesquisadora e, quem sabe um dia, como professora. Pela colaboração, paciência e seus conhecimentos repassados durante todo o desenvolvimento do trabalho, além da amizade formada e apoio em todos os momentos.

Ao Dr. Jesus Guerido Tofoli, pela confiança, pela paciência e por prontamente me ajudar sempre que o procurei. Eu aprendi muito com você.

Ao Dr. Fernando Javier Sanhueza Salas por me trazer à bataticultura. Esse universo maravilhoso onde nada é monótono. Pela confiança e por prontamente me ajudar sempre que o procurei.

A Dra. Marta Helena Vechiato Maziero, por ter aberto as portas do Instituto Biológico de São Paulo, confiando na minha competência. Hoje acima de tudo agradeço principalmente pela sua amizade e seu apoio incondicional sempre.

A Ieda Mascarenhas Louzeiro Terçariol, a Dra. Eliana Borges Rivas, a MSc. Josiane Takassaki Ferrari, ao MSc. Ricardo Domingues e ao mestrando Guilherme Augusto Cabral Silva pela amizade e por tornarem mais alegre e agradável o nosso ambiente de trabalho ao longo desses anos. 
Agradeço pela confiança e livre acesso às dependências do Laboratório de Diagnóstico Fitopatológico, ao Laboratório de Doenças Fúngicas em Horticultura e a Unidade Laboratorial de Referencia em Biologia Molecular Aplicada - Instituto Biológico de São Paulo, assim como a utilização dos reagentes e equipamentos necessários para a conclusão deste trabalho. Agradeço muito pelo reconhecimento da minha dedicação ao trabalho e confiança a minha pessoa.

A Dra. Ana María Florencia Lucca, Dra. Andrea Fabiana Puebla e María Florencia Servici, do Instituto de Biotecnologia Agropecuária - Instituto Nacional de Tecnología Agropecuária (INTA), por aceitarem a colaboração neste projeto, pelos ensinamentos e auxílio nas análises de microssatélites (SSR).

Ao Dr. Eduardo Seite Gomide Mizubuti, pela colaboração, e por sempre estar disposto a compartilhar seu conhecimento.

A Associação Brasileira de Batata (ABBA) e ao Sr. Natalino Yassushi Shimoyama (diretor executivo) que enxergaram um potencial neste estudo e foram um dos maiores apoiadores. Este apoio foi primordial para a divulgação deste por todas as regiões brasileiras produtoras de batata.

Aos inúmeros bataticultores, que sofreram com essa doença no campo, e viram um grande potencial neste projeto e auxiliaram este se colocando a disposição para o envio de amostras sempre que necessário.

Ao Instituto Biológico de São Paulo, pela oportunidade de vivenciar o trabalho de um instituto com tanta história e de grande importância nacional certamente ajudou na minha formação como profissional.

A Dra. Carmen Lidia Amorim Pires-Zottarelli, a Dra. Flávia Rodrigues Alves Patrício, a Dra. Marise Cagnin Martins Parisi, ao Dr. Ailton Reis, ao Dr. Eduardo Feichtenberg e ao Dr. Leonardo Pires Boava pelas colaborações importantíssimas, melhorando a qualidade e valorizando o trabalho final.

À Coordenação de Aperfeiçoamento de Pessoal de Nível Superior (CAPES) pela concessão de bolsa de estudo.

Agradeço aos professores do curso de Pós Graduação do IB, amigos e colegas pelo agradável convívio e companheirismo.

A todos os meus amigos que me apoiaram, me corrigiram, me aturaram, souberam entender a importância deste momento do trabalho que por tantas vezes justificou a minha ausência e me fizeram saber que, antes de tudo, a vida sem eles não 
teria graça alguma. Sem duvida, este, que até o momento é o capítulo mais louco da minha vida, não poderia de deixar de ser escrito sem a presença de vocês.

Enfim, a todos aqueles que contribuíram direta ou indiretamente na elaboração deste trabalho, quer me criticando, quer incentivando, gostaria de manifestar meus sinceros agradecimentos. 
"A menos que modifiquemos a nossa maneira de pensar, não seremos capazes de resolver os problemas causados pela forma como nos acostumamos a ver o mundo". (Albert Einstein) 


\section{RESUMO}

ZANOTTA, Samantha. Caracterização da população de Phytophthora infestans (Mont) de Bary em regiões produtoras de batata (Solanum tuberosum L.) no Brasil. 2019. 124f. Tese (Doutorado em Segurança Alimentar e Sanidade no Agroecossistema) - Instituto Biológico, Agência Paulista de Tecnologia dos Agronegócios, Secretaria de Agricultura e Abastecimento do Estado de São Paulo, São Paulo, 2019.

A requeima, causada por Phytophthora infestans (Oomycota, Stramenopila), é uma das doenças mais destrutivas na bataticultura mundial, podendo comprometer a produção em poucos dias. Este trabalho tem como principal objetivo a caracterização da população de Phytophthora infestans nas regiões produtoras de batata no Brasil e, para isso, teve como objetivos específicos: i) obter isolados de P. infestans a partir de plantas de batata com sintomas de requeima oriundas de diferentes regiões produtoras do país; ii)iIdentificar e monitorar o tipo de reprodução de isolados de $P$. infestans existentes no Brasil; iii) caracterizar os isolados do patógeno quanto ao grupo de compatibilidade; iv) caracterizar os isolados do patógeno quanto ao genótipo empregando-se marcadores moleculares tipo SSR; v) avaliar a sensibilidade dos genótipos de P. infestans a quatro ingredientes ativos com diferentes mecanismos de ação, utilizados para o controle químico do patógeno. Para isso, material botânico (folhas, hastes, caules, frutos e tubérculos) manifestando sintomatologia típica de requeima, provenientes de diversos locais produtores de batata pelo Brasil, foi coletado. Destas coletas foram realizadas as análises quanto ao tipo de reprodução presente e o isolamento do patógeno para estudo da população de $P$. infestans. Reprodução sexuada provenientes de isolados autoférteis de P. infestans foi detectada em três Estados no Brasil, São Paulo (Divinolândia e Itobi), Paraná (Campo do Tenente) e Minas Gerais (Serra do Salitre). O grupo de compatibilidade predominante neste estudo foi o A1. Na identificação quanto ao grupo de compatibilidade dos isolados coletados, a correlação entre os resultados do pareamento "in vitro" e os obtidos molecularmente foi de $100 \%$ no presente estudo. Ao realizar a caracterização molecular por microssatélite, utilizando os 12 pares de marcadores microssatélites estabelecido para o monitoramento das populações de $P$. infestans ao redor do mundo, forma identificadas duas linhagens de P. infestans foram identificadas, a linhagem 2_A1 e a linhagem US-1, sendo a linhagem 2_A1, a mais 
abundante. A sensibilidade de dezessete isolados de $P$. infestans coletados pelo Brasil aos princípios ativos ciazofamida, clorotalonil, dimetomorfe e propamocarbe, que possuem mecanismos de ação diferentes, pelo método de microtitulação colorimétrica, não tendo sido observado perda de sensibilidade aos princípios pela maioria dos isolados avaliados.

Palavras-chave: requeima, bataticultura, autofértil, microssatélites, fungicidas, sensibilidade. 


\begin{abstract}
ZANOTTA, Samantha. Characterization of population of Phytophthora infestans

(Mont) de Bary potato-producing areas (Solanum tuberosum L.) in Brazil. 2019..
\end{abstract}

124s. Doctoral Thesis of the Postgraduate Program in Health, Food and Environmental

Security in Agribusiness, Instituto Biológico.

Late blight, caused by Phytophthora infestans (Oomycota, Stramenopila), is one of the most destructive diseases in world potato production, and may compromise production in a few days. The main objective of this work is to characterize the population of Phytophthora infestans in potato-producing regions in Brazil and, for this purpose, its specific objectives were: i) to obtain isolates of $P$. infestans from potato plants with late blight symptoms originating from different producing regions of the country; ii) identify and monitor the type of reproduction of $P$. infestans isolates in Brazil; iii) characterize the pathogen isolates according to the compatibility group; iv) characterize the pathogen isolates according to genotype using SSR-type molecular markers; v) evaluate the sensitivity of $P$. infestans genotypes to four active ingredients with different mechanisms of action, used for chemical control of the pathogen. Plant material (leaves, stems, stems, fruits and tubers) showing typical symptoms of late blight from various potato-producing sites in Brazil was collected. From these collections, analyzes were performed regarding the type of reproduction and the pathogen was isolated to study $P$. infestans population. Sexual reproduction by $P$. infestans self-fertile isolates was detected in three states in Brazil: São Paulo (Divinolândia and Itobi), Paraná (Campo do Tenente) and Minas Gerais (Serra do Salitre). The predominant compatibility group in this study was A1. Regarding determination of the compatibility group of the isolates, correlation between results of in vitro pairing and molecular tests was $100 \%$ in the present study. Monitoring of $P$. infestans population using twelve microsatellite markers resulted in the detection of two $P$. infestans lineages: 2_A1 and US-1, the former being the most abundant. Sensitivity of seventeen $P$. infestans isolates to the active ingredients ciazofamide, chlorotalonil, dimetomorph and propamocarb was measured by the colorimetric microtiter method. Significant loss of sensitivity to the principles was not observed for the isolates evaluated.

Key - words: late blight, potato production, self fertile, microsatellite markers, fungicides, sensitivity. 


\section{LISTA DE ILUSTRAÇÕES}

\section{Figura}

$\mathbf{n}^{\mathbf{o}}$

\section{Descrição}

Página

01 Ilustração de uma planta de batata. Fonte: INTERNATIONAL POTATO CENTER, 2019 - Adaptado.

02 Distribuição (em porcentagem - \%) por região, da produção de batata no Brasil. Fonte: IBGE, 2019.

03 Sintomas de Requeima em batata. A) sintoma de requeima na par adaxial da folha; B) esporulação do patógeno ( $P$. infestans) na par abaxial da folha; C) sintoma de requeima em haste; D) fruto de bata sadio e com sintomas de requeima; E) Sintoma de requeima e tubérculos de batata externamente e $(F)$ internamente

04 Locais de coletas de amostras de batata com sintomas de requeima: A) Divinolândia/SP (março/2015), B) Itararé (julho/2015), C) Pilar do Sul (março/2015), D) Divinolândia/SP (abril/2015).

05 Formulário desenvolvido para o envio de amostra de requeima ao Instituto Biológico.

06 Esquema da diluição seriada dos princípios ativos de diferentes fungicidas, para a obtenção das concentrações utilizadas

07 Esquema da microplaca de poliestireno estéril com 96 poços. Nas colunas são distribuídos isolados, e nas linhas as diluições dos princípios ativos

08 Origem das amostras de material botânico com sintomas típicos de requeima (Phytophthora infestans) coletadas por região no Brasil.....

09 Estruturas reprodutivas sexuais de isolado de Phytophythora infestans do presente estudo. A, B e D - gametângios (anterídio, oogônio) e oósporo; C - oósporo; . Fonte: A - Carmen Lidia Amorim Pires-Zottarelli, B, C e D - Samantha Zanotta.

10 Estruturas reprodutivas assexuais de isolado de Phytophthora infestans do presente estudo. A a D - esporângios.

11.a Sequências de fragmentos de DNA de isolados de Phytophthora infestans pertencentes ao grupo de compatibilidade A1 e A2, 73 
amplificados com iniciadores W16-1 e W16-2

11.b Polimorfismo encontrado em eletroferograma de um isolado pertencente ao grupo de compatibilidade A1. A seta indica a sobreposição de picos das bases $\mathrm{C}$ e $\mathrm{T}$.

12 Perfil de um isolado de Phytophthora infestans obtido com os 12 pares de marcadores microssatélites.

13 Árvore de distância genética construída pelo método de Neighbor Joining com os dados de microssatélites dos isolados de Phytophthora infestans do presente estudo e de outras linhagens mundiais

14 Gráfico da rede de extensão mínima (minimum spanning network) construído com os dados de microssatélites de isolados de Phytophthora infestans do presente estudo e de outras linhagens mundiais 
LISTA DE TABELAS

\section{Tabela}

$\mathbf{n}^{\mathbf{0}}$

\section{Descrição}

Página

01 Ranking dos 24 maiores países produtores de batata, no ano de 2017, classificados por produção (ton) e por rendimento (kg/ha).......

02 Iniciadores utilizados para identificação dos grupos de compatibilidade dos isolados de Phytophthora infestans.

03 Descrição dos iniciadores para amplificação dos 12 lócus polimórficos microssatélites usados na caracterização de isolados de Phytophthora infestans

04 Descrição dos iniciadores para amplificação dos12 lócus polimórficos microssatélites usados na caracterização de isolados de Phytophthora infestans.

05 Identificação, procedência e identificação do grupo de compatibilidade dos isolados de Phytophthora infestans coletados no presente estudo

06 Número de isolados de Phytophthora infestans pertencentes a cada Grupo de Compatibilidade quando avaliados pelo método de pareamento "in vitro" e pelos métodos moleculares.

07 Número de alelos existentes mundialmente para Phytophthora infestans e número de alelos detectado por lócus nos isolados presente estudo.

08 Frequência dos alelos no estudo molecular por SSR nos isolados de Phytophthora infestans do presente estudo

09 Variações encontradas entre os perfis polimórficos obtidos com os marcadores microssatélites (SSR) dos isolados Phytophthora infestans do presente estudo.

10 Comparação dos perfis polimórficos das variações 04 e 11 deste trabalho, com os perfis polimórficos encontrados por Li (2012).

11 Perfis polimórficos dos isolados brasileiros estudados por Saville e colaboradores (2016), pertencentes à linhagem BR-1

12 Comparação dos perfis polimórficos dos isolados autoférteis 
encontrados neste estudo, com os perfis polimórficos dos isolados autoférteis encontrados por Casa-Coila e colaboradores (2017)

13 Médias das absorbâncias obtidas nas diferentes concentrações de ciazofamida para isolados de Phytophthora infestans e EC50 obtido por isolado.

14 Médias das absorbâncias obtidas nas diferentes concentrações de clorotalonil para isolados de Phytophthora infestans e EC50 obtido por isolado

15 Médias das absorbâncias obtidas nas diferentes concentrações de dimetomorfe para isolados de Phytophthora infestans e EC50 obtido por isolado

16 Médias das absorbâncias obtidas nas diferentes concentrações de propamocarbe para isolados de Phytophthora infestans e EC50 obtido por isolado

17 Valores de EC50 $\left(\mu \mathrm{g} \mathrm{mL}^{-1}\right)$ para os 17 isolados de Phytophthora infestans para os fungicidas ciazofamida, clorotalonil, dimetomorfe e propamocarbe.

18 Valores de EC50 para os 17 isolados subdivididos por variações dos genótipos, para ciazofamida, clorotalonil, dimetomorfe e propamocarbe

19 Valores de EC50 máximo e mínimo entre as variações de Phytophthora infestans para ciazofamida, clorotalonil, dimetomorfe e propamocarbe 


\section{LISTA DE ABREVIATURAS, SIGLAS E SIMBOLOS}

\begin{tabular}{|c|c|}
\hline $\begin{array}{c}\text { Abreviatura / Siglas / } \\
\text { Símbolos }\end{array}$ & Definição \\
\hline${ }^{\circ} \mathrm{C}$ & Graus Celsius \\
\hline$\%$ & Porcentagem \\
\hline o & Graus \\
\hline , & Minutos \\
\hline ” & Segundos \\
\hline$\mu \mathrm{m}$ & Micrometro \\
\hline$\mu \mathrm{g}$ & Microgramas \\
\hline Abr & Abril \\
\hline $\mathrm{AF}$ & Autofértil \\
\hline Ago & Agosto \\
\hline $\mathrm{Al}$ & Alelo \\
\hline BOD & Incubadora com regulagem de temperatura \\
\hline CABI & Center for Agriculture and Biosciences International \\
\hline CIA & Clorofórmio Álcool Isoamílico \\
\hline CIP & International Potato Center \\
\hline $\mathrm{Cm}$ & Centímetros \\
\hline CTAB & Brometo de cetiltrimetilamônio \\
\hline $\mathrm{CV} \%$ & Coeficiente de variação em \% \\
\hline Dez & Dezembro \\
\hline DMS & Diferença mínima significativa \\
\hline $\mathrm{EC}_{50}$ & $\begin{array}{c}\text { Concentração do fungicida capaz de reduzir } 50 \% \text { do } \\
\text { crescimento do patógeno }\end{array}$ \\
\hline EUA & Estados Unidos da América \\
\hline Fev & Fevereiro \\
\hline GPS & Global Positioning System \\
\hline ha & Hectare \\
\hline IBGE & Instituto Brasileiro de Geografia e Estatística \\
\hline INTA & Instituto Nacional de Tecnología Agropecuária \\
\hline FAO & Food and Agriculture Organization of The United Nations \\
\hline
\end{tabular}




\begin{tabular}{|c|c|}
\hline IB & Instituto Biológico \\
\hline Jan & Janeiro \\
\hline Jul & Julho \\
\hline Jun & Junho \\
\hline $\mathrm{Kg}$ & Quilograma \\
\hline LDFH & Laboratório de Doenças Fúngicas em Horticultura \\
\hline LDF & Laboratório de Diagnóstico Fitopatológico \\
\hline $\mathrm{M}$ & Metros \\
\hline Mai & Maio \\
\hline Mar & Março \\
\hline $\mathrm{MG}$ & Minas Gerais \\
\hline Ml & Mililitro \\
\hline Nov & Novembro \\
\hline Out & Outubro \\
\hline P. infestans & Phytophthora infestans \\
\hline $\mathrm{Pb}$ & Pares de bases \\
\hline PCR & Reação em Cadeia da Polimerase \\
\hline Ppm & Partes por Milhão \\
\hline PR & Paraná \\
\hline RPM & Rotações por minuto \\
\hline $\mathrm{RR}$ & Roraima \\
\hline $\mathrm{RS}$ & Rio Grande do Sul \\
\hline $\mathrm{S}$ & South / Sul \\
\hline Set & Setembro \\
\hline SP & São Paulo \\
\hline SSR & Simple Sequence Repeats / Sequencias Simples Repetidas \\
\hline Ton & Tonelada \\
\hline $\mathrm{W}$ & West / Oeste \\
\hline
\end{tabular}




\section{SUMÁRIO}

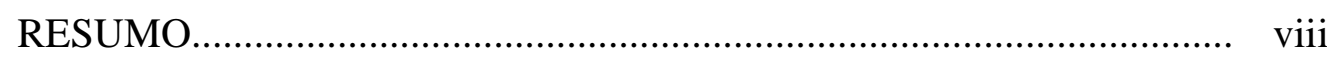

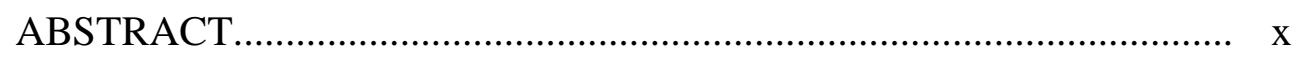

LISTA DE ILUSTRAÇÕES.......................................................... xii

LISTA DE TABELAS............................................................... xiv

LISTA DE ABREVIATURAS, SIGLAS E SIMBOLOS........................ xvi

1. INTRODUÇÃO ......................................................................... 20

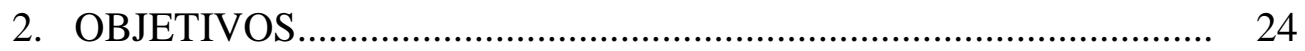

3. REVISÃO DE LITERATURA...................................................... 26

3.1. A Bataticultura....................................................................... 27

3.2. A Requeima................................................................. 31

3.3. O patógeno - Phytophthora infestans...................................... 32

3.4. Marcadores Moleculares Microssatélites.................................. 38

3.5. Manejo da Requeima............................................................... 40

4. MATERIAL E MÉTODOS........................................................... 45

4.1. Coleta de material infectado..................................................... 46

4.2. Monitoramento do tipo de reprodução....................................... 47

4.2.1. Indução à produção de estruturas de reprodução................ 47

4.3. Isolamento de Phytophthora infestans...................................... 48

4.4. Extração de DNA....................................................................... 48

4.5. Identificação do grupo de compatibilidade................................. 49

4.5.1. Amplificação por PCR (Reação em Cadeia da

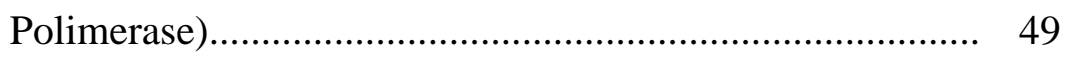

4.5.2. Sequenciamento........................................................... 49

4.5.3. Pareamento "in vitro" ..................................................... 50

4.6. Caracterização molecular por microssatélite (SSR).................. 51

4.7. Teste de sensibilidade in vitro de 17 isolados de Phytophthora infestans pertencentes a seis variações genotípicas, aos fungicidas, ciazofamida, clorotalonil, dimetomorfe e propamocarbe ..................................................................... 54

5. RESULTADOS E DISCUSSÃO................................................. 59

5.1. Coleta de material infectado.............................................. 60 
5.2. Monitoramento do tipo de reprodução...................................... 60

5.3. Identificação do grupo de compatibilidade................................ 63

5.4. Caracterização molecular por microssatélite (SSR)................ 74

5.5. Teste de sensibilidade in vitro de 17 isolados de Phytophthora infestans pertencentes a seis variações genotípicas, aos fungicidas, ciazofamida, clorotalonil, dimetomorfe e propamocarbe .................................................................. 87

6. CONCLUSÕES.......................................................................... 96

7. REFERÊNCIAS BIBLIOGRÁFICAS............................................. 98

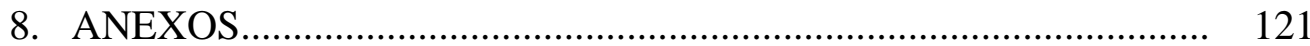


1. INTRODUÇÃO 
A bataticultura possui grande importância econômica e social no cenário agrícola brasileiro. Hoje, a cadeia produtiva da batata assume características empresariais bem definidas, com avanços tecnológicos constantes e gerenciamento avançado de todo o processo produtivo (TOFOLI; MELO; DOMINGUES, 2012).

Vários são os fatores que limitam a produção de batata, dentre eles podem ser destacadas as pragas e doenças, as quais se estabelecem nas lavouras quando as condições ambientais são favoráveis. A principal doença da cultura da batata é a requeima, também conhecia como mela, causada pelo oomiceto Phytophthora infestans (Mont,) de Bary, que pode comprometer todo o campo de produção em poucos dias, sendo uma doença importante em todo o mundo (KAMOUN; HUITEMA; VLEESHOUWERS, 1999; FRY; MIZUBUTI, 1998; LOPES; SANTOS， 1994; HENFLING, 1987; STEVENSON, 1983).

A requeima ganhou destaque mundial entre os anos 1845-1849, ao causar a escassez alimentar na Irlanda, que resultou na fome, morte e migração de grande parte da população irlandesa daquela época. Cerca de 1 milhão de pessoas morreram e outros milhões emigraram devido ao seu efeito devastador (TURNER, 2005; SALAMAN; BURTON, 1985). Esta doença até hoje ainda é considerada uma grande ameaça para a segurança alimentar mundial. No Brasil, a ocorrência inicial da requeima sobre a cultura da batata foi atribuída a uma introdução de batata-semente infectada, proveniente da Europa em 1898 (NIEDERHAUSER, 1991).

Com ao seu rápido desenvolvimento e alto potencial destrutivo, a requeima é uma ameaça econômica muito grave na grande maioria dos sistemas de produção de batata, podendo ocorrer em qualquer fase da cultura, afetando folhas, pecíolos, hastes, frutos e tubérculos. Seu controle é feito através de aplicações de fungicidas, tanto que em locais onde existe alta pressão da doença, uma variedade de batata suscetível pode exigir aplicações de fungicida a cada 3 ou 5 dias. No Brasil, as aplicações de fungicidas são em geral excessivas, devido a serem realizadas sem considerar a interação entre aspectos biológicos do ciclo de vida do patógeno e as condições meteorológicas prevalescentes durante o ciclo da cultura. A doença é altamente dependente das condições ambientais, tornando sua epidemia variável no espaço e no tempo. Como consequência, pode havertem causado aumento no custo de produção e no impacto ambiental, devido à contaminação da água e do solo por agroquímicos (BOSCO et al., 2010; GARCÍA, 2005; HIJMANS; FORBES; WALKER, 2000; NAZARENO et al., 1999; ERWIN; RIBEIRO, 1996). 
Devido à importância da requeima como fator limitante à cultura da batata, diferentes métodos de controle integrado têm sido usados, como por exemplo, a utilização de tubérculos-sementes sadios, cultivares menos suscetíveis, retirada e destruição de plantas voluntárias e controle químico (BOSCO et al., 2010; TAYLOR et al., 2003).

Considera-se que todas as cultivares comerciais são suscetíveis a alguma linhagem do patógeno (genótipo), pois $P$. infestans, por meio da reprodução sexuada, é capaz de rapidamente formar novas raças fisiológicas. Por esta razão, o método mais empregado para o controle da requeima ainda é o controle químico (BOSCO et al., 2010; KIRK et al., 2005).

O genoma de $P$. infestans foi sequenciado em 2009 por Haas e colaboradores, sendo caracterizado pela presença de grande número de transposons (elementos genéticos móveis) e regiões hipervariáveis abundantes, explicando, a nível genético, as grandes variações de fenótipo, agressividade e adaptabilidade observadas para esse patógeno no decorrer da sua evolução (GUO et al., 2009; KAMOUN, 2003). Por estas características, este patógeno tem sido capaz de se adaptar a diferentes climas e latitudes ao longo da história,com o aparecimento de novos genótipos nas duas ultimas décadas, e que a tornam mais difícil de controlar (FRY, GOODWIN, 1997).

A compreensão da dinâmica da variabilidade genética dos fitopatógenos se faz necessária para o entendimento de como as populações evoluem e as implicações desse processo na durabilidade de cultivares resistente e no controle da doença. Esta compreensão pode ser traduzida na duração da efetividade da adoção de uma cultivar resistente ou de um fungicida específico para o manejo da doença (OLIVEIRA, 2010; MILGROOM; PEEVER, 2003). Segundo Lees e colaboradores (2006), diversos trabalhos já foram desenvolvidos para caracterizar o grupo de compatibilidade e a resistência a fungicidas das populações de $P$. infestans, no entanto, os estudos relacionados à diversidade genética eram limitados pela sensibilidade dos marcadores genéticos utilizados no passado. Este aspecto incentivou a adoção de novos marcadores nas análises de biologia de populações de fitopatógenos, como o caso dos microssatélites, também conhecidos como Sequências Simples Repetidas (SSR) (COOKE; LEES, 2004).

Os marcadores moleculares têm sido uma ferramenta de grande importância na caracterização de populações de fungos fitopatogênicos, permitindo avaliar os níveis de diversidade genética, as relações filogenéticas intra e interespecíficas, além da 
identificação de raças e patótipos (CERQUEIRA, 2014; DAVIS; KUBISIAK; MILGROOM, 2005; HENSEN; OBERPRIELER; WESCHE, 2005; JAMES; LIOU; VILGALYS, 2004; BELABID et al., 2004; LEAL-BERTIOLI, 1998).

O acompanhamento das variações na população de $P$. infestans ao longo dos anos permite melhor embasamento no desenvolvimento e na adoção de práticas de manejo da requeima, especialmente no auxílio ao desenvolvimento de cultivares resistentes a requeima e melhorará a eficiência do controle químico. 
2. OBJETIVOS 
Este trabalho tem como principal objetivo a caracterização da população de Phytophthora infestans nas regiões produtoras de batata no Brasil e, para isso, teve como objetivos específicos:

- Obter isolados de P. infestans a partir de plantas de batata com sintomas de requeima oriundas de diferentes regiões produtoras do país

- Identificar e monitorar o tipo de reprodução de isolados de P. infestans existentes no Brasil;

- Caracterizar os isolados do patógeno quanto ao grupo de compatibilidade;

- Caracterizar os isolados do patógeno quanto ao genótipo empregando-se marcadores moleculares tipo SSR;

- Avaliar a sensibilidade dos genótipos de P. infestans a quatro ingredientes ativos com diferentes mecanismos de ação, utilizados para o controle químico do patógeno. 
3. REVISÃO DE LITERATURA 


\subsection{A Bataticultura}

A batata, Solanum tuberosum L. (Figura 1), é uma planta dicotiledônea, pertencente à família Solanaceae, gênero Solanum (FORTES; PEREIRA, 2003). É originária dos Andes (América do Sul) e possui mais de 4.000 variedades comestíveis cultivadas em mais de 100 países (INTERNATIONAL POTATO CENTER, 2019).

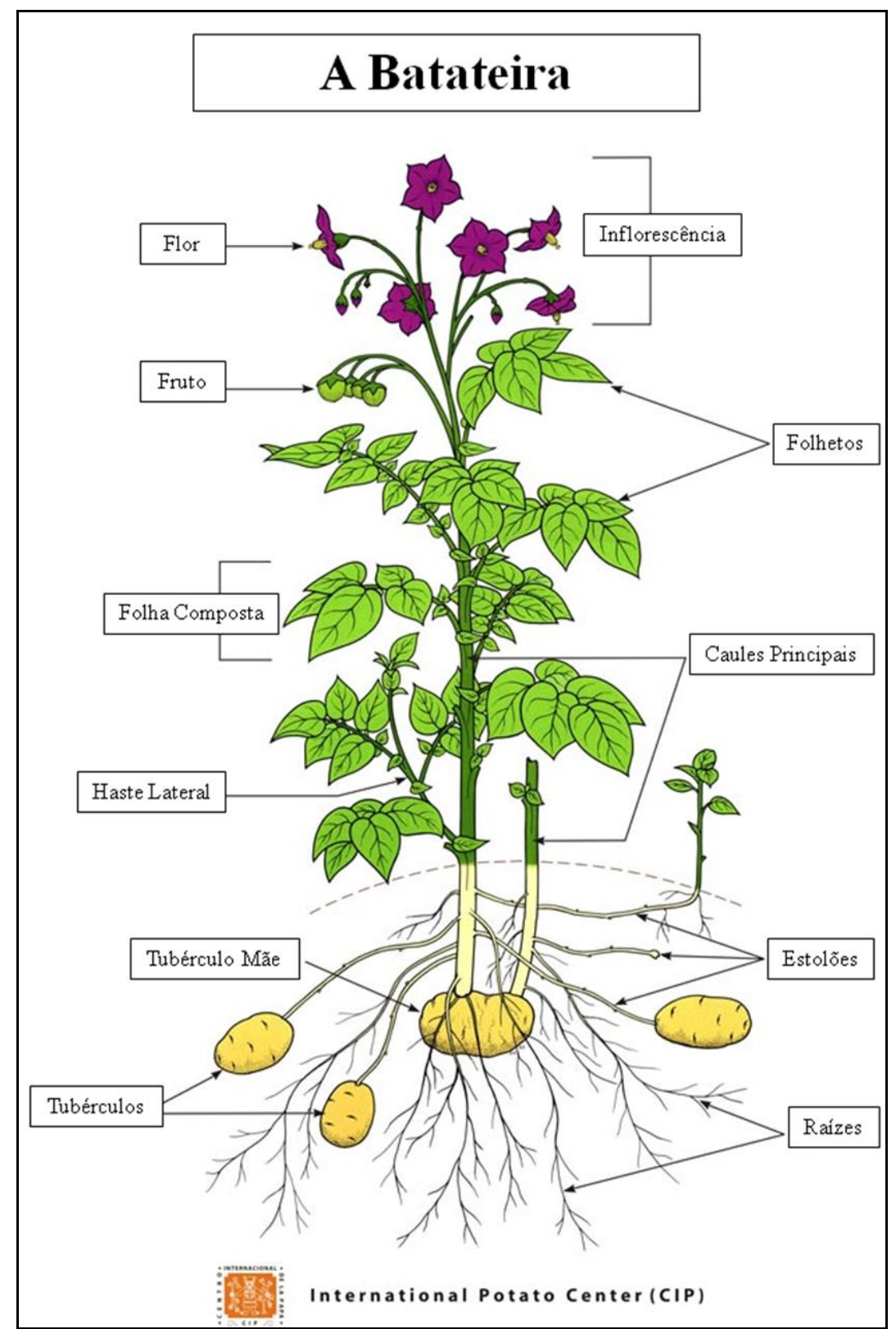

Figura 1. Ilustração de uma planta de batata. Fonte: INTERNATIONAL POTATO CENTER, 2019 - Adaptado.

Esta espécie vegetal é de grande importância mundial devido ao elevado valor nutricional, pois é rica em carboidratos, fósforo e vitaminas do complexo $\mathrm{B}$, que 
caracterizam o seu potencial na segurança alimentar. Trata-se da terceira maior fonte de alimento para o ser humano, atrás apenas do arroz e do trigo (INTERNATIONAL POTATO CENTER, 2019).

Mundialmente, em 2017, a produção total de batata foi de 288.190.674,00 toneladas em 19.302.642,00 hectares. O continente que mais produz é a Ásia (50,40\%), seguida pela Europa (31,37\%), África (6,44\%), América do Norte (6,30\%), América do Sul (4,37\%), América Central (0,71\%) e Oceania (0,41\%) (FOOD AND AGRICULTURE ORGANIZATION OF THE UNITED NATIONS - FAO, 2019).

Dentre os 24 países que mais produziram batata em 2017 (Tabela 1), a liderança ficou com a China (99.205.580 ton), seguida pela Índia (48.605.000 ton), Rússia (29.589.976 ton), Ucrânia (22.208.220 ton) e Estados Unidos da América (20.017.350 ton), enquanto o Brasil ocupou a $20^{\mathrm{a}}$ posição (FOOD AND AGRICULTURE ORGANIZATION OF THE UNITED NATIONS - FAO, 2019).

Na América do Sul (Tabela 1), o Brasil se destaccou como o segundo maior produtor de batata com 3.656.846,00 ton, ficando atrás somente do Peru que produziu 4.776.294,00 ton (FOOD AND AGRICULTURE ORGANIZATION OF THE UNITED NATIONS - FAO, 2019). 
Tabela 1. Ranking dos 24 maiores países produtores de batata, no ano de 2017, classificados por produção (ton) e por rendimento (kg/ha).

\begin{tabular}{|c|c|c|c|c|c|}
\hline País & $\begin{array}{c}\text { Área } \\
\text { Plantada } \\
\text { (ha) }\end{array}$ & Produção (ton) & Ranking & Rendimento (kg/ha) & Ranking \\
\hline China & 5767481 & 99205580 & $1^{\circ}$ & 172009 & $19^{\circ}$ \\
\hline Índia & 2179000 & 48605000 & $2^{\circ}$ & 223061 & $15^{\circ}$ \\
\hline Rússia & 1889208 & 29589976 & $3^{\circ}$ & 156626 & $21^{\circ}$ \\
\hline Ucrânia & 1323200 & 22208220 & $4^{\circ}$ & 167837 & $20^{\circ}$ \\
\hline EUA & 415010 & 20017350 & $5^{\circ}$ & 482334 & $1^{\mathrm{o}}$ \\
\hline Alemanha & 250500 & 11720000 & $6^{\circ}$ & 467864 & $3^{\circ}$ \\
\hline Bangladesh & 499725 & 10215957 & $7^{\circ}$ & 204432 & $16^{\circ}$ \\
\hline Holanda & 160791 & 7391881 & $8^{\circ}$ & 459720 & $4^{\circ}$ \\
\hline França & 173486 & 7342203 & $9^{\circ}$ & 423216 & $6^{\circ}$ \\
\hline Belarus & 275997 & 6414755 & $10^{\circ}$ & 232421 & $13^{\circ}$ \\
\hline Reino Unido & 146000 & 6218000 & $11^{\circ}$ & 425890 & $5^{\circ}$ \\
\hline Irã & 160902 & 5102342 & $12^{\circ}$ & 317109 & $8^{\circ}$ \\
\hline Turquia & 142851 & 4800000 & $13^{\circ}$ & 336014 & $7^{\circ}$ \\
\hline Peru & 310400 & 4776294 & $14^{\mathrm{o}}$ & 153875 & $22^{\circ}$ \\
\hline Argélia & 148692 & 4606403 & $15^{\circ}$ & 309795 & $10^{\circ}$ \\
\hline Bélgica & 92855 & 4416665 & $16^{\circ}$ & 475652 & $2^{\circ}$ \\
\hline Canadá & 342218 & 4410829 & $17^{\circ}$ & 128889 & $24^{\circ}$ \\
\hline Egito & 163939 & 4325478 & $18^{\circ}$ & 263848 & $12^{\circ}$ \\
\hline Paquistão & 183961 & 4142399 & $19^{\circ}$ & 225178 & $14^{\circ}$ \\
\hline Brasil & 118030 & 3656846 & $20^{\circ}$ & 309823 & $9^{\circ}$ \\
\hline Cazaquistão & 182895 & 3551114 & $21^{\circ}$ & 194161 & $17^{\circ}$ \\
\hline Romênia & 171390 & 3116910 & $22^{\circ}$ & 181861 & $18^{\circ}$ \\
\hline Nepal & 194115 & 2691037 & $23^{\circ}$ & 138631 & $23^{\circ}$ \\
\hline Polônia & 329323 & 917133 & $24^{\circ}$ & 278503 & $11^{\circ}$ \\
\hline
\end{tabular}

No entanto, quando se analisa o rendimento ( $\mathrm{kg} / \mathrm{ha}$ ), no ano de 2017 , o panorama muda completamente (Tabela 1), com os Estados Unidos (482.334 kg/ha), Bélgica (475.652 kg/ha), Alemanha (467.864 kg/ha), Holanda (459.720 kg/ha) e Reino Unido (425.890 kg/ha), liderando o ranking. A China cai para a $19^{\mathrm{a}}$ colocação com um rendimento de $172.009 \mathrm{~kg} / \mathrm{ha}$, enquanto o Brasil sobe para a 9 ${ }^{\mathrm{a}}$, com $309.823 \mathrm{~kg} / \mathrm{ha}$ (FOOD AND AGRICULTURE ORGANIZATION OF THE UNITED NATIONS FAO, 2019).

Segundo dados do IBGE (2019), no Brasil foram registrados 126.999,00 hectares de área colhida de batata, com uma produção de 3.900.737,00 toneladas em quatro regiões: Sudeste, Sul, Centro-Oeste e Nordeste (Figura 2). As regiões Sudeste e 
Sul juntas são responsáveis por quase $90 \%$ da produção nacional de batata, com destaque para os Estados de Minas Gerais (1.150.220,00 ton), São Paulo (936.302,00 ton), Paraná (790.885,00 ton) e Rio Grande do Sul (406.736,00 ton), que respectivamente, são os maiores produtores (INSTITUTO BRASILEIRO DE GEOGRAFIA E ESTATISTICA - IBGE, 2019).

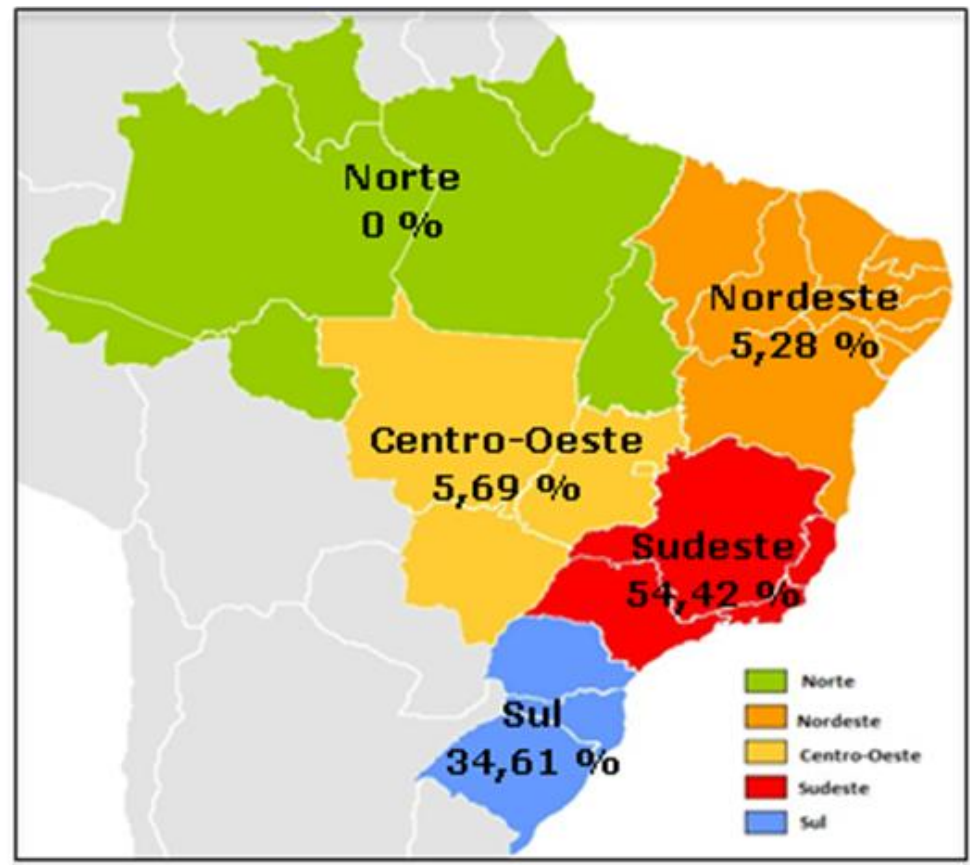

Figura 2. Distribuição (em porcentagem - \%) por região, da produção de batata no Brasil. Fonte: IBGE, 2019.

A produção nacional ocorre em três épocas de cultivo, denominadas safra das águas, da seca e de inverno (WATANABE, 2013; FILGUEIRA, 2003). O período de plantio dessas safras pode variar em função da região e da variedade da batata a ser plantada, porém estão sempre concatenadas, sendo que cada região desenvolve dois cultivos predominantes (FILGUEIRA, 2003).

Embora importante para o agronegócio mundial, a cultura da batata está sujeita a fatores que limitam a sua produção, como os ambientais e os sanitários, ou seja, as pragas e as doenças. A principal doença da batata, em todo o mundo, é a requeima ou mela, causada pelo oomiceto Phytophthora infestans, pois é das doenças mais devastadoras em campos de produção (WANG et al., 2017; HOOKER, 1981). 


\subsection{A Requeima}

A requeima ou mela, causada por $P$. infestans, é conhecida por diversos nomes em outros idiomas, sendo os mais comuns: "late blight", "blight" e "downy mildew" em inglês; "mildiu" e "tizon tardio" em espanhol; "mildiou" em francês; "fitoftoros" em russo; "wan yi Bing" em chinês; "braunfaeule" e "kraut und knollenfaeule" em alemão; "aaloo ka jhulsa" em indiano; e "phytophthorosis" em ucraniano (CENTER FOR AGRICULTURE AND BIOSCIENCES INTERNATIONAL - CABI, 2019).

Mundialmente, $P$. infestans é considerado um dos patógenos mais significativos na bataticultura e até hoje é temido pelos agricultores e pelas agroindústrias devido às perdas de bilhões de dólares em danos decorrentes de infecções todos os anos (DAHLIN, 2016; KAMOUN et al., 2015; COOKE; LEES, 2004).

A requeima da batata ficou conhecida mundialmente por causar "A Grande Fome" na Irlanda entre 1845-1849, resultando em morte de cerca de 1 milhão de pessoas por desnutrição e a migração de milhões de irlandeses, devido ao efeito devastador dessa doença (TURNER, 2005; SALAMAN; BURTON, 1985).

Até hoje a requeima é considerada uma grande ameaça para a segurança alimentar mundial. No Brasil, a ocorrência da doença na cultura da batata em 1898 foi atribuída a uma introdução de batata-semente infectada, proveniente da Europa (NIEDERHAUSER, 1991).

Os sintomas da requeima (Figura 3) em folhas são caracterizados por manchas de tamanho variável, coloração verde-clara ou escura, aspecto úmido, localizados nas bordas dos folíolos. Ao evoluírem, as manchas se tornam escuras, irregulares ou parcialmente circulares, apresentando geralmente aspecto encharcado. Sob condições de temperatura amenas e umidade elevada observa-se na face inferior das lesões a formação de um anel de esporulação formado por esporângios e esporangióforos do patógeno. $\mathrm{O}$ anel tem aspecto aveludado, com coloração branco-acinzentada, e localizase principalmente ao redor das lesões, nos limites entre o tecido sadio e o necrótico. À medida que o tecido foliar é afetado, as lesões tornam-se necróticas e ressecadas, apresentando um aspecto de queima intensa e generalizada. Nas hastes foliares, as lesões são marrom-escuras, contínuas e aneladas, podendo causar a morte das áreas abaixo da lesão. Nos tubérculos, as lesões são superficiais, de cor castanha, com formatos irregulares e bordos definidos. No interior dos tubérculos, a necrose é irregular, de coloração marrom, aparência granular e mesclada (TÖFOLI; 
DOMINGUES; ZANOTTA., 2017; SOUZA DIAS; IAMAUTI; FISCHER,2016; WALE; PLAT; CATTLIN, 2008; STEVENSON; KIRK; ATALLAH, 2008).

A dispersão dos propágulos do patógeno ocorre pelo vento, água e insetos. O ciclo completo de $P$. infestans pode ocorrer em menos de cinco dias em cultivares suscetíveis e os esporos também infectam os tubérculos, os quais apodrecem durante o armazenamento ou podem atuar como fonte de inóculo primário se no plantio seguinte forem utilizados como tubérculos-semente (FRY; GOODWIN, 1997).

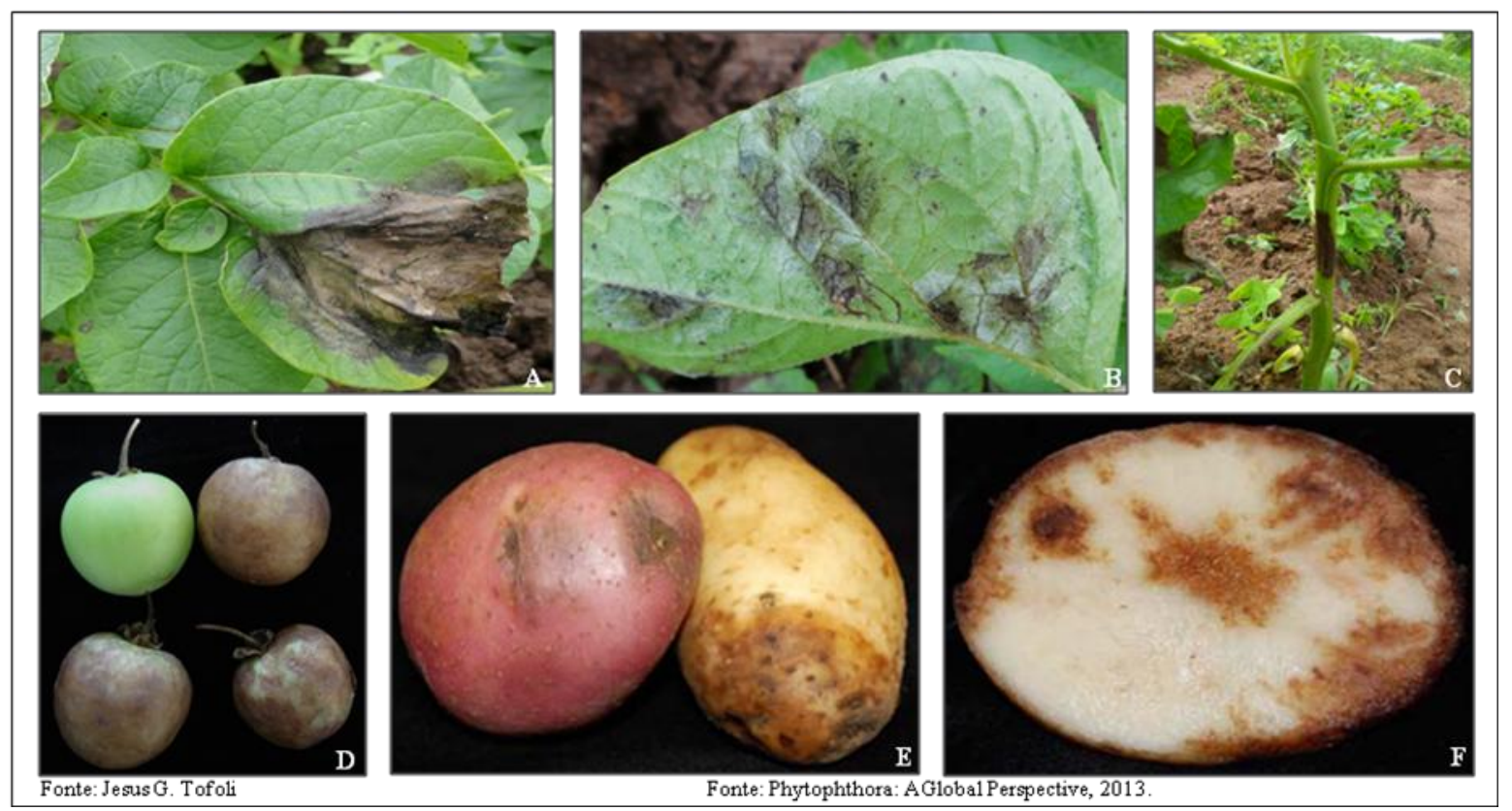

Figura 3. Sintomas de Requeima em batata. A) sintoma de requeima na parte adaxial da folha; B) esporulação do patógeno (P. infestans) na parte abaxial da folha; C) sintoma de requeima em haste; D) fruto de batata sadio e com sintomas de requeima; E) Sintoma de requeima em tubérculos de batata externamente e $(F)$ internamente.

\subsection{O patógeno - Phytophthora infestans}

O gênero Phytophthora, palavra derivada do grego, sendo phyto = planta e phthora $=$ destruidor, foi assim nomeado por Anton de Bary em 1876, em alusão ao seu poder de disseminação e destruição (MOURA, 2002).

Phytophthora infestans é um representante dos oomicetos, um grupo de organismos genericamente conhecidos como "mofos aquáticos". Muito embora compartilhem muitas características biológicas, ecológicas e epidemiológicas dos fungos, não pertencem ao Reino Fungi (BOSCO et al., 2010; SCHUMANN; D'ARCY, 2000; SCHUMANN, 1991). 
Estudos filogenéticos mostraram que os oomicetos estão mais intimamente relacionados às algas marrons e às plantas verdes do que aos fungos. A principal diferença reside na composição da parede celular. Enquanto em fungos, a parede celular é composta em sua maior parte por quitina, em oomicetos é constituída predominantemente por 1-3- $\beta$-glucanas e, em menor proporção, por 1-4- $\beta$-glucanas e 16- $\beta$-glucanas (BARBOZA, 2014; FRY, GRUNWALD, 2010; KIRK, et al., 2005; LATIJNHOUWERS, DE WIT, GOVERS, 2003; WERNER et al., 2002; CAVALIERSMITH, 1998).

O gênero Phytophthora pertence ao Domínio Eukaryota, Reino Stramenopila, Filo Oomycota, Classe Oomycetes, Ordem Peronosporales, família Peronosporaceae (RIBEIRO， 2013， CENTER FOR AGRICULTURE AND BIOSCIENCES INTERNATIONAL - CABI, 2019; MYCOBANK DATABASE , 2019).

Inferências filogenéticas apontam para algum lugar no Novo Mundo como centro de origem de $P$. infestans, embora haja discordância quanto à localização geográfica. Para Goss e colaboradores (2014) P. infestans é nativa do México central, enquanto Martin e colaboradores (2015) defendem a hipótese de que seja das terras andinas da América do Sul.

O México foi considerado o centro de origem de $P$. infestans devido à alta diversidade genética do patógeno nesta região, à presença dos dois tipos de grupo de compatibilidade (A1 e A2) e a presença de duas espécies próximas, $P$. ipomoeae e $P$. miriabilis, as quais são endêmicas do México Central (GOSS et al., 2014). Para corroborar com esta hipótese, acrescenta-se o fato das populações de $P$. infestans, nas terras altas do México, se reproduzir sexualmente uma vez que os dois grupos de compatibilidade ocorrem em uma proporção de 1: 1 (GOODWIN, DRENTH, FRY, 1992a, GRUNWALD et al., 2001), os oósporos são formados nas folhas e nos caules (FERNANDEZ-PAVIA; GRÜNWALD, FRY., 2002, FLIER et al., 2001, GALLEGLY; GALINDO, 1958) e os marcadores genéticos mostram que os isolados nesta região apresentam alta variabilidade (GRUNWALD et al., 2001, TOOLEY et al., 1985).

Por outro lado, como a batata é nativa da América do Sul, na região Andina (AMES; SPOONER, 2008), há a hipótese de ser este o centro de origem de $P$. infestans (GÓMEZ-ALPIZAR; CARBONE; RISTAINO, 2007; ABAD; ABAD, 1997). No entanto, a ausência de reprodução sexuada em populações de campo e a presença de clonalidade na América do Sul depõem contra essa hipótese (FRY et al., 2009), apesar dos grupos de compatibilidade A1 e A2 serem encontrados na Argentina, Brasil, 
Paraguai e Uruguai (FORBES, 2004). No Brasil, acredita-se que o alto grau de especificidade dos isolados presente aos hospedeiros, com o grupo A1 predominando em tomate e o A2 em batata, desempenhe um papel importante no impedimento da reprodução sexuada (OLIVA et al. 2002).

O micélio de $P$. infestans é composto por filamentos (hifas) hialinos, ramificados e não septados, com um diâmetro entre 5 e $8 \mu \mathrm{m}$, onde se formam os esporangióforos. São nesses esporangióforos que se desenvolvem as estruturas assexuadas denominadas esporângios ou zoosporângios. Os esporângios são hialinos, com forma de limões e papilados, dimensões entre 21 - 38 x 12 - $23 \mu \mathrm{m}$ e são formados durante período de alta umidade relativa $(91-100 \%)$ e temperaturas entre $12-25^{\circ} \mathrm{C}$ (TOKESHI; CARVALHO, 1980).

Os esporângios de $P$. infestans podem germinar de modo direto ou indireto, dependendo da temperatura. A germinação direta consiste na formação do tubo germinativo e é favorecida por temperaturas acima de $20^{\circ} \mathrm{C}$. A germinação indireta é caracterizada pela formação e liberação de zoósporos (geralmente oito por esporângio), os quais são liberados quando a parede do esporângio se rompe em temperaturas iguais ou inferiores a $12^{\circ} \mathrm{C}$. Os zoósporos podem nadar num filme de água sobre o tecido da planta e, ao perderem seus flagelos, podem encistar, germinar, formar o tubo germinativo e penetrar na planta, iniciando assim um novo ciclo. Portanto, em baixas temperaturas, a quantidade de inóculo é muito maior do que na germinação direta do esporângio, devido à formação de zoósporos. Por esta razão, os efeitos da temperatura na germinação de esporângios têm implicações diretas no manejo da requeima. Temperaturas acima de $30^{\circ} \mathrm{C}$ são consideradas desfavoráveis para a ocorrência da doença (SOUZA, 2013; FRY; 2008; JUDELSON; BLANCO. 2005; SATO, 1994a; SATO, 1994b; TOKESHI; CARVALHO, 1980; CROSIER, 1934).

Phytophthora infestans possui características que o torna um patógeno com grande capacidade de causar danos à cultura, uma vez que possui alto potencial de esporulação, fácil disseminação via batata-semente, vento e água e curto período de incubação. Esse patógeno pode causar perdas maiores ou até totais quando ocorrem equívocos na adoção de medidas de controle, o plantio de cultivares suscetíveis é massivo, o inóculo está presente e as condições climáticas são favoráveis (TOFOLI et al., 2013; TÖFOLI, MELO, DOMINGUES, 2012; MIZUBUTI, FRY, 2006; STEVENSON et al., 2001; FRY, 1994). Acrescenta-se a isso o fato de que, na ausência do hospedeiro, os oósporos podem persistir no solo, constituindo-se como inóculo 
primário para novas infecções em novos plantios (CASA-COILA, 2014; PORTER; DASGUPTA; JOHNSON, 2005; MAYTON et al., 2000).

Dentre as condições climáticas que afetam o ciclo de vida de $P$. infestans, se destacam a temperatura e a umidade relativa do ar. A temperatura influencia a esporulação, a infecção e a expansão das lesões, além da sobrevivência de propágulos e a germinação dos esporângios (MIZUBUTI; FRY, 1998; HARTILL et al., 1990; SUJKOWSKI, 1987; MINOGUE; FRY, 1981). Já a presença de água no estado líquido e o tempo de molhamento foliar são essenciais para a esporulação, a sobrevivência do patógeno, a germinação dos esporângios e o estabelecimento da infecção (DE WEILLE, 1964; MINOGUE; FRY, 1981; HARRISON; LOWE, 1989; HARTILL et al., 1990; HARRISON, 1992; MAZIERO, 2001).

O ciclo completo do patógeno pode ocorrer em menos de cinco dias em cultivares suscetíveis, sendo que os esporos infectam também os tubérculos, causando apodrecimento durante o armazenamento e servindo de fonte primária de inóculo, se no plantio seguinte forem utilizados esses tubérculos como semente (FRY; GOODWIN, 1997).

O ciclo reprodutivo de $P$. infestans pode ser separado em assexuado e sexuado. $\mathrm{Na}$ forma assexuada ocorre a produção de esporângios (zoosporângios) e zoósporos, e na reprodução sexuada há a produção de oósporos. O oósporo também é conhecido por esporo sexual de resistência, por possuir a capacidade de se manter viável no solo na ausência de hospedeiros (CASA-COILA, 2014; DANIES et al., 2013; TRIGIANO; AMENT; LAMOUR, 2010; VARGAS et al., 2009; WIDMARK et al., 2007; MIZUBUTI; FRY, 2006; RISTAINO; GUMPERTZ, 2000; FLIER et al., 2003; ERWIN; RIBEIRO, 1996; FRY et al., 1992).

O ciclo sexual dos oomicetos pode ser dividido em duas formas, o homotálico (autofértil) e o heterotálico (autoestéril).

Phytophthora infestans é considerado um organismo heterotálico (autoestéril) com dois grupos de compatibilidade conhecidos como A1 e A2, apesar da existência também de isolados autoférteis (homotálicos) (ZHU et al., 2016).

As espécies homotálicas são capazes de produzir oósporos durante o crescimento vegetativo, seja em placas de Petri com meio de cultura ou durante a infecção dos tecidos do hospedeiro, por meio de um mecanismo de autofertilização. Em 1911, Clinton foi o primeiro a observar oogônio, anterídio e oósporos em cultura pura de $P$. infestans. De acordo com Zhu e colaboradores (2016), de maneira geral os 
isolados autoférteis mostraram maior adaptação e agressividade, além de serem mais resistentes aos princípios ativos de fungicidas, do que os isolados pertencentes ao grupo de compatibilidade A1.

Isolados autoférteis de $P$. infestans já foram identificados no México (GALLEGLY; GALINDO, 1958; GALLEGLY, 1960; GALINDO; NIEDERHAUSER, 1961; GOODWIN et al., 1992b), Estados Unidos (;MILLER; HAMM; JOHNSON, 1997); VARTANIAN; ENDO, 1985) Inglaterra e País de Gales (FYFE; SHAW, 1992; TANTIUS et al., 1986), Japão (MOSA et al., 1989), Canadá (FABRITIUS; JUDELSON, 1997) e Brasil (CASA-COILA et al., 2017).

A reprodução sexual heterotálica envolve distintos grupos de compatibilidade sexual, conhecidos como grupos de compatibilidade A1 e A2. Para que ocorra a reprodução sexual, é necessário que estes dois grupos de compatibilidade ocorram ao mesmo tempo na mesma área. Os grupos de compatibilidade A1 e A2 secretam hormônios $\alpha 1$ e $\alpha 2$, respectivamente, para induzir a formação de oósporos no grupo de compatibilidade oposto (QI et al., 2005).

A reprodução sexual começa com a formação de gametângios masculino (anterídio) e feminino (oogônio). O anterídio é confinado por um septo e secreta material adesivo que facilita o emparelhamento. Simultaneamente, a meiose ocorre tanto no anterídio quanto no oogônio e um tubo de fertilização se desenvolve entre eles, permitindo que um núcleo haplóide atinja o oogônio e a fecundação ocorra (KANDEL, 2014; JUDELSON et al., 2009).

O ciclo assexuado envolve apenas um grupo de compatibilidade, A1 ou A2. Neste caso, não ocorre uma recombinação meiótica e a variabilidade genética se origina de mutações (FRY, 2008).

A reprodução assexuada de $P$. infestans leva à baixa variabilidade genética do patógeno, enquanto que a reprodução sexuada aumenta a variabilidade do oomiceto, podendo originar híbridos mais agressivos. O conjunto de isolados de uma cepa que se reproduz de forma assexuada é conhecido como linhagem clonal (CASA-COILA, 2014; PORTER; DASGUPTA; JOHNSON, 2005; MAYTON et al., 2000).

Em 2009, Haas e colaboradores realizaram o sequenciamento completo do genoma de $P$. infestans. A análise do genoma apontou como característica marcante a presença de transposons (elementos genéticos móveis) e regiões hipervariáveis abundantes, explicando as grandes variações de fenótipo, a agressividade (KAMOUN, 2003; GUO et al., 2009), e a capacidade de se adaptar a diferentes climas e latitudes ao 
longo de sua evolução. Essas características tornam $P$. infestans um patógeno de difícil controle (FRY, GOODWIN, 1997).

O sequenciamento de DNA de folhas de batata e tomate infectadas por $P$. infestans que haviam sido herborizadas nos EUA e na Europa na época da Grande Fome Irlandesa (principalmente entre 1845 e 1849), permitiu a obtenção de diversos genomas completos de linhagens do fungo daquele período (MARTIN et al., 2013; YOSHIDA et al., 2013). Estas análises evidenciaram que uma linhagem denominada HERB-1 foi responsável pela epidemia que se iniciou em 1842 nos EUA e atingiu a Europa dois anos depois.

Os primeiros estudos que envolveram a caracterização de populações de $P$. infestans no Brasil foram realizados em meados para fins da década de 1980 (GOODWIN; COHEN; FRY, 1994; BROMMONSCHENKEL, 1988). Neste período, a linhagem clonal US-1, do grupo de compatibilidade A1, era a predominante em tomate enquanto em batata, era encontrada somente a linhagem clonal BR-1, do grupo de compatibilidade A2. Este cenário permaneceu inalterado conforme estudos realizados com isolados de tomate e batata obtidos nos anos de 1998 a 2000, nos estados de RS, SC, PR, SP, MG, RJ e ES (REIS et al., 2003) e nos anos de 2001 a 2003, no DF e GO (REIS; RIBEIRO; MIZUBUTI, 2006). No estudo de REIS e colaboradores (2003), isolados A1 foram encontrados em batata somente em campo experimental da Universidade Federal de Viçosa, infectando as variedades altamente suscetíveis Bintje e Monalisa, em uma região em que se cultivava comercialmente o tomate mas não a batata. A presença das duas linhagens clonais US-1/A1 em tomate e BR-1/A2 em batata, sem que se observasse reprodução sexuada entre as duas, devia-se provavelmente à especificidade de hospedeiro que dificultaria a ocorrência de ambas na mesma cultura (SUASSUNA; MAFFIA; MIZUBUTI, 2004).

Mudança nesse cenário foi constatada em estudo com isolados de tomate e batata coletados entre 2004 e 2005 nos estados de RS, SC e PR por Santana (2006) e Santana e colaboradores (2013). Esses autores constataram em batata, somente no RS, a presença de diferentes populações clonais e/ou reproduzindo-se sexualmente de $P$. infestans dos grupos A1 e A2, enquanto que em tomate, nos três estados, permanecia a ocorrência exclusiva da linhagem clonal US-1 do grupo A1.

Oliveira (2010) observou a ocorrência de isolados A1 e A2 de P. infestans em batata em MG e SP entre os anos de 2008 e 2010. Casa-Coila (2014), entre os anos de 
2010 a 2012, detectou isolados A1, A2 e A1/A2 em batata no RS e, em SC e PR, além dos grupos A1 e A2, observou grande quantidade de isolados autoférteis.

Nota-se, portanto, uma gradativa mudança nas populações de $P$. infestans em batata, ao longo dos anos e nas diversas regiões produtoras, com substituição da linhagem clonal BR-1, do grupo de compatibilidade A2, por novas linhagens do grupo A1 ou autoférteis. Desde o trabalho de Casa-Coila (2014), com isolados obtidos entre os anos de 2010 a 2012, não foram realizados novos estudos para a caracterização das populações de $P$. infestans de batata no Brasil.

Nestes estudos de caracterização da população brasileira de $P$. infestans foram utilizados marcadores fenotípicos, como grupo de compatibilidade sexual, resistência a mefenoxam, além de marcadores moleculares, como RFLP e haplótipos mitocondriais (mtDNA), e bioquímicos, como as isoenzimas GPI (glicose-6-fosfato isomerase) e PEP (peptidase).

A compreensão da dinâmica da variabilidade genética dos fitopatógenos se faz necessária para o entendimento de como as populações evoluem e as implicações desse processo na durabilidade de cultivares resistentes e no controle da doença. Esta compreensão pode ser traduzida na duração da efetividade da adoção de uma cultivar resistente ou de um fungicida específico para o manejo da doença (OLIVEIRA, 2010; MILGROOM; PEEVER, 2003). Segundo Lees e colaboradores (2006), diversos trabalhos já foram desenvolvidos no mundo todo para caracterizar o grupo de compatibilidade e a resistência a fungicidas das populações de $P$. infestans. No entanto, os estudos relacionados à diversidade genética eram limitados pelo baixo poder discriminatório dos marcadores genéticos então utilizados. A partir da década de 2000 , novos marcadores passaram a ser utilizados nas análises de biologia de populações de fitopatógenos, como o caso dos microssatélites ou sequencias simples repetidas (SSR) (COOKE; LEES, 2004).

\subsection{Marcadores Moleculares Microssatélites (SSR)}

Os marcadores moleculares têm sido cada vez mais utilizados para caracterizar populações de fungos fitopatogênicos, permitindo avaliar os níveis de diversidade genética, as relações filogenéticas intra e interespecíficas e a identificação de raças e patótipos (HENSEN; OBERPRIELER; WESCHE, 2005; DAVIS, KUBISIAK, 
MILGROOM, 2005; LEAL-BERTIOLI, 1998; BELABID et al., 2004; JAMES, LIOU, VILGALYS, 2004;).

Em estudos de genética populacional de fitopatógenos, os marcadores microssatélites também conhecidos como SSR ("Simple Sequence Repeats"), têm sido amplamente utilizados para verificar a estrutura e a variabilidade genética em populações. A estrutura genética refere-se à distribuição heterogênea (não aleatória) dos alelos e linhagens, no espaço e no tempo, resultante da ação de forças evolutivas tais como: mutação, migração, seleção e deriva genética que atuam dentro do contexto de cada espécie ou população (HAMRICK, 1982). Os marcadores de SSR são utilizados para investigar a estrutura genética e biologia reprodutiva de numerosos patógenos de plantas (TENZER et al., 1999).

Para Grunwald e colaboradores (2003), a análise da diversidade genética é avaliada com base nas diversidades gênica e genotípica. A primeira considera o número e a frequência dos alelos por lócus na população, enquanto que a segunda avalia o número de linhagens observadas, sua distribuição e uniformidade dentro da população. Os marcadores microssatélites têm natureza multialélica, são de fácil detecção por PCR, relativamente abundantes e podem estar distribuídos em várias partes do genoma. Eles são muito utilizados em estudos genéticos, por combinarem codominância e poliformismo em abundância. Sua identificação depende de conhecer as sequências das regiões adjacentes ao SSR, para então desenhar um par de iniciadores apropriado para essa determinada região, sendo possível nos indivíduos da população, amplificar esses SSR por PCR (polymerase chaing reaction ou reação em cadeia pela polimerase) (VIGNA et al., 2011).

$\mathrm{Na}$ literatura já foram descritos diversos lócus microssatélites (SSR) para algumas espécies de Phytophthora como: P. capsici (OGUNDIWIN et al., 2005; SUGITA et al., 2006; WANG et al. 2009), P. cinnamomi (DOBROWOLSKI, et al., 2003), P. infestans (KNAPOVA; GISI, 2002; LEES et al., 2006; LI et al., 2010) e $P$. ramorum (IVORS et al., 2006a; IVORS et al. 2006b; PROSPERO; BLACK; WINTON, 2004).

Desde 2013, baseado em estudo de Li e colaboradores (2013), um conjunto de 12 marcadores SSR foi estabelecido para o monitoramento das populações de $P$. infestans ao redor do mundo. Na Europa, o consórcio de pesquisa EuroBlight coordena os levantamentos realizados pelos diferentes países membros. Nos Estados Unidos e na América Latina essa coordenação é realizada pelos consórcios USABlight e Tizón 
Latino, respectivamente. No Brasil, esse conjunto de 12 marcadores SSR padronizados ainda não haviam sido utilizados para a caracterização das populações locais de $P$. infestans.

O emprego de técnicas moleculares, como o sequenciamento de genomas completos e diferentes marcadores incluindo SSRs, mostrou que a linhagem causadora da Grande Fome na Irlanda no século dezenove, também presente na América do Norte e denominada FAM-1 (também conhecida pelo haplótipo mitocondrial como HERB-1), foi substituída globalmente pela linhagem US-1 no século XX (SAVILLE; MARTIN; RISTAINO, 2016; MARTIN et al., 2013, YOSHIDA et al., 2013). A linhagem US-1 predominou por décadas nos EUA e Europa e ainda prevalece em algumas regiões do mundo. Pertencendo ao grupo de compatibilidade A1, a linhagem US-1 não sofreu recombinação sexual até a década de 1970, quando foram introduzidas nos EUA e Europa novas linhagens pertencentes tanto ao grupo A1 como A2, oriundas do México. A partir da diversificação genética resultante da recombinação sexual, novas linhagens clonais nos EUA (US-8, US-22 e US-23) e Europa (13_A2), tornando-se dominantes localmente por diferentes períodos (MARTIN et al., 2019). Nos últimos anos, tem-se observado o rápido surgimento e a expansão de novas linhagens clonais como, por exemplo, 36_A2, 37_A2 e 41_A2, cujo a frequência na Europa aumentou de 10\%, em 2016, para 36\%, em 2018 (EUROBLIGHT, 2019).

Em países da África ocidental (Quênia, Uganda, Tanzânia, Burundi e Ruanda), a linhagem 2_A1, originária da Europa, suplantou a então predominante US-1 em um período de nove anos (2007 a 2016) (NJOROGE et al., 2019).

Na América do Sul, a linhagem EC-1 é predominante na Colômbia (CHAVES et al., 2018), Equador (DELGADO et al., 2013) e Peru (GARRY et al., 2005). Levantamentos recentes realizados com isolados do Chile, Argentina e Brasil (parte dos isolados do presente estudo) indicaram que a linhagem 2_A1 é a predominante (LUCCA; RESTREPO, 2018).

\subsection{Manejo da Requeima}

Devido à importância da requeima para a cultura da batata, diferentes métodos de controle têm sido integrados, como por exemplo, a utilização de tubérculos-sementes sadios e de cultivares menos suscetíveis, a retirada e destruição de plantas voluntárias e 
o controle químico (BOSCO et al., 2010; TAYLOR et al., 2003). Dentre as medidas recomendadas para prevenção e controle da requeima, a mais utilizada pelos bataticultores é a aplicação de fungicidas (TOFOLI, DOMINGUES, ZANOTTA, 2017; STEVENSON; KIRK; ATALLAH, 2008).

Fungicidas de uso agrícola são compostos químicos, de origem natural ou sintética, que conferem proteção às plantas quando em contato, evitando a penetração e/ou posterior desenvolvimento de fungos e bactérias patogênicos em seus tecidos (BLUM, 2009). Estes desempenham um papel fundamental como ferramenta no controle de doenças, como a requeima.

A eficácia, o modo de ação, o risco de resistência, os efeitos colaterais e os aspectos econômicos e sociais, além das legislações, são fatores que devem ser tecnicamente considerados em programas de manejo de doenças que visem a sustentabilidade da cadeia produtiva da batata (TOFOLI, DOMINGUES, ZANOTTA, 2017).

A constante evolução técnico-científica dos princípios ativos permitiu o desenvolvimento de fungicidas com diversos mecanismos de ação na planta e nas diferentes fases do processo infeccioso (AGRIOS, 2005; RUSSEL, 2005).

Em relação ao comportamento na planta, os princípios ativos podem ser classificados em produtos de contato, mesostêmicos, translaminares e sistêmicos (TOFOLI, DOMINGUES, ZANOTTA, 2017).

Os produtos de contato caracterizam-se por formar uma película protetora na superfície da planta, que impede a penetração do patógeno. Os mesostêmicos apresentam alta afinidade com a camada cerosa superficial das folhas, podendo redistribuir na fase de vapor ou ser absorvidos pelo tecido, entretanto não apresentam nenhum movimento. Os produtos sistêmicos são aqueles que possuem movimento pela planta, através de vasos condutores, podendo atingir locais distantes do local onde foi depositado, enquanto os translaminares movimentam-se de forma mais limitada nos tecidos (TOFOLI, DOMINGUES, ZANOTTA, 2017; TOFOLI, 2011; AZEVEDO, 2007; REIS, REIS, FORCELINI, 2007). Os fungicidas mesostêmicos, translaminares e sistêmicos são considerados produtos seletivos, porque, em geral, inibem processos metabólicos específicos inerentes a grupos restritos de fungos (TOFOLI, DOMINGUES, ZANOTTA, 2017).

O custo mundial da cultura de batata excede os US\$ 5 bilhões/ano, sendo 1/5 desse valor gasto em fungicidas (USABLIGHT, 2017). Em 1998, no Brasil, calculou-se 
que o percentual destinado ao controle da requeima representava entre 15 e $20 \%$ dos custos de produção da cultura (SEAB-DERAL, 1998).

Todas as cultivares comerciais são suscetíveis a alguma raça do patógeno, pois P. infestans, por meio da reprodução sexuada, é capaz de formar novas raças fisiológicas. Portanto, o método mais eficiente existente para o controle da requeima ainda é o químico (BOSCO et al., 2010; KIRK et al., 2005).

No Brasil, as aplicações de fungicidas na cultura da batata são, em geral, excessivas por serem realizadas sem considerar a interação entre o ciclo de vida do patógeno e as condições meteorológicas, o que gera, por consequência, o aumento no custo de produção e no impacto ambiental, devido à contaminação da água e do solo por fungicidas (BOSCO et al., 2010; GARCÍAS, 2005; HIJMANS et al., 2000; NAZARENO et al., 1999; ERWIN; RIBEIRO, 1996). Em casos extremos, os produtores de batata podem efetuar até 30 aplicações por ciclo da cultura para controlar a requeima (NAZARENO; JACCOUND FILHO, 2003).

Os fungicidas têm sido eficazes para o controle de $P$. infestans, porém o uso contínuo pode trazer como consequência a seleção de populações de patógenos menos sensíveis ou até mesmo resistentes. Esse tipo de situação já está presente por todo o mundo, ou seja, os fungicidas acabam atuando como agentes de seleção (BRENT; HOLLOMON, 2007).

A resistência de fungos a fungicidas pode ser classificada qualitativa ou quantitativamente. Na qualitativa, ocorre a perda de efetividade do fungicida de modo repentino e marcante, pela presença bem definida de populações de patógenos que apresentam sensibilidade e resistência com respostas que variam amplamente. $\mathrm{Na}$ quantitativa, ocorre a diminuição da eficácia no controle da doença, assim como a diminuição da sensibilidade das populações do patógeno, demonstrada por testes de monitoramento. Esse tipo de resistência se manifesta gradualmente (FRAC, 2018).

Para observar se está, ou não, ocorrendo a diminuição da sensibilidade ao principio ativo, é indicado calcular o EC50, ou seja, a concentração efetiva para matar $50 \%$ dos microrganismos submetidos ao fungicida, que neste caso é a fungitoxicidade de uma substância química (VALENCIO, 2017; OGA; CAMARGO; BATISTUZZO, 2008; RUSSEL, 2004;.LOOMIS, 1995; EDGINGTON，KHEW，BARRON，1971; TORGESON, 1967; SHARVELLE, 1961).

Para se realizar um monitoramento de resistência de fungos a fungicidas é de extrema importância que se analise um grande número de isolados, além disso, as 
técnicas de monitoramento requerem um alto investimento e tempo (RAPOSO, et al. 2015). Um dos métodos mais utilizados para medir essa resistência e determinar o $\mathrm{EC}_{50}$, é o método de inibição do crescimento micelial da colônia em meio de cultura (ICM) (DEKKER, 1987; GEORGOPOULOS, 1982).

Como alternativa, a sensibilidade de fungos a fungicidas pode ser avaliada através da metodologia de microtitulação colorimétrica. Essa metodologia vem sendo recomendada pelo FRAC Internacional, já sendo empregada em diversos estudos de monitoramento de resistência (VALÊNCIO, 2017; VEGA et al., 2012; RAMPERSAR, 2011; STAMMLER; BENZINGER; SPEAKMAN, 2007).

No teste de microtitulação, a quantidade de biomassa fúngica presente nos poços afeta a passagem de luz proporcionalmente, possibilitando quantificar o efeito do fungicida de forma rápida e reprodutível. Essas características tornam esse método muito apropriado para um monitoramento rápido e preciso de resistência em uma população de fungos a fungicidas (RAPOSO et al., 2015). Este método consiste no fungo ser cultivado em poços de microplacas de poliestireno, sendo seu crescimento analisado por espectofotômetro (LUDWING; BOLLER, 1990).

No Brasil, o controle da requeima tem sido realizado basicamente com fungicidas à base de metalaxil-M, dimetomorfe, cimoxanil, famoxadona e fluazinam. Os fungicidas de contato pertencentes às classes dos ditiocarbamatos (mancozebe, metiram) e cloronitrilas (clorotalonil) têm sido empregados no controle preventivo, seja em aplicações isoladas, ou formulados em mistura com produtos específicos (TOFOLI, DOMINGUES, ZANOTTA, 2017).

Nos últimos anos, novos produtos foram introduzidos no mercado brasileiro para o controle da requeima. Novas misturas, mecanismos de ação e características técnicas diferenciadas abrem novas perspectivas para o controle dessa doença (TOFOLI, DOMINGUES, ZANOTTA, 2017). Entre as opções para o controle da requeima destacam-se os fungicidas à base de ametoctradina (TOFOLI et al., 2016; REIMANN et al., 2010; GOLD et al., 2009), bentiavalicarbe (MIYAKE et al., 2005), ciazofamida (EBERSOLD, 2002), cimoxanil (GENET et al., 2000), dimetomorfe (JOHNSON, CUMMINGS, GEARY, 2000), fenamidona (TAFFOREAU et al., 2009), fluopicolida (LATORSE et al., 2007; TAFFOREAU et al., 2006), mandipropamida (THOMPSON; COOKE, 2009; HUGGENBERGER; KNAUFBEITER, 2007; HERMANN et al., 2005), mefenoxam (BODKER; NIELSEN 2002; BODKER; NIELSEN, 2001), propamocarbe (BODKER; NIELSEN, 2002; 
BODKER; NIELSEN, 2001; JOHNSON, CUMMINGS, GEARY, 2000) e zoxamida (BRADSHAW; SCHEPERS, 2001).

Levantamento sobre a sensibilidade o metalaxil de $P$. infestans de tomate e batata obtidos entre os anos de 1998 a 2000 nas regiões Sul e Sudeste do Brasil indicou elevada frequência de resistência em isolados de tomate (55\%) e batata (38\%) (REIS et al., 2003). Reis e colaboradores (2005) confirmaram alta incidência de isolados de tomate e batata insensíveis ao metalaxil, nas linhagens US-1 e BR-1, enquanto que, para mancozebe, clorotalonil e cimoxanil, os isolados foram altamente sensíveis. Em estudo com isolados de tomate e batata obtidos no estado de Goiás e em cidades satélites de Brasília, foi observada alta frequência de isolados de tomate resistentes (36\%) e intermediários (48\%) ao mefenoxam (metalaxil-M), enquanto que a maioria dos isolados de batata (82\%) foi sensível (REIS; RIBEIRO; MIZUBUTI, 2006). No mesmo estudo, quando utilizado metalaxil, a maioria dos isolados de batata (87\%) foi resistente ou intermediária. Casa-Coila (2014) observou, nos três estados da Região Sul, alta proporção de isolados de $P$. infestans de batata, moderadamente resistentes $(77,44 \%)$ e resistentes $(17,29 \%)$ a metalaxil, enquanto que para clorotalonil não se constatou perda de sensibilidade. 
4. MATERIAL E MÉTODOS 


\subsection{Coleta de material infectado}

Material botânico (folhas, hastes, caules, frutos e/ou tubérculos) manifestando sintomatologia típica de requeima foi coletado em diversos locais onde ocorre a produção de batata pelo Brasil (Figura 4). As coordenadas geográficas dos locais de coleta das amostras foram registradas com um aparelho GPS.

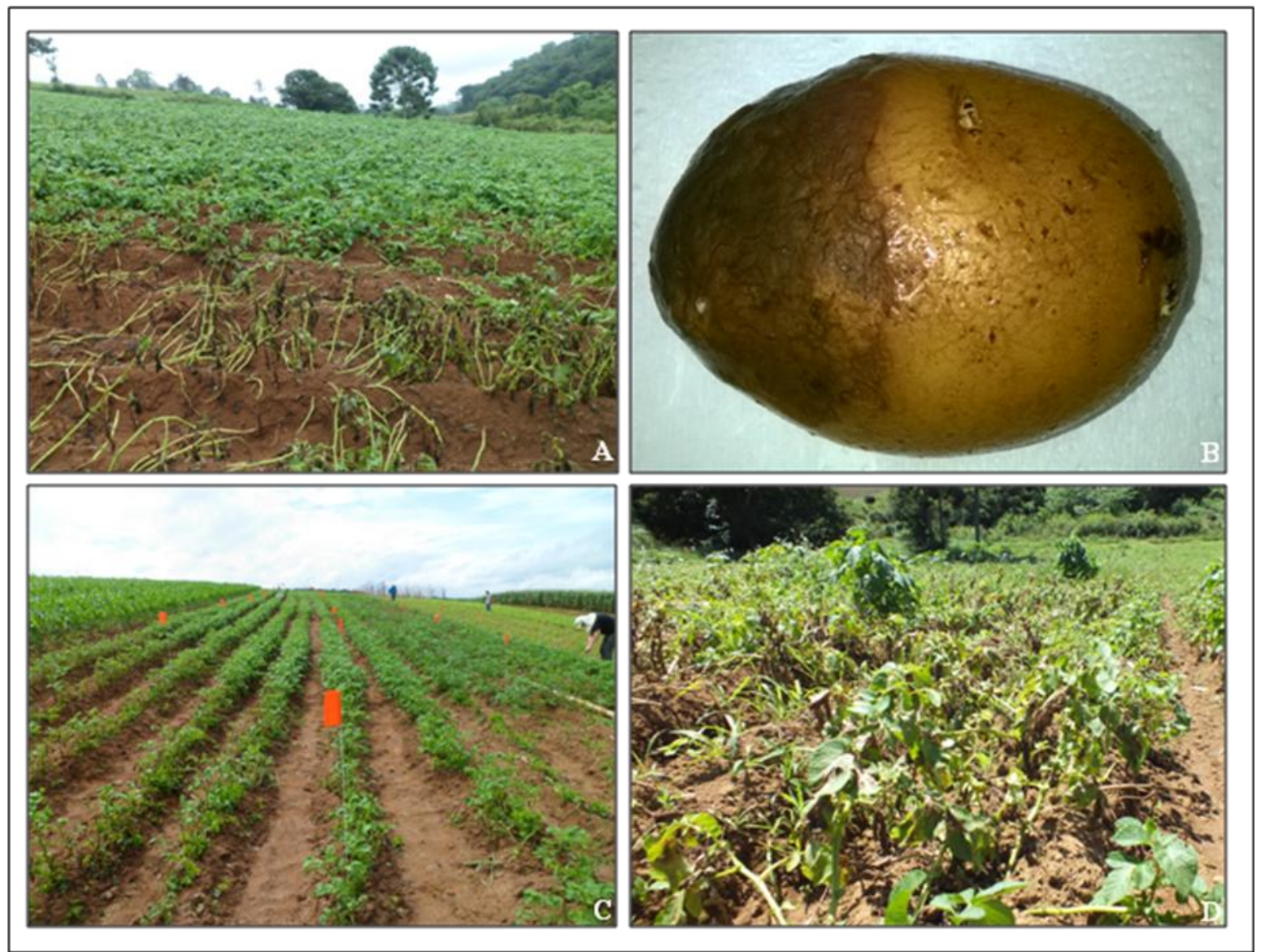

Figura 4. Locais de coletas de amostras de batata com sintomas de requeima: A) Divinolândia/SP (março/2015), B) Itararé (julho/2015), C) Pilar do Sul (março/2015), D) Divinolândia/SP (abril/2015).

Quando a coleta não podia ser feita presencialmente, foi desenvolvido um formulário (Figura 5) para coleta e este era encaminhado ao produtor ou engenheiro agrônomo responsável pela área.

Amostras de tomateiros infectados com $P$. infestans também foram encaminhadas por produtores para o projeto. 


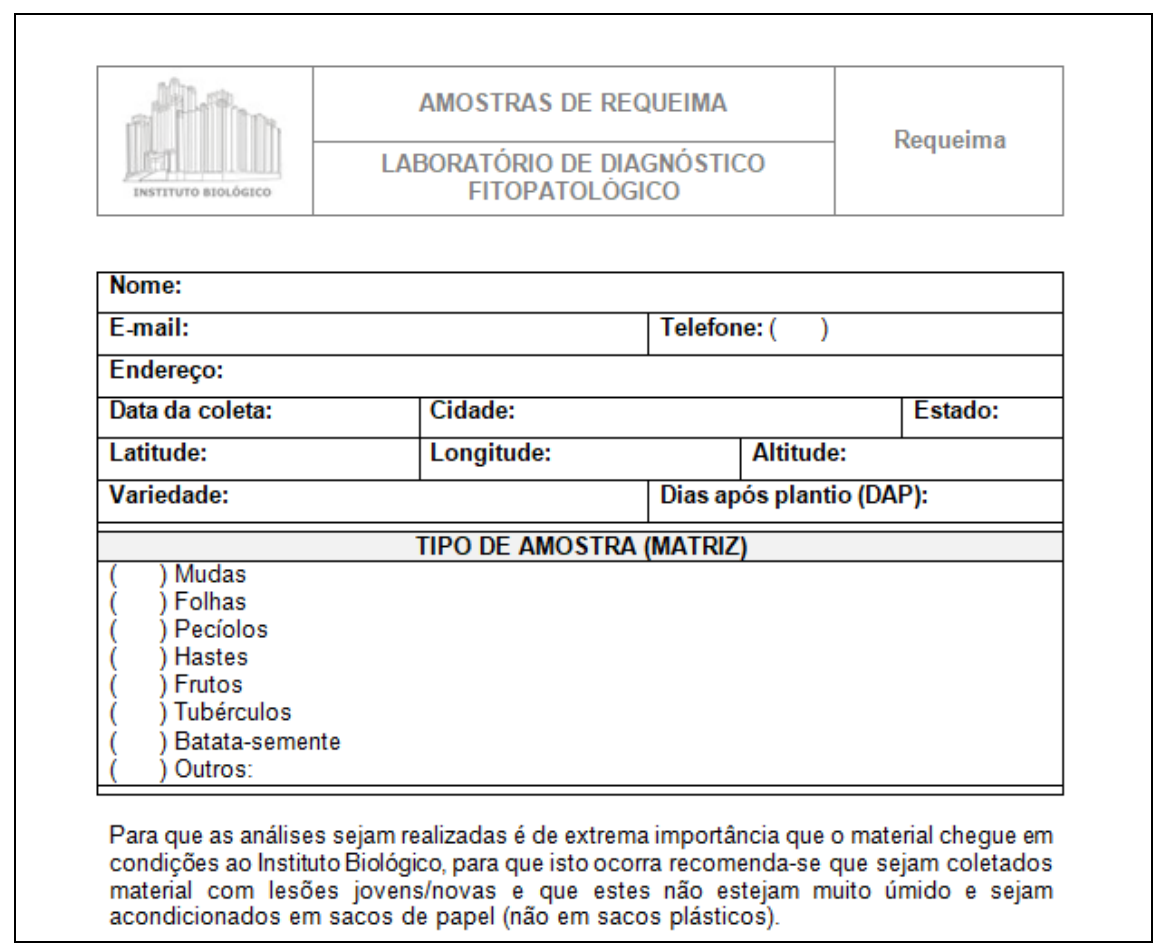

Figura 5. Formulário desenvolvido para o envio de amostra de requeima ao Instituto Biológico.

As amostras foram levadas ao Laboratório de Doenças Fúngicas em Horticultura (LDFH) ou para o Laboratório de Diagnóstico Fitopatológico (LDF) no Instituto Biológico (IB), em São Paulo, SP.

\subsection{Monitoramento do tipo de reprodução}

\subsubsection{Indução à produção de estruturas de reprodução}

No laboratório, as amostras foram observadas sob microscópios estereoscópico e óptico, para que fossem analisadas as estruturas de reprodução presentes nas mesmas. Quando a amostra apresentava os sintomas típicos de requeima, mas nenhuma estrutura de reprodução, a amostra era colocada em câmara úmida (dentro de caixa gerbox sobre papel filtro umedecido com água destilada) e mantidas em câmara incubadora (BOD) com temperatura de $16 \pm 2^{\circ} \mathrm{C}$, com fotoperíodo de 12 horas. Após três dias, as estruturas de reprodução eram analisadas. As análises continuaram diariamente por até 15 dias. 


\subsection{Isolamento de Phytophthora infestans}

Para o isolamento de $P$. infestans foi utilizado meio indicado pelo Fry Lab (2014) com modificações, que consistiram no preparo do meio V8 não clarificado (suco V8, água destilada, $\beta$-sitosterol, carbonato de cálcio e ágar) com adição de antibióticos (ampicilina e rifampicina) e fungicidas (cercobin e flutriafol).

Durante o período de incubação, para a esporulação do patógeno, o material infectado foi visualizado em microscópios (esteroscópico e óptico) e, posteriormente, fragmentos do material, contendo estruturas do patógeno, foram transferidos para o meio de cultura descrito acima e incubados a $16^{\circ} \mathrm{C}$ com fotoperíodo de 12 horas.

\subsection{Extração de DNA}

Discos de micélios de nove milímetros de diâmetro de isolados de P. infestans foram transferidos para tubos de ensaio contendo meio líquido de ervilha (FRY LAB, 2014). Estes foram mantidos a $18^{\circ} \mathrm{C}$ por sete dias, posteriormente o micélio foi coletado e transferido para microtubos de $1,5 \mathrm{~mL}$.

As amostras de tomate não foram utilizadas para isolamento do patógeno em meio de cultura, sendo a extração de DNA feita diretamente do tecido infectado.

A extração de DNA foi realizada segundo método descrito por Dellaporta e colaboradores (1983) com modificações. O material foi triturado sob nitrogênio líquido dentro de tubos de $1,5 \mathrm{~mL}$, adicionou-se solução de extração CTAB e seguiu-se incubação por $30-45$ minutos a $65^{\circ} \mathrm{C}$ com agitação moderada. Adicionou-se clorofórmio/álcool isoamílico (24:1), a mistura foi agitada por inversão e centrifugada a $14.000 \mathrm{G}$ por $5 \mathrm{~min}$. O sobrenadante foi transferido para novos tubos e a extração com clorofórmio/álcool isoamílico foi repetida. O sobrenadante foi novamente transferido para novos tubos de 1,5 mL, aos quais foram adicionados 0,6 volumes de isopropanol e mantidos a $-4^{\circ} \mathrm{C}$ durante a noite. Após este período, os tubos foram centrifugados a $12.000 \mathrm{G}$ por $10 \mathrm{~min}$ e o sobrenadante foi descartado. $\mathrm{O}$ precipitado foi lavado com etanol absoluto seguido de lavagem com etanol 70\%. O sobrenadante foi descartado e o sedimento foi seco a $36{ }^{\circ} \mathrm{C}$ por $20 \mathrm{~min}$. O DNA foi suspendido em $40 \mu \mathrm{L}$ de água de osmose reversa esterilizada. 


\subsection{Identificação do grupo de compatibilidade}

\subsubsection{Amplificação por PCR (Reação em Cadeia da Polimerase)}

Os fragmentos de DNA foram submetidos à amplificação por reação em cadeia de polimerase (PCR) utilizando os iniciadores S1-A e S1-B, iniciadores modificados a partir dos descritos por Judelson (1996), que amplifica um fragmento de aproximadamente $1250 \mathrm{pb}$ para isolados pertencentes ao grupo de compatibilidade A1, os iniciadores PHYB-1 e PHYB-2, descritos por Kim e Lee (2002), que amplificam um fragmento de $347 \mathrm{pb}$ para isolados que pertencem ao grupo de compatibilidade A2 e com os iniciadores W16-1 e W16-2, descritos por Judelson, Spielman e Shattock (1995), que amplificam fragmento de 547 pb para ambos os grupos de compatibilidade, mas permitem discriminar os grupos após digestão com a enzima de restrição Hae III ou sequenciamento. As sequências dos iniciadores utilizados estão descritas na Tabela 2.

Tabela 2. Iniciadores utilizados para identificação dos grupos de compatibilidade dos isolados de Phytophthora infestans

\begin{tabular}{cccc}
\hline Iniciador & Sequência (5'-3') & $\begin{array}{c}\text { Fragmento / Grupo } \\
\text { de Compatibilidade }\end{array}$ & Referência \\
\hline S1-F & AGGATTTCAACAA & $1250 \mathrm{pb} / \mathrm{A} 1$ & JUDELSON, \\
S1-R & TGCTTCCTAAGG & & 1996 \\
\hline PHYB-1 & GATCGGATTAGTCAGACGAG & $347 \mathrm{pb} / \mathrm{A} 2$ & KIM; LEE, \\
PHYB-2 & GCGTCTGCAAGGCGCATTTT & & 2002 \\
\hline W16-1 & AACACGCACAAGGCATATAAATGTA & & JUDELSON, \\
& & $547 \mathrm{pb} / \mathrm{A} 1$ e A2 & SPIELMAN e \\
W16-2 & GCGTAATGTAGCGTAACAGCTCTC & & SHATTOCK, \\
& & & 1995 \\
\hline
\end{tabular}

\subsubsection{Sequenciamento}

Os produtos da PCR foram purificados seguindo protocolo descrito por Schmitz e Riesner (2006). Em microtubo de 1,5 mL, foi misturados 1,6 $\mu 1$ de EDTA 0,5 M, 21,0 $\mu \mathrm{L}$ PEG 6.000 a $50 \%$ e $8,1 \mu \mathrm{L}$ de $\mathrm{NaCl} 5 \mathrm{M}$. Adicionou-se o produto da PCR $(50 \mu \mathrm{L})$ à mistura e incubou-se a temperatura ambiente por $10 \mathrm{~min}$. Após centrifugação 
a $14.000 \mathrm{G}$ por $10 \mathrm{~min}$, o sobrenadante foi descartado e o pellet foi lavado com $125 \mu \mathrm{L}$ de etanol $70 \%$. O pellet foi seco a $36^{\circ} \mathrm{C}$ por 20 minutos. O DNA foi ressuspendido em $30 \mu \mathrm{L}$ água de osmose reversa esterilizada.

Os produtos purificados foram sequenciados pelo método de terminação de cadeia, descrito por Sanger et al. (1977). As reações para sequenciamento foram efetuadas com o kit Big Dye 3.1 (Applied Biosystems) e analisadas em sequenciador ABI 3500 xL (Applied Biosystems), conforme instruções do fabricante.

As sequências obtidas foram alinhadas e analisadas utilizando-se o programa BioEdit (HALL, 1999).

\subsubsection{Pareamento "in vitro"}

O pareamento in vitro foi feito seguindo protocolo do Lab Fry (2014), com modificações. Em placa de Petri de $9 \mathrm{~cm}$, contendo meio V8 10\% clarificado, foram colocados dois discos de micélios separados por aproximadamente $6,0 \mathrm{~cm}$. Um dos discos de micélio pertencente a um dos isolados padrões e o outro pertencente a um isolado desconhecido. Cada isolado desconhecido foi pareado com ambos os isolados padrões (A1 e A2). Posteriormente placas foram mantidas em BOD a $16 \pm 2^{\circ} \mathrm{C}$ no escuro. Após 15 dias de incubação, as placas foram observadas sob microscópio estereoscópico e, se necessário, microscópio óptico, para observar a presença ou não de oósporos.

Os isolados que apresentaram formação de oósporos quando pareados com o padrão A1 foram classificados como A2 e os que o fizeram com o padrão A2, foram classificados como A1.

Os isolados padrões 151 (Santa Maria do Herval/RS) - isolado de batata pertencente ao grupo de compatibilidade A2; CRI-2 (Cristal/RS) - isolado de batata pertencente ao grupo de compatibilidade A1 e PRT - isolado de tomate pertencente ao grupo de compatibilidade A1, foram fornecidos pelo Dr. Cesar Bauer Gomes, Pesquisador da Embrapa Clima Temperado (Pelotas-RS). 


\subsection{Caracterização molecular por microssatélite (SSR)}

Os procedimentos para a análise molecular por microssatélite dos isolados de $P$. infestans foram realizados inicialmente no Instituto de Biotecnologia Agropecuária, situado no Instituto Nacional de Tecnología Agropecuária (INTA) em Hurlingham, Província de Buenos Aires, Argentina, com a colaboração das pesquisadoras Dra. Ana María Florencia Lucca, Dra. Andrea Fabiana Puebla e María Florencia Servici. Posteriormente, as análises foram realizadas na Unidade Laboratorial de Referencia em Biologia Molecular Aplicada (ULRBMA), no Instituto Biológico, em São Paulo, SP.

A partir do DNA total extraído e quantificado em equipamento Nanodrop, foi realizada reação de PCR para amplificação de 12 marcadores microssatélites (SSR), (Tabela 3): Pi4B e PiG11 (KNAPOVA, GISI, 2002), D13, Pi04, Pi63, Pi70 (LEES et al., 2006) e PinfSSR2, PinfSSR3, PinfSSR4, PinfSSR6, PinfSSR8 e PinfSSR11 (LI et al., 2010).

O iniciador forward de cada um dos lócus foi marcado com um fluoróforo, com exceção do lócus PinfSSR6 para o qual o iniciador reverse foi marcado. Foram utilizados quatro fluoróforos: NED para amarelo (PiG11, PinfSSR3, PinfSSR11), FAM para azul (D13, PinfSSR4, PinfSSR8), VIC para verde (Pi04, Pi63, Pi70, PinfSSR6) e PET para vermelho (Pi4B, PinfSSR2) (Tabela 7).

A amplificação dos marcadores microssatélites foi realizada em um volume final de $12,5 \mu \mathrm{L}$, com aproximadamente $150 \mathrm{ng}$ de DNA e o Type-it® Microsatellite PCR Kit (QIAGEN), seguindo instruções do fabricante. A reação de PCR foi realizada em termociclador Veriti (Applied Biosystems) ou T100 (BioRad), com a programação de uma etapa inicial de desnaturação a $95^{\circ} \mathrm{C}$ por $5 \mathrm{~min}$, seguida de 30 ciclos de $95^{\circ} \mathrm{C}$ por $30 \mathrm{~s}$ para desnaturação, $58^{\circ} \mathrm{C}$ por $90 \mathrm{~s}$ para anelamento e $72^{\circ} \mathrm{C}$ por 20 s para extensão, e uma extensão final a $72^{\circ} \mathrm{C}$ por $30 \mathrm{~min}$.

Após a amplificação, o produto da PCR foi visualizado em gel de agarose a $1,5 \%$, contendo $0,5 \mathrm{mg} / \mathrm{mL}$ de brometo de etídeo. Posteriormente, os produtos foram diluídos (5 a 50 vezes), em água Milli Q autoclavada, com base na intensidade no gel de agarose.

Dois microlitros da diluição foram misturados com $8 \mu \mathrm{L}$ de formamida contendo o padrão GeneScan 500 LIZ (Thermo Scientific), desnaturados a $92{ }^{\circ} \mathrm{C}$ durante 5 minutos e analisados em sequenciador ABI Prism® 3500 xL Genetic Analyzer (Applied Biosystems). 
Os fragmentos foram avaliados através do software GeneMapper® versão 4.0 (Applied Biosystems ${ }^{\circledR}$ ) na Argentina e com o software STRand no Brasil. O tamanho dos alelos foi comparado com a lista de alelos cedida pela Euroblight e Tizón Latino (Anexos 1, 2 e 3) e a nomenclatura dos alelos foi dada seguindo a descrição da tabela no tópico "final name".

Árvore de distância genética, calculada por Neighbor Joining, e gráfico de "minimum spanning network" foram construídos com os dados de microssatélites do presente estudo, comparando com linhagens de referência, com a ferramenta GenotypeID do website Phytophthora-ID versão 2.0 (www.phytophthora-id.org) (LEES et al., 2006; LI et al., 2013). Também foram incluídos dados de microssatélites da linhagem BR-1 (cedidos por Jean Ristaino, North Carolina State University) e de outras linhagens mundiais presentes no estudo de Martin e colaboradores (2019). 
Tabela 3. Descrição dos iniciadores para amplificação dos12 lócus polimórficos microssatélites usados na caracterização de isolados de Phytophthora infestans.

\begin{tabular}{|c|c|c|c|c|c|}
\hline Lócus & Iniciador & Sequência $\left(5^{\prime}-3^{\prime}\right)$ & Fluoróforo & Faixa de tamanho do produto & Referência \\
\hline \multirow{2}{*}{ D13 } & D13-Fwd & FAM - TGCCCCCTGCTCACTC & FAM & & \multirow{4}{*}{ LEES et al., 2006} \\
\hline & D13-Rev & GCTCGAATTCATTTTACAGACTTG & (Azul) & $100-185 \mathrm{pb}$ & \\
\hline \multirow{2}{*}{ Pi04 } & Pi04-Fwd & VIC - AGCGGCTTACCGATGG & $\mathrm{VIC}$ & \multirow{2}{*}{$162-170 \mathrm{pb}$} & \\
\hline & Pi04-Rev & GTTTCAGCGGCTGTTTCGAC & (Verde) & & \\
\hline \multirow{2}{*}{ Pi4B } & Pi4B-Fwd & PET - AAAATAAAGCCTTTGGTTCA & PET & \multirow{2}{*}{$200-295 \mathrm{pb}$} & \multirow{2}{*}{ KNAPOVA; GISI, 2002} \\
\hline & Pi4B-Rev & GCAAGCGAGGTTTGTAGATT & (Vermelho) & & \\
\hline \multirow{2}{*}{ Pi63 } & Pi63-Fwd & VIC - ATGACGAAGATGAAAGTGAGG & VIC & \multirow{2}{*}{$265-280 \mathrm{pb}$} & \multirow{4}{*}{ LEES et al., 2006} \\
\hline & Pi63-Rev & CGTATTTTCCTGTTTATCTAACACC & (Verde) & & \\
\hline \multirow{2}{*}{ Pi70 } & Pi70-Fwd & VIC - ATGAAAATACGTCAATGCTCG & VIC & \multirow{2}{*}{$189-195 \mathrm{pb}$} & \\
\hline & Pi70-Rev & CGTTGGATATTTCTATTTCTTCG & (Verde) & & \\
\hline \multirow{2}{*}{ PiG11 } & PiG11-Fwd & NED - TGCTATTTATCAAGCGTGGG & NED & \multirow{2}{*}{$130-180 \mathrm{pb}$} & \multirow{2}{*}{ KNAPOVA; GISI, 2002} \\
\hline & PiG11-Rev & GTTTCAATCTGCAGCCGTAAGA & (Amarelo) & & \\
\hline \multirow{2}{*}{ PinfSSR2 } & SSR2-Fwd & PET - CGACTTCTACATCAACCGGC & PET & \multirow{2}{*}{$165-180 \mathrm{pb}$} & \multirow{12}{*}{ LI et al., 2010} \\
\hline & SSR2-Rev & GTTTGCTTGGACTGCGTCTTTAGC & (Vermelho) & & \\
\hline \multirow{2}{*}{ PinfSSR3 } & SSR3-Fwd & NED - ACTTGCAGAACTACCGCCC & NED & \multirow{2}{*}{$254-274 \mathrm{pb}$} & \\
\hline & SSR3-Rev & GTTTGACCACTTTCCTCGGTTC & (Amarelo) & & \\
\hline \multirow{2}{*}{ PinfSSR4 } & SSR4-Fwd & FAM - TCTTGTTCGAGTATGCGACG & FAM & $280-305 \mathrm{nh}$ & \\
\hline & SSR4-Rev & GTTTCACTTCGGGAGAAAGGCTTC & (Azul) & $200-300$ po & \\
\hline \multirow{2}{*}{ PinfSSR6 } & SSR6-Fwd & GTTTTGGTGGGGCTGAAGTTTT & VIC & \multirow{2}{*}{$230-250 \mathrm{pb}$} & \\
\hline & SSR6-Rev & VIC - TCGCCACAAGATTTATTCCG & (Verde) & & \\
\hline \multirow{2}{*}{ PinfSSR8 } & SSR8-Fwd & FAM - AATCTGATCGCAACTGAGGG & FAM & \multirow{2}{*}{$250-275 \mathrm{pb}$} & \\
\hline & SSR8-Rev & GTTTACAAGATACACACGTCGCTCC & (Azul) & & \\
\hline \multirow{2}{*}{ PinfSSR11 } & SSR11-Fwd & NED - TTAAGCCACGACATGAGCTG & NED & \multirow{2}{*}{$325-360 \mathrm{pb}$} & \\
\hline & SSR11-Rev & GTTTAGACAATTGTTTTGTGGTCGC & (Amarelo) & & \\
\hline
\end{tabular}




\subsection{Teste de sensibilidade in vitro de isolados de Phytophthora infestans aos fungicidas, ciazofamida, clorotalonil, dimetomorfe e propamocarbe}

Para o experimento foram selecionados 17 isolados de $P$. infestans, de seis variações genotípicas escolhidas dentre as mais frequentes no presente estudo (Tabela 4).

O experimento foi instalado seguindo protocolo de Microtitulação de Dimetomorfe do FRAC (2006), com adaptações.

Discos de 0,7 cm de diâmetro dos isolados escolhidos foram retirados dos bordos de colônias, com dez dias de idade, e transferidos para o centro de placas de Petri (9 cm de diâmetro) contendo meio V8. Após as repicagens, as placas foram mantidas em fotoperíodo de 12 horas, a $16^{\circ} \mathrm{C} \pm 2^{\circ} \mathrm{C}$ por um período de dez dias.

Para obtenção do inóculo, os esporângios foram coletados adicionando-se $10 \mathrm{~mL}$ de meio líquido de ervilha (FRAC, 2006) em cada placa de Petri contendo o isolado crescido e feita uma raspagem do micélio com lâmina descartável estéril. A suspensão de esporângios foi filtrada em gaze esterilizada e a concentração foi ajustada para $10^{4}$ esporângios. $\mathrm{mL}^{-1}$ com o auxílio de câmara de Neubauer.

Os princípios ativos utilizados neste experimento foram: ciazofamida (concentração: $34,50 \% \mathrm{~m} / \mathrm{v}$ ), propamocarbe (concentração: $72,20 \% \mathrm{~m} / \mathrm{v}$ ), clorotalonil (concentração: $50,00 \% \mathrm{~m} / \mathrm{v}$ ) e dimetomorfe (concentração: $50,00 \% \mathrm{~m} / \mathrm{v}$ ).

Para padronizar o teste de sensibilidade, todos os fungicidas selecionados foram utilizados nas concentrações de: $0 ; 0,01 ; 0,03 ; 0,1 ; 0,3 ; 1 ; 3$ e $10 \mu \mathrm{g} \cdot \mathrm{mL}^{-1}$, diluídas a partir de solução estoque dos fungicidas na concentração de $1000 \mu \mathrm{g} \cdot \mathrm{mL}^{-1}$. (Figura 6).

Cada concentração do fungicida foi incubada com a suspensão de esporângios em triplicata. 
Tabela 4. Isolados de Phytophthora infestans selecionados para o experimento de sensibilidade a fungicidas

\begin{tabular}{cccc}
\hline Variação & Denominação & $\begin{array}{c}\text { Cidade - Estado de } \\
\text { Procedência }\end{array}$ & $\begin{array}{c}\text { Planta } \\
\text { hospedeira/Variedade }\end{array}$ \\
\hline 06 & 151 & Santa Maria do Herval - RS & Batata \\
- & PRT & - & Batata \\
04 & CRI-2 & Cristal - RS & Batata \\
04 & 006 & Pilar do Sul - SP & Batata / Agata \\
07 & $012 \mathrm{C}$ & Campo do Tenente - PR & Batata / Atlantic \\
09 & 023 & Santa Juliana - MG & Batata / Markies \\
02 & $035 B$ & Serra do Salitre - MG & Batata / Atlantic \\
07 & 042 & Vargem Grande do Sul - SP & Batata / Ioná \\
07 & 051 & Boa Vista - RR & Tomate / - \\
02 & 061 & Ponta Grossa - PR & Batata / - \\
08 & 064 & Tapira - MG & Batata / Atlantic \\
04 & 077 & Vargem Grande do Sul - SP & Batata / FL 1867 \\
04 & 093 & Ponta Grossa - PR & Batata / - \\
04 & 109 & Ponta Grossa - PR & Batata / Agata \\
04 & 117 & Lapa - PR & Batata / Atlantic \\
04 & 136 & Itapetininga - SP & Batata / Romeo \\
04 & 140 & Leme - SP & Batata / - \\
\hline
\end{tabular}

*- Não consta. 


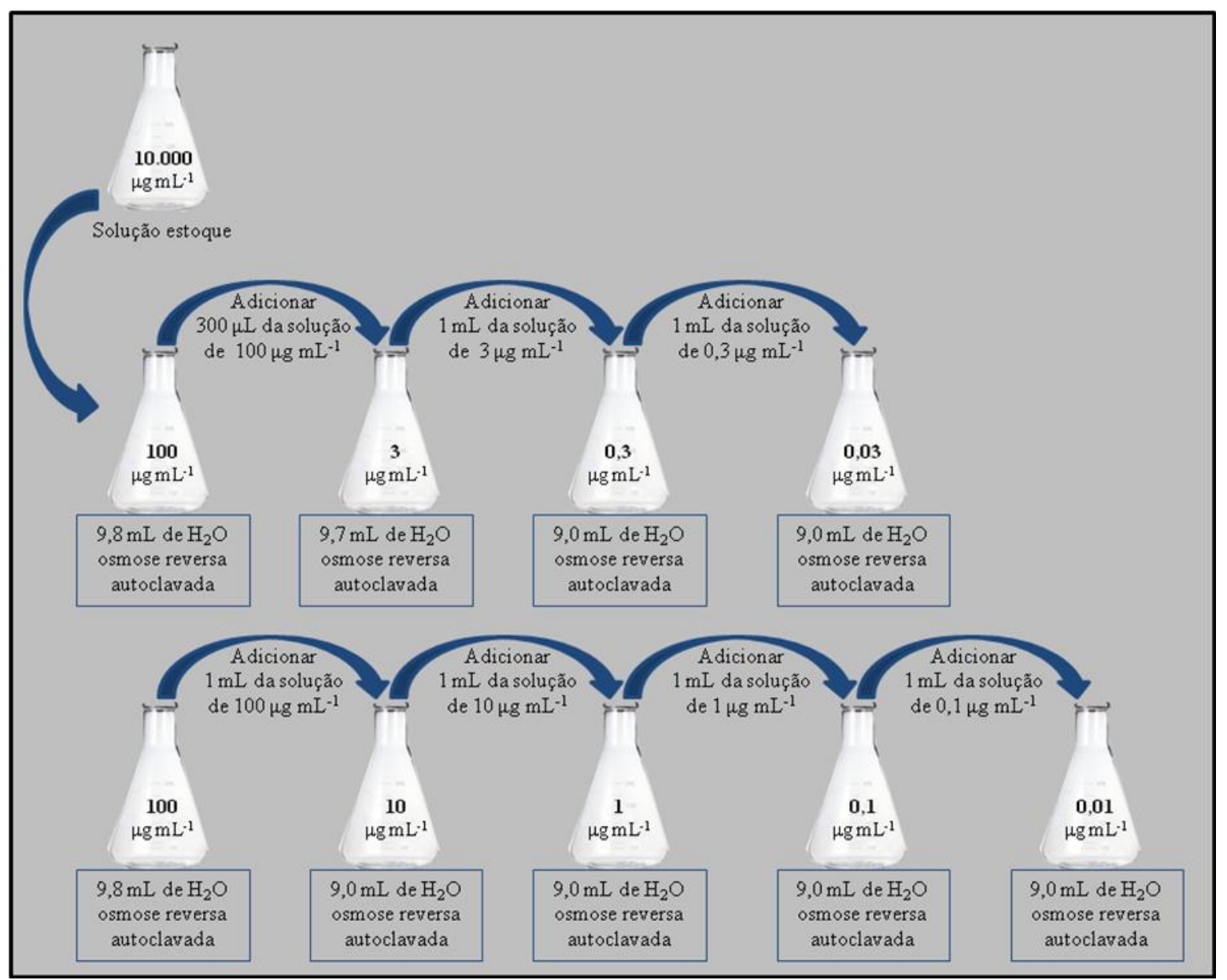

Figura 6. Esquema da diluição seriada dos princípios ativos de diferentes fungicidas, para a obtenção das concentrações utilizadas.

Para estudar a sensibilidade de cada isolado ao fungicida pelo teste de microtitulação colorimétrica, foram utilizadas microplacas de poliestireno estéreis de 96 poços onde foram adicionados $50 \mu \mathrm{L}$ da suspensão de esporângios na concentração $10^{4}$ esporângios. $\mathrm{mL}^{-1}$, seguido da adição de $50 \mu \mathrm{L}$ das diferentes concentrações do fungicida, atingindo um volume final de $100 \mu \mathrm{L}$ por poço. 


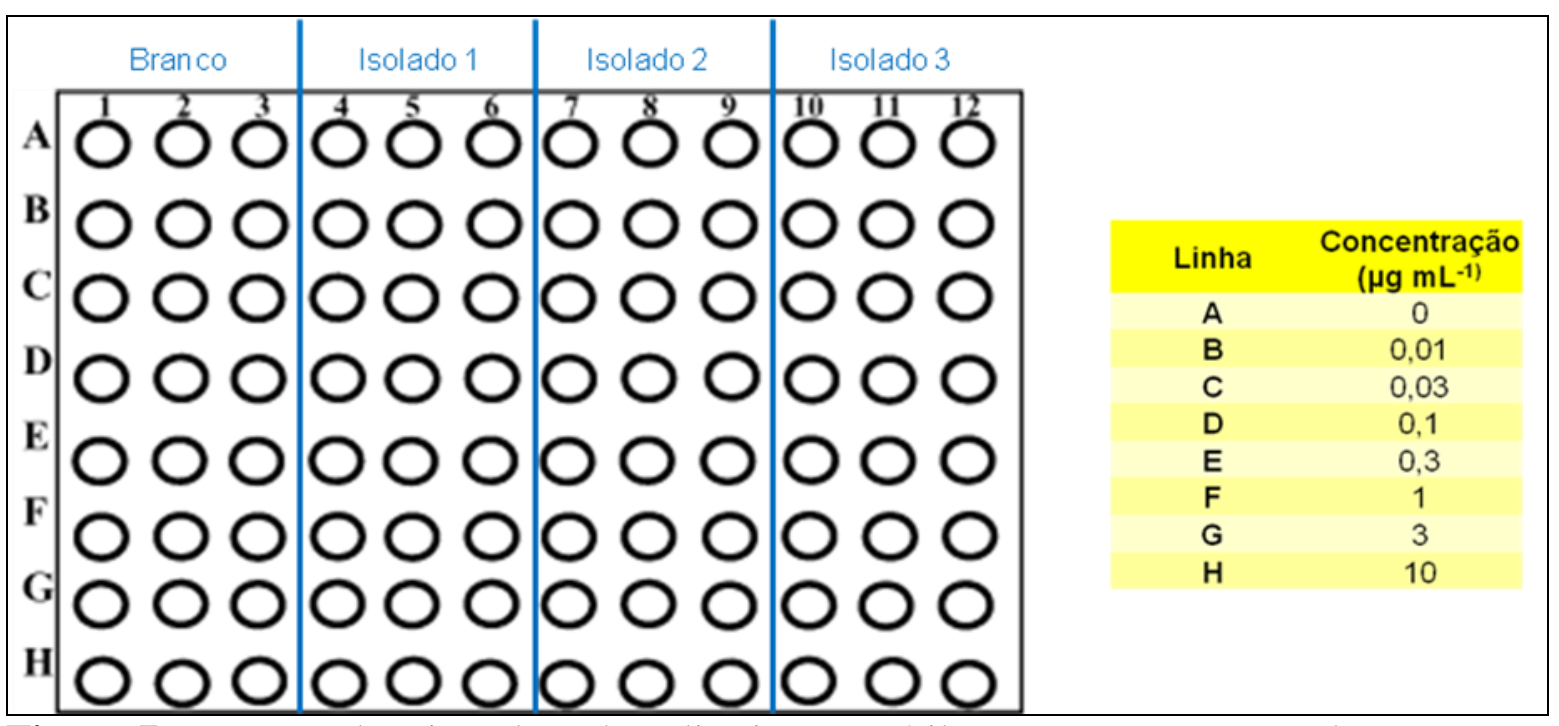

Figura 7. Esquema da microplaca de poliestireno estéril com 96 poços. Nas colunas são distribuídos isolados, e nas linhas as diluições dos princípios ativos.

As diluições dos fungicidas foram distribuídas em valores crescentes nas linhas (A H) e os isolados em triplicata por coluna (4 a 12) (Figura 7). Cada microplaca continha a testemunha (branco ou controle negativo) nas três primeiras colunas, onde foram adicionados $50 \mu \mathrm{L}$ das diferentes concentrações do fungicida e $50 \mu \mathrm{L}$ do meio líquido de ervilha sem esporângios, num volume final de $100 \mu \mathrm{L}$. Na primeira linha das colunas 4 a 12 foram colocados os controles positivos, onde eram adicionados $50 \mu \mathrm{L}$ da suspensão de esporângios na concentração $10^{4}$ esporângios. $\mathrm{mL}^{-1}$, seguido da adição de $50 \mu \mathrm{L}$ de água de osmose reversa autoclavada.

As placas de poliestireno foram tampadas e envoltas com parafilme, para evitar a evaporação, e colocadas em mesa agitadora por 15 minutos, para homogeneizar a mistura do produto com a suspensão de esporângios. Posteriormente, foram mantidas em câmara de crescimento a $16{ }^{\circ} \mathrm{C}$ no escuro (as placas foram envoltas com papel alumínio), por cinco dias. Os experimentos foram repetidos duas vezes.

A absorbância foi medida em um leitor de microplacas no comprimento de onda de $405 \mathrm{~nm}$. A média dos valores de absorbância obtida para as triplicatas de cada isolado em cada diluição do fungicida foi subtraída pela média da absorbância das triplicatas do branco/controle negativo da respectiva diluição.

Os dados foram analisados estatisticamente pela análise da variância e comparados pelo teste de Tukey a $5 \%$ de probabilidade.

Para calcular os valores de $\mathrm{EC}_{50}$ (concentração do fungicida capaz de reduzir $50 \%$ do crescimento do patógeno) a partir das médias das absorbâncias obtidas nas 
diferentes concentrações dos princípios ativos, plotou-se a \% de redução no eixo Y e a concentração dos fungicidas $\left(\mu \mathrm{g} \cdot \mathrm{mL}^{-1}\right)$ no eixo $\mathrm{X}$, este em escala logarítmica. A equação logarítmica de ajuste dos dados foi calculada, bem como o valor de $\mathrm{R}^{2}$ para cada isolado em cada fungicida testado.

Equação das retas: $\mathrm{Y}=-\mathrm{a}^{*} \ln (\mathrm{x})+\mathrm{b}$

Onde:

$\mathrm{a}$ e b = parâmetros da equação

$\mathrm{X}=$ concentração do fungicida $\left(\mu \mathrm{g} \cdot \mathrm{mL}^{-1}\right)$

$\mathrm{Y}=\%$ redução do crescimento do patógeno

O valor de Y foi substituído por 50, em cada equação, obtendo-se a concentração do fungicida capaz de reduzir $50 \%$ do crescimento do patógeno. 
5. RESULTADOS E DISCUSSÃO 


\subsection{Coleta de material infectado}

No total, 144 amostras foram coletadas (Tabela 6) em campos e estufas de batata e tomate, sendo 82 amostras no Estado de São Paulo, 27 no Paraná, 20 em Minas Gerais, 13 no Rio Grande do Sul e duas em Roraima.

Com exceção das duas amostras de Roraima (1,39\%), provenientes de estufa de tomate, as demais amostras de $P$. infestans foram coletadas nas regiões Sudeste $(70,83 \%)$ e Sul $(27,78 \%)$ do Brasil (Figura 8), regiões responsáveis por quase $90 \%$ da produção nacional e que apresentam condições climáticas ideais para o desenvolvimento da doença em períodos do ano com baixa temperatura e alta umidade.

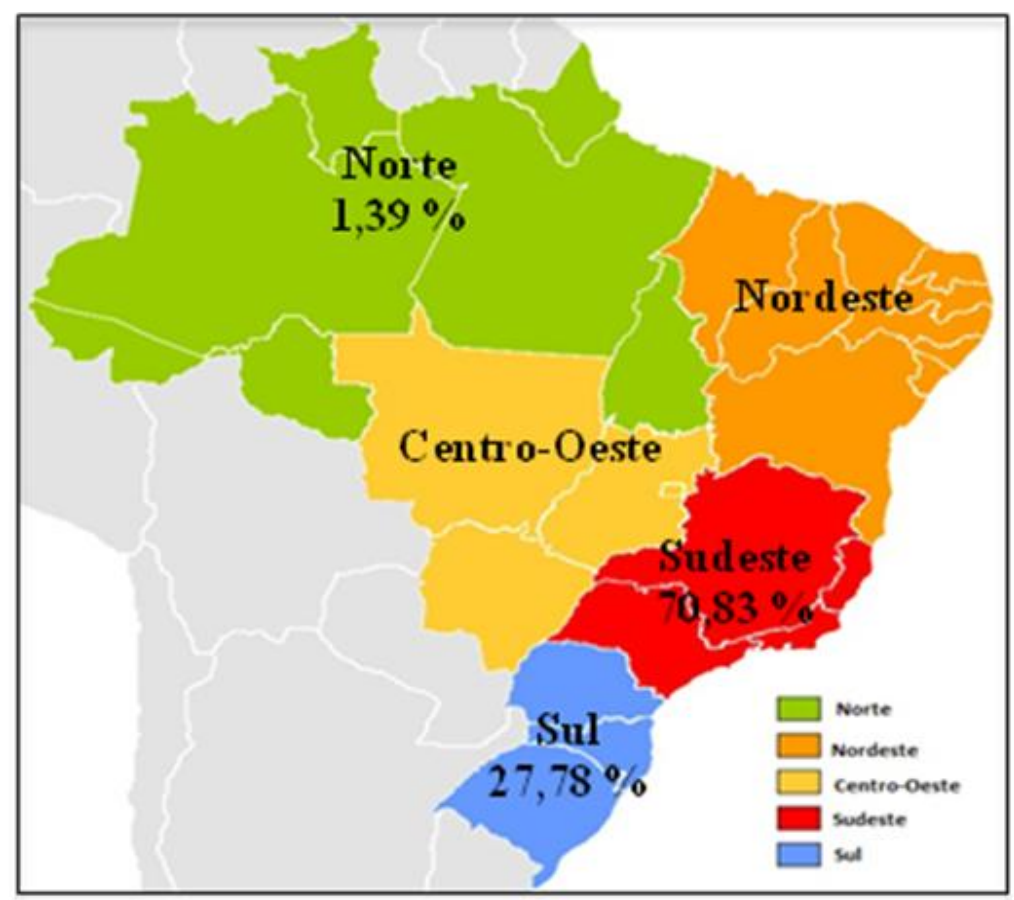

Figura 8. Origem das amostras de material botânico com sintomas típicos de requeima (Phytophthora infestans) coletadas por região no Brasil.

\subsection{Monitoramento do tipo de reprodução}

Das 144 amostras coletadas (Tabela 5), quatro apresentaram oósporos em órgãos infectados (Figura 9), indicando que nestes ocorreu reprodução sexuada de $P$. infestans: amostra $n^{\circ}$ 011, proveniente de Divinolândia/SP; $n^{\circ}$ 012, de - Campo do Tenente/PR; $n^{\circ}$ 
035, de Serra do Salitre/MG e $\mathrm{n}^{\circ}$ 142, de Itobi/SP. As demais amostras apresentaram apenas esporângios (Figura 10), estruturas de reprodução assexuada do patógeno.

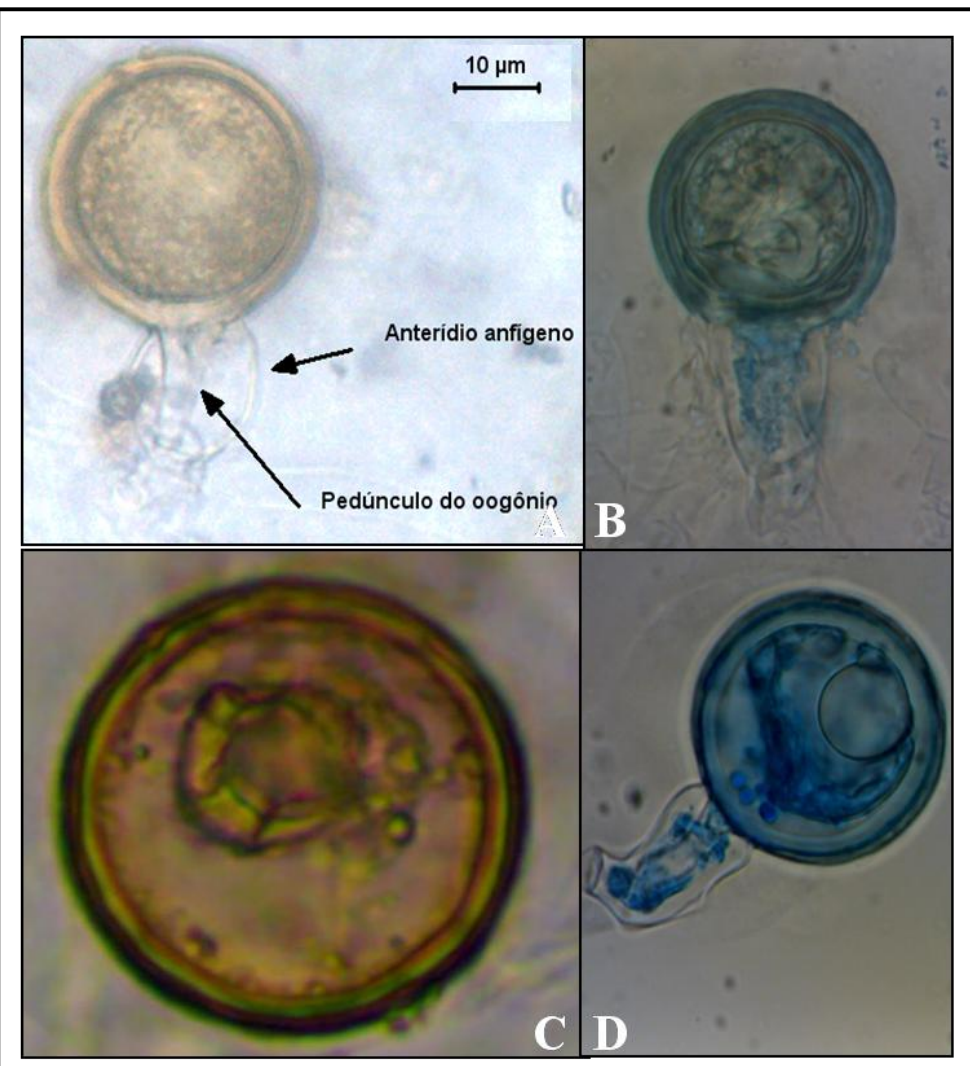

Figura 9. Estruturas reprodutivas sexuais de isolado de Phytophythora infestans do presente estudo. A, B e D gametângios (anterídio, oogônio) e oósporo; C - oósporo; . Fonte: A - Carmen Lidia Amorim Pires-Zottarelli, B, C e D - Samantha Zanotta. 


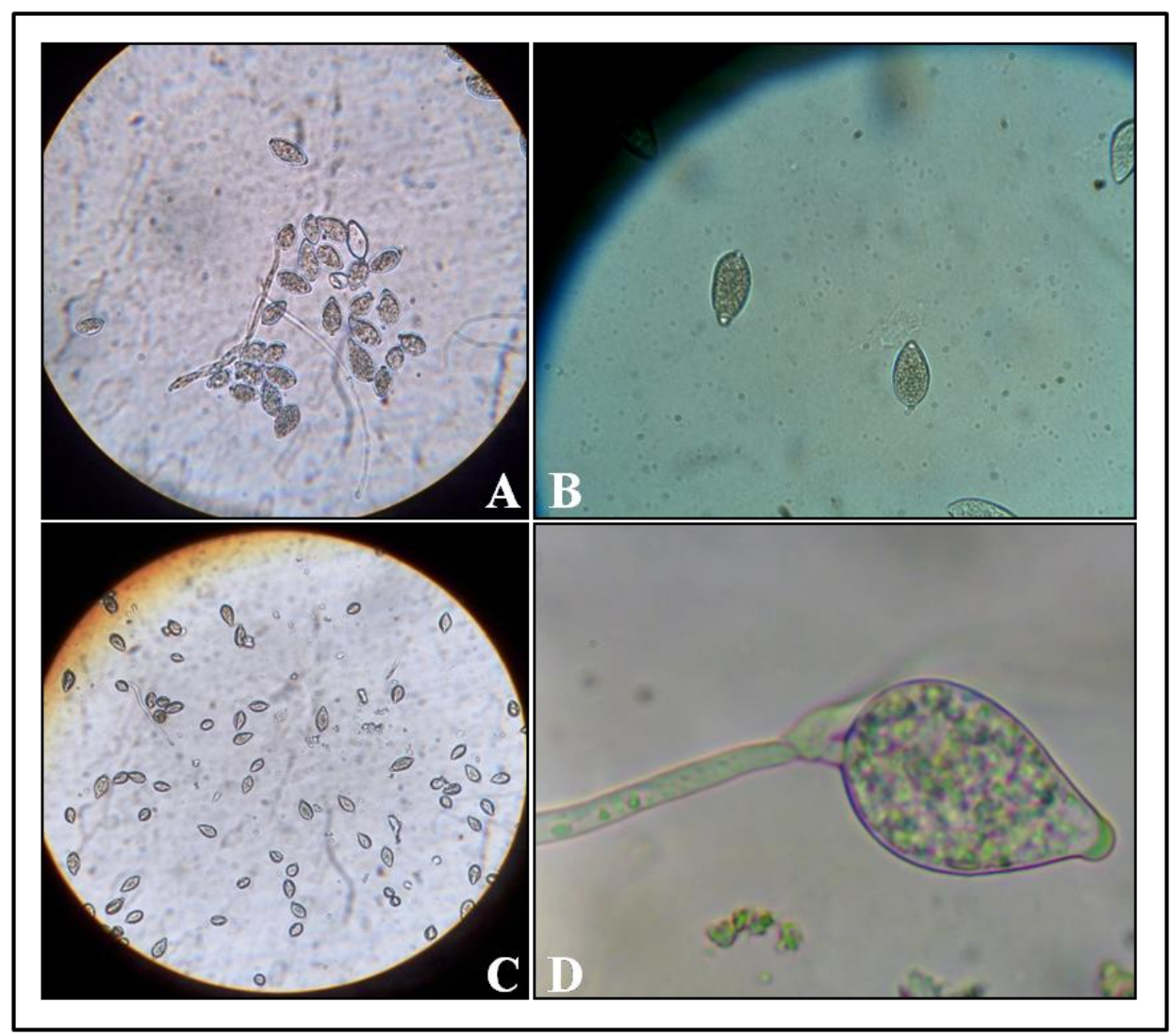

Figura 10. Estruturas reprodutivas assexuais de isolado de Phytophthora infestans do presente estudo. A a D - esporângios.

Segundo a bibliografia, a reprodução sexuada de $P$. infestans no Brasil por isolados autoférteis é recente. Em 2017, Casa-Coila e colaboradores, relataram a existência de isolados autoférteis de P. infestans no Brasil, no Estado do Paraná. Já a reprodução sexuada do patógeno numa mesma localidade, pelo pareamento de isolados pertencentes aos dois grupos de compatibilidade, ainda não foi registrada no Brasil.

Reis (2001) concluiu que a reprodução sexuada não ocorria nas populações de $P$. infestans amostradas no Brasil, levantando como hipóteses: (i) a especificidade do hospedeiro de duas linhagens clonais, como é o caso no Equador (OYARZUN et al., 1998), característica que faz com que a chance de ambos os tipos de acasalamento ocorrerem na mesma planta ser rara; (ii) se A1 e A2 estão presentes e se acasalam os oósporos não são viáveis, como observado por Mosa e colaboradores (1989) no Japão; (iii) se os oósporos são produzidos e germinados, a progênie é menos adaptada do que as cepas parentais, podendo não sobreviver, conforme observado em 2000 por Mayton e colaboradores.

Suassuna e colaboradores (2004) e Trentin (2006) também afirmaram que não existia reprodução sexuada de $P$. infestans no Brasil. 
Em 2014, Casa-Coila mostrou a coexistência dos dois grupos de compatibilidade A1 e A2 de $P$. infestans, no Rio Grande do Sul, o que possibilitaria a ocorrência de reprodução sexuada, mas não foi possível afirmar a existência de reprodução sexual do patógeno.

\subsection{Identificação do grupo de compatibilidade}

As 144 coletas resultaram em 153 isolados (Tabela5). Nas coletas realizadas em Divinolandia-SP ( $\left.n^{\circ} 11\right)$, Campo do Tenente-PR ( $\left.{ }^{\circ} 12\right)$ e Serra do Salitre-MG ( $\left.n^{\circ} 35\right)$, que apresentaram oósporos nos órgãos sintomáticos coletados, foram realizados mais de um isolamento.

Nos estudos de pareamento in vitro, foram avaliados 146 isolados, sendo um isolado de planta voluntária e os demais de batata, uma vez que os patógenos presentes em tomate não foram isolados em meio de cultura (seis isolados, ou seja, 3,92\%). Dos isolados estudados, 130 foram identificados como pertencentes ao grupo de compatibilidade A1 (84,97\%), quatro ao grupo A2 (2,61\%) e 13 foram classificados como autoférteis $(8,50 \%)$, pois apresentaram produção de oósporo sem a necessidade de pareamento com outro grupo de compatibilidade (Tabela 6).

Nos testes moleculares, foram analisados os 153 isolados. Destes, 142 apresentaram amplificação de um fragmento de aproximadamente 1250pb, quando amplificados com os iniciadores específicos S1-F e S1-R, indicando que estes pertencem ao grupo de compatibilidade A1, incluindo os isolados autoférteis. Quatro isolados apresentaram amplificação de um fragmento de aproximadamente $347 \mathrm{pb}$, quando amplificados com os iniciadores específicos PHYB-1 e PHYB-2, indicando pertencerem ao grupo de compatibilidade A2. Sete isolados não apresentaram amplificação para nenhum dos iniciadores dos grupos de compatibilidade (Tabela 6). 
Tabela 5. Identificação, procedência e identificação do grupo de compatibilidade dos isolados de Phytophthora infestans coletados no presente estudo

\begin{tabular}{|c|c|c|c|c|c|c|c|c|}
\hline \multirow[b]{2}{*}{$\mathbf{N}^{\circ}$} & \multirow[b]{2}{*}{$\begin{array}{c}\text { Coleta } \\
\text { (mês/ano) }\end{array}$} & \multirow[b]{2}{*}{ Cidade / Estado } & \multirow[b]{2}{*}{ Latitude } & \multirow[b]{2}{*}{ Longitude } & \multirow[b]{2}{*}{ Altitude } & \multirow[b]{2}{*}{ Cultura / Variedade } & \multicolumn{2}{|c|}{ Grupo de Compatibilidade } \\
\hline & & & & & & & $\begin{array}{c}\text { Pareamento "in } \\
\text { vitro" }\end{array}$ & Molecular \\
\hline 001 & $\operatorname{mar} / 15$ & Mogi das Cruzes - SP & $21^{\circ} 59^{\prime} 23^{\prime \prime} \mathrm{S}$ & $46^{\circ} 30^{\prime} 28^{\prime \prime} \mathrm{W}$ & $1.305 \mathrm{~m}$ & Batata / Agata & A1 & A1 \\
\hline 002 & $\operatorname{mar} / 15$ & Mogi das Cruzes - SP & $21^{\circ} 59^{\prime} 23^{\prime \prime} \mathrm{S}$ & $46^{\circ} 30^{\prime} 28^{\prime \prime} \mathrm{W}$ & $1.305 \mathrm{~m}$ & Batata / Agata & A1 & A1 \\
\hline 003 & $\operatorname{mar} / 15$ & Divinolândia - SP & $21^{\circ} 45^{\prime} 15,3^{\prime \prime} \mathrm{S}$ & $46^{\circ} 37^{\prime} 50,5^{\prime \prime} \mathrm{W}$ & $1.337 \mathrm{~m}$ & Batata / Agata & A1 & A1 \\
\hline 004 & $\operatorname{mar} / 15$ & Divinolândia - SP & $21^{\circ} 45^{\prime} 15,3^{\prime \prime} \mathrm{S}$ & $46^{\circ} 37^{\prime} 50,5^{\prime \prime} \mathrm{W}$ & $1.337 \mathrm{~m}$ & Batata / Agata & A1 & A1 \\
\hline 005 & $\operatorname{mar} / 15$ & Divinolândia - SP & $21^{\circ} 45^{\prime} 15,3^{\prime \prime} \mathrm{S}$ & $46^{\circ} 37^{\prime} 50,5^{\prime \prime} \mathrm{W}$ & $1.337 \mathrm{~m}$ & Batata / Agata & A1 & A1 \\
\hline 006 & $\operatorname{mar} / 15$ & Pilar do Sul - SP & $23^{\circ} 47^{\prime} 57,60^{\prime \prime} \mathrm{S}$ & $47^{\circ} 35^{\prime} 29,38^{\prime \prime} \mathrm{W}$ & $881 \mathrm{~m}$ & Batata / Agata & A1 & A1 \\
\hline 007 & $\operatorname{mar} / 15$ & Pilar do Sul - SP & $23^{\circ} 47^{\prime} 57,60^{\prime \prime} \mathrm{S}$ & $47^{\circ} 35^{\prime} 29,38^{\prime \prime} \mathrm{W}$ & $881 \mathrm{~m}$ & Batata / Agata & A1 & A1 \\
\hline 008 & $\operatorname{mar} / 15$ & Pilar do Sul - SP & $23^{\circ} 47^{\prime} 57,60^{\prime \prime} \mathrm{S}$ & $47^{\circ} 35^{\prime} 29,38^{\prime \prime} \mathrm{W}$ & $881 \mathrm{~m}$ & Batata / Agata & A1 & A1 \\
\hline 009 & $\mathrm{abr} / 15$ & Divinolândia - SP & $21^{\circ} 45^{\prime} 14,65^{\prime \prime} \mathrm{S}$ & $46^{\circ} 37^{\prime \prime} 50,06^{\prime \prime} \mathrm{W}$ & $1354,5 \mathrm{~m}$ & Batata / Agata & A1 & A1 \\
\hline 010 & $\mathrm{abr} / 15$ & Divinolândia - SP & $21^{\circ} 45^{\prime} 14,65^{\prime \prime} \mathrm{S}$ & $46^{\circ} 37 " 50,06^{\prime \prime} \mathrm{W}$ & $1354,5 \mathrm{~m}$ & Batata / Agata & A1 & A1 \\
\hline 011A & $\mathrm{abr} / 15$ & Divinolândia - SP & $21^{\circ} 45^{\prime} 14,65^{\prime \prime} \mathrm{S}$ & $46^{\circ} 37^{\prime \prime} 50,06^{\prime \prime} \mathrm{W}$ & $1354,5 \mathrm{~m}$ & Batata / Agata & $\mathrm{AF}$ & A1 \\
\hline 011B & $\mathrm{abr} / 15$ & Divinolândia - SP & $21^{\circ} 45^{\prime} 14,65^{\prime \prime} \mathrm{S}$ & $46^{\circ} 37^{\prime \prime} 50,06^{\prime \prime} \mathrm{W}$ & $1354,5 \mathrm{~m}$ & Batata / Agata & $\mathrm{AF}$ & A1 \\
\hline $012 \mathrm{~A}$ & $\mathrm{abr} / 15$ & Campo do Tenente - PR & $25^{\circ} 57^{\prime} 25^{\prime \prime} \mathrm{S}$ & $49^{\circ} 36^{\prime} 16^{\prime \prime} \mathrm{W}$ & $840 \mathrm{~m}$ & Batata / Atlantic & $\mathrm{AF}$ & A1 \\
\hline 012B & $\mathrm{abr} / 15$ & Campo do Tenente - PR & $25^{\circ} 57^{\prime} 25^{\prime \prime} \mathrm{S}$ & $49^{\circ} 36^{\prime} 16^{\prime \prime} \mathrm{W}$ & $840 \mathrm{~m}$ & Batata / Atlantic & $\mathrm{AF}$ & A1 \\
\hline $012 \mathrm{C}$ & $\mathrm{abr} / 15$ & Campo do Tenente - PR & $25^{\circ} 57^{\prime} 25^{\prime \prime} \mathrm{S}$ & $49^{\circ} 36^{\prime} 16^{\prime \prime} \mathrm{W}$ & $840 \mathrm{~m}$ & Batata / Atlantic & $\mathrm{AF}$ & A1 \\
\hline $012 \mathrm{D}$ & $\mathrm{abr} / 15$ & Campo do Tenente - PR & $25^{\circ} 57^{\prime} 25^{\prime \prime} \mathrm{S}$ & $49^{\circ} 36^{\prime} 16^{\prime \prime} \mathrm{W}$ & $840 \mathrm{~m}$ & Batata / Atlantic & $\mathrm{AF}$ & A1 \\
\hline $012 \mathrm{E}$ & $\mathrm{abr} / 15$ & Campo do Tenente - PR & $25^{\circ} 57^{\prime} 25^{\prime \prime} \mathrm{S}$ & $49^{\circ} 36^{\prime} 16^{\prime \prime} \mathrm{W}$ & $840 \mathrm{~m}$ & Batata / Atlantic & $\mathrm{AF}$ & A1 \\
\hline
\end{tabular}




\begin{tabular}{|c|c|c|c|c|c|c|c|c|}
\hline 013 & $\mathrm{abr} / 15$ & São Roque da Fartura - SP & $21^{\circ} 50^{\prime} 3,45^{\prime \prime} \mathrm{S}$ & $46^{\circ} 44^{\prime} 4.24^{\prime \prime} \mathrm{W}$ & $1.303 \mathrm{~m}$ & Batata / - & A1 & A1 \\
\hline 014 & $\mathrm{abr} / 15$ & São Roque da Fartura - SP & $21^{\circ} 50^{\prime} 3,45^{\prime \prime} \mathrm{S}$ & $46^{\circ} 44^{\prime} 4.24^{\prime \prime} \mathrm{W}$ & $1.303 \mathrm{~m}$ & Batata / - & A1 & $\mathrm{A} 1$ \\
\hline 015 & $\mathrm{abr} / 15$ & São Roque da Fartura - SP & $21^{\circ} 50^{\prime} 3,45^{\prime \prime} \mathrm{S}$ & $46^{\circ} 44^{\prime} 4.24^{\prime \prime} \mathrm{W}$ & $1.303 \mathrm{~m}$ & Batata / - & $\mathrm{A} 1$ & $\mathrm{~A} 1$ \\
\hline 016 & $\mathrm{abr} / 15$ & São Roque da Fartura - SP & $21^{\circ} 50^{\prime} 3,45^{\prime \prime} \mathrm{S}$ & $46^{\circ} 44^{\prime} 4.24^{\prime \prime} \mathrm{W}$ & $1.303 \mathrm{~m}$ & Batata / - & A1 & A1 \\
\hline 017 & $\mathrm{abr} / 15$ & São Roque da Fartura - SP & $21^{\circ} 50^{\prime} 3,45^{\prime \prime} \mathrm{S}$ & $46^{\circ} 44^{\prime} 4.24^{\prime \prime} \mathrm{W}$ & $1.303 \mathrm{~m}$ & Batata / - & A1 & A1 \\
\hline 018 & $\mathrm{abr} / 15$ & Itararé (UPD) - SP & $24^{\circ} 6^{\prime} 32.17^{\prime \prime} \mathrm{S}$ & $49^{\circ} 20^{\prime} 8.47 " \mathrm{~W}$ & $764 \mathrm{~m}$ & Batata / Agata & A1 & $\mathrm{A} 1$ \\
\hline 019 & $\mathrm{abr} / 15$ & Itararé (UPD) - SP & $24^{\circ} 6^{\prime} 32.17^{\prime \prime} \mathrm{S}$ & $49^{\circ} 20^{\prime} 8.47^{\prime \prime} \mathrm{W}$ & $764 \mathrm{~m}$ & Batata / Agata & A1 & A1 \\
\hline 020 & $\mathrm{abr} / 15$ & Itararé (UPD) - SP & $24^{\circ} 6^{\prime} 32.17^{\prime \prime} \mathrm{S}$ & $49^{\circ} 20^{\prime} 8.47^{\prime \prime} \mathrm{W}$ & $764 \mathrm{~m}$ & Batata / Agata & A1 & A1 \\
\hline 021 & $\mathrm{abr} / 15$ & Itararé (UPD) - SP & $24^{\circ} 6^{\prime} 32.17^{\prime \prime} \mathrm{S}$ & $49^{\circ} 20^{\prime} 8.47^{\prime \prime} \mathrm{W}$ & $764 \mathrm{~m}$ & Batata / Agata & A1 & $\mathrm{A} 1$ \\
\hline 022 & $\mathrm{abr} / 15$ & Itararé (UPD) - SP & $24^{\circ} 6^{\prime} 32.17^{\prime \prime} \mathrm{S}$ & $49^{\circ} 20^{\prime} 8.47^{\prime \prime} \mathrm{W}$ & $764 \mathrm{~m}$ & Batata / Asterix & A1 & $\mathrm{A} 1$ \\
\hline 023 & mai/15 & Santa Juliana - MG & $19^{\circ} 21^{\prime} 2,74^{\prime \prime} \mathrm{S}$ & $47^{\circ} 21^{\prime} 25,67^{\prime \prime} \mathrm{W}$ & $1.072 \mathrm{~m}$ & Batata / Markies & A1 & $\mathrm{A} 1$ \\
\hline 024 & mai/15 & Santa Juliana - MG & $19^{\circ} 21^{\prime} 2,74^{\prime \prime} \mathrm{S}$ & $47^{\circ} 21^{\prime} 25,67^{\prime \prime} \mathrm{W}$ & $1.072 \mathrm{~m}$ & Batata / Markies & A1 & $\mathrm{A} 1$ \\
\hline 025 & mai/15 & Santa Juliana - MG & $19^{\circ} 21^{\prime} 2,74^{\prime \prime} \mathrm{S}$ & $47^{\circ} 21^{\prime} 25,67^{\prime \prime} \mathrm{W}$ & $1.072 \mathrm{~m}$ & Batata / Markies & A1 & A1 \\
\hline 026 & mai/15 & Santa Juliana - MG & $19^{\circ} 21^{\prime} 2,74^{\prime \prime} \mathrm{S}$ & $47^{\circ} 21^{\prime} 25,67^{\prime \prime} \mathrm{W}$ & $1.072 \mathrm{~m}$ & Batata / Markies & A1 & $\mathrm{A} 1$ \\
\hline 027 & mai/15 & Santa Juliana - MG & $19^{\circ} 21^{\prime} 2,74^{\prime} \mathrm{S}$ & $47^{\circ} 21^{\prime} 25,67^{\prime \prime} \mathrm{W}$ & $1.072 \mathrm{~m}$ & Batata / Markies & A1 & $\mathrm{A} 1$ \\
\hline 028 & mai/15 & Mogi Mirim - SP & $22^{\circ} 25^{\prime} 23,36^{\prime \prime} \mathrm{S}$ & $46^{\circ} 57^{\prime} 29,701^{\prime \prime} \mathrm{W}$ & $642 \mathrm{~m}$ & Tomate / - & $\mathrm{NA}$ & A2 \\
\hline 029 & jun/15 & Passo Fundo - RS & $28^{\circ} 15^{\prime} 44.14^{\prime \prime} \mathrm{S}$ & $52^{\circ} 24^{\prime} 37.01 " \mathrm{~W}$ & $679 \mathrm{~m}$ & $\begin{array}{c}\text { Batata / Mistura de } \\
\text { Cultivares }\end{array}$ & A1 & A1 \\
\hline 030 & jun/15 & Passo Fundo - RS & $28^{\circ} 15^{\prime} 44.14^{\prime \prime} \mathrm{S}$ & $52^{\circ} 24^{\prime} 37.01^{\prime \prime} \mathrm{W}$ & $679 \mathrm{~m}$ & $\begin{array}{c}\text { Batata / Mistura de } \\
\text { Cultivares }\end{array}$ & A1 & A1 \\
\hline 031 & jun/15 & Passo Fundo - RS & $28^{\circ} 15^{\prime} 44.14^{\prime \prime} \mathrm{S}$ & $52^{\circ} 24^{\prime} 37.01^{\prime \prime} \mathrm{W}$ & $679 \mathrm{~m}$ & Batata / Macaca & A1 & $\mathrm{A} 1$ \\
\hline 032 & jun/15 & Passo Fundo - RS & $28^{\circ} 15^{\prime} 44.14^{\prime \prime} \mathrm{S}$ & $52^{\circ} 24^{\prime} 37.01 " \mathrm{~W}$ & $679 \mathrm{~m}$ & Batata / Macaca & A1 & A1 \\
\hline
\end{tabular}




\begin{tabular}{|c|c|c|c|c|c|c|c|c|}
\hline 033 & jun/15 & Passo Fundo - RS & $28^{\circ} 15^{\prime} 44.14^{\prime \prime} \mathrm{S}$ & $52^{\circ} 24^{\prime} 37.01^{\prime \prime} \mathrm{W}$ & $679 \mathrm{~m}$ & Batata / Macaca & A1 & A1 \\
\hline 034 & jun/15 & Ibiraiaras - RS & $28^{\circ} 22^{\prime} 17.28^{\prime \prime} \mathrm{S}$ & $51^{\circ} 38^{\prime} 2.039^{\prime \prime} \mathrm{W}$ & $769 \mathrm{~m}$ & Planta voluntária & A1 & A1 \\
\hline 035A & jul/15 & Serra do Salitre - MG & $18^{\circ} 56^{\prime} 31,93 " \mathrm{~S}$ & $46^{\circ} 36^{\prime} 21,93 " \mathrm{~W}$ & $889 \mathrm{~m}$ & Batata / Atlantic & $\mathrm{AF}$ & A1 \\
\hline 035B & $\mathrm{jul} / 15$ & Serra do Salitre - MG & $18^{\circ} 56^{\prime} 31,93^{\prime \prime} \mathrm{S}$ & $46^{\circ} 36^{\prime} 21,93 " \mathrm{~W}$ & $889 \mathrm{~m}$ & Batata / Atlantic & $\mathrm{AF}$ & A1 \\
\hline 035C & jul/15 & Serra do Salitre - MG & $18^{\circ} 56^{\prime} 31,93^{\prime \prime} \mathrm{S}$ & $46^{\circ} 36^{\prime} 21,93 " \mathrm{~W}$ & $889 \mathrm{~m}$ & Batata / Atlantic & $\mathrm{AF}$ & A1 \\
\hline 035D & $\mathrm{jul} / 15$ & Serra do Salitre - MG & $18^{\circ} 56^{\prime} 31,93^{\prime \prime} \mathrm{S}$ & $46^{\circ} 36^{\prime} 21,93^{\prime \prime} \mathrm{W}$ & $889 \mathrm{~m}$ & Batata / Atlantic & $\mathrm{AF}$ & A1 \\
\hline 035E & $\mathrm{jul} / 15$ & Serra do Salitre - MG & $18^{\circ} 56^{\prime} 31,93^{\prime \prime} \mathrm{S}$ & $46^{\circ} 36^{\prime} 21,93^{\prime \prime} \mathrm{W}$ & $889 \mathrm{~m}$ & Batata / Atlantic & $\mathrm{AF}$ & A1 \\
\hline 036 & jul/15 & Itararé (UPD) - SP & $24^{\circ} 6^{\prime} 32.17 " \mathrm{~S}$ & $49^{\circ} 20^{\prime} 8.47^{\prime \prime} \mathrm{W}$ & $764 \mathrm{~m}$ & Batata / - & $\mathrm{A} 1$ & $\mathrm{~A} 1$ \\
\hline 037 & jul/15 & Itararé (UPD) - SP & $24^{\circ} 6^{\prime} 32.17^{\prime \prime} \mathrm{S}$ & $49^{\circ} 20^{\prime} 8.47^{\prime \prime} \mathrm{W}$ & $764 \mathrm{~m}$ & Batata / - & A1 & $\mathrm{A} 1$ \\
\hline 038 & $\mathrm{jul} / 15$ & Itararé (UPD) - SP & $24^{\circ} 6^{\prime} 32.17^{\prime \prime} \mathrm{S}$ & $49^{\circ} 20^{\prime} 8.47^{\prime \prime} \mathrm{W}$ & $764 \mathrm{~m}$ & Batata / - & $\mathrm{A} 1$ & $\mathrm{~A} 1$ \\
\hline 039 & jul/15 & Vargem Grande do Sul - SP & $21^{\circ} 49^{\prime} 31,4^{\prime \prime} \mathrm{S}$ & $46^{\circ} 57^{\prime} 49,3^{\prime \prime} \mathrm{W}$ & $690,5 \mathrm{~m}$ & Batata / Atlantic & A1 & $\mathrm{A} 1$ \\
\hline 040 & $\mathrm{jul} / 15$ & Vargem Grande do Sul - SP & $21^{\circ} 51^{\prime} 27,8^{\prime \prime} \mathrm{S}$ & $47^{\circ} 0 ’ 45,1$ ' W & $701 \mathrm{~m}$ & $\begin{array}{c}\text { Batata / } 5 \text { variedades } \\
\text { diferentes }\end{array}$ & A1 & A1 \\
\hline 041 & $\mathrm{jul} / 15$ & Vargem Grande do Sul - SP & $21^{\circ} 51^{\prime} 27,8^{\prime \prime} \mathrm{S}$ & $47^{\circ} 0 ' 45,1$ ' W & $701 \mathrm{~m}$ & $\begin{array}{c}\text { Batata / } 5 \text { variedades } \\
\text { diferentes }\end{array}$ & A1 & A1 \\
\hline 042 & $\mathrm{jul} / 15$ & Vargem Grande do Sul - SP & $21^{\circ} 51^{\prime} 27,8^{\prime \prime} \mathrm{S}$ & $47^{\circ} 0^{\prime} 45,1^{\prime \prime} \mathrm{W}$ & $701 \mathrm{~m}$ & Batata / Ioná & A1 & NIM \\
\hline 043 & ago/15 & Itobi - SP & $21^{\circ} 43^{\prime} 24,8^{\prime \prime} \mathrm{S}$ & $46^{\circ} 59^{\prime} 41,3^{\prime \prime} \mathrm{W}$ & $654,5 \mathrm{~m}$ & Batata / - & $\mathrm{A} 2$ & $\mathrm{~A} 2$ \\
\hline 044 & ago/15 & Itobi - SP & $21^{\circ} 43^{\prime} 24,8^{\prime \prime} \mathrm{S}$ & $46^{\circ} 59^{\prime} 41,3^{\prime \prime} \mathrm{W}$ & $654,5 \mathrm{~m}$ & Batata / - & $\mathrm{A} 2$ & $\mathrm{~A} 2$ \\
\hline 045 & ago/15 & Vargem Grande do Sul - SP & $21^{\circ} 50^{\prime} 14,5^{\prime \prime} \mathrm{S}$ & $47^{\circ} 0^{\prime} 46,2^{\prime \prime} \mathrm{W}$ & $714 \mathrm{~m}$ & Batata / Taurus & A1 & A1 \\
\hline 046 & $\mathrm{jul} / 15$ & Vargem Grande do Sul - SP & $21^{\circ} 49^{\prime} 31,4^{\prime \prime} \mathrm{S}$ & $46^{\circ} 57^{\prime} 49,3^{\prime \prime} \mathrm{W}$ & $690,5 \mathrm{~m}$ & Batata / Atlantic & A1 & $\mathrm{A} 1$ \\
\hline 047 & out/15 & Lavras - MG & $21^{\circ} 14^{\prime} 54,43 " \mathrm{~S}$ & $45^{\circ} 0^{\prime} 5.01 " \mathrm{~W}$ & $928 \mathrm{~m}$ & Batata / - & A1 & A1 \\
\hline 048 & out/15 & Lavras - MG & $21^{\circ} 14^{\prime} 54,43 " \mathrm{~S}$ & $45^{\circ} 0^{\prime} 5.01^{\prime \prime} \mathrm{W}$ & $928 \mathrm{~m}$ & Batata / - & A1 & A1 \\
\hline
\end{tabular}




\begin{tabular}{|c|c|c|c|c|c|c|c|c|}
\hline 049 & out/15 & Tatuí - SP & $23^{\circ} 20^{\prime} 57.19^{\prime \prime} \mathrm{S}$ & $47^{\circ} 50^{\prime} 47.67^{\prime \prime} \mathrm{W}$ & $614 \mathrm{~m}$ & Batata / - & $\mathrm{A} 1$ & A1 \\
\hline 050 & nov/15 & Guarapuava - PR & $25^{\circ} 23^{\prime} 26.60^{\prime \prime} \mathrm{S}$ & $51^{\circ} 27^{\prime} 46.11^{\prime \prime} \mathrm{W}$ & $1.103 \mathrm{~m}$ & Batata / Agata & $\mathrm{A} 1$ & A1 \\
\hline 051 & nov/15 & Boa Vista - RR & $2^{\circ} 49^{\prime} 24.63 " \mathrm{~N}$ & $60^{\circ} 40^{\prime} 33^{\prime \prime} \mathrm{W}$ & $82 \mathrm{~m}$ & Tomate / - & $\mathrm{NA}$ & A1 \\
\hline 052 & nov/15 & Lapa - PR & $25^{\circ} 43^{\prime} 58.71 " \mathrm{~S}$ & $49^{\circ} 43^{\prime} 51.874^{\prime \prime} \mathrm{W}$ & $926 \mathrm{~m}$ & Batata / - & A1 & A1 \\
\hline 053 & nov/15 & Lapa - PR & $25^{\circ} 43^{\prime} 58.71 " \mathrm{~S}$ & $49^{\circ} 43^{\prime} 51.874^{\prime \prime} \mathrm{W}$ & $926 \mathrm{~m}$ & Batata / - & A1 & A1 \\
\hline 054 & nov/15 & Cordeirópolis - SP & $22^{\circ} 28^{\prime} 4,7^{\prime \prime} \mathrm{S}$ & $47^{\circ} 24^{\prime} 29,7^{\prime \prime} \mathrm{W}$ & $720,5 \mathrm{~m}$ & Tomate / - & NA & A1 \\
\hline 055 & $\mathrm{dez} / 15$ & Divinolândia - SP & $21^{\circ} 38^{\prime} 17,25^{\prime \prime} \mathrm{S}$ & $46^{\circ} 43^{\prime} 54,45^{\prime \prime} \mathrm{W}$ & $1.242 \mathrm{~m}$ & Batata / Agata & A1 & $\mathrm{A} 1$ \\
\hline 056 & $\mathrm{dez} / 15$ & Divinolândia - SP & $21^{\circ} 38^{\prime} 17,25^{\prime \prime} \mathrm{S}$ & $46^{\circ} 43^{\prime} 54,45^{\prime \prime} \mathrm{W}$ & $1.242 \mathrm{~m}$ & Batata / Agata & A1 & NIM \\
\hline 057 & $\operatorname{dez} / 15$ & Divinolândia - SP & $21^{\circ} 38^{\prime} 17,25^{\prime \prime} \mathrm{S}$ & $46^{\circ} 43^{\prime} 54,45^{\prime \prime} \mathrm{W}$ & $1.242 \mathrm{~m}$ & Batata / Agata & A1 & $\mathrm{A} 1$ \\
\hline 058 & $\mathrm{dez} / 15$ & Divinolândia - SP & $21^{\circ} 41^{\prime} 20,78^{\prime \prime} \mathrm{S}$ & $46^{\circ} 38^{\prime} 34,41 ” \mathrm{~W}$ & $1.360 \mathrm{~m}$ & Batata / Agata & A1 & A1 \\
\hline 059 & $\operatorname{dez} / 15$ & Divinolândia - SP & $21^{\circ} 41^{\prime} 20,78^{\prime \prime} \mathrm{S}$ & $46^{\circ} 38^{\prime} 34,41^{\prime \prime} \mathrm{W}$ & $1.360 \mathrm{~m}$ & Batata / Agata & A1 & A1 \\
\hline 060 & $\mathrm{jan} / 16$ & Lapa - PR & $25^{\circ} 43^{\prime} 58.70^{\prime \prime} \mathrm{S}$ & $49^{\circ} 43^{\prime} 51.87^{\prime \prime} \mathrm{W}$ & $926 \mathrm{~m}$ & Batata / - & A1 & A1 \\
\hline 061 & $\mathrm{jan} / 16$ & Ponta Grossa - PR & $25^{\circ} 4^{\prime} 13.25^{\prime \prime} \mathrm{S}$ & $50^{\circ} 17^{\prime} 47.61 " \mathrm{~W}$ & $938 \mathrm{~m}$ & Batata / - & A1 & A1 \\
\hline 062 & $\mathrm{jan} / 16$ & Ponta Grossa - PR & $25^{\circ} 4^{\prime} 13.25^{\prime \prime} \mathrm{S}$ & $50^{\circ} 17^{\prime} 47.61 " \mathrm{~W}$ & $938 \mathrm{~m}$ & Batata / - & $\mathrm{A} 1$ & A1 \\
\hline 063 & $\mathrm{jan} / 16$ & Tapira - MG & $19^{\circ} 55^{\prime} 03,8^{\prime \prime} \mathrm{S}$ & $46^{\circ} 42^{\prime} 01,2^{\prime \prime} \mathrm{W}$ & $1.313,5 \mathrm{~m}$ & Batata / Atlantic & A1 & NIM \\
\hline 064 & $\mathrm{jan} / 16$ & Tapira - MG & $19^{\circ} 58^{\prime} 05,9^{\prime \prime} \mathrm{S}$ & $46^{\circ} 37^{\prime} 34,5^{\prime \prime} \mathrm{W}$ & $1.231,5 \mathrm{~m}$ & Batata / Atlantic & A1 & NIM \\
\hline 065 & $\mathrm{jan} / 16$ & São Roque da Fartura - SP & $21^{\circ} 50^{\prime} 46^{\prime \prime} \mathrm{S}$ & $46^{\circ} 44^{\prime} 11^{\prime \prime} \mathrm{W}$ & $1.367 \mathrm{~m}$ & Batata / Agata & A1 & A1 \\
\hline 066 & $\operatorname{mar} / 16$ & Pilar do Sul - SP & $23^{\circ} 47^{\prime} 57,59^{\prime \prime} \mathrm{S}$ & $47^{\circ} 35^{\prime} 29,38^{\prime \prime} \mathrm{W}$ & $881 \mathrm{~m}$ & Batata / Agata & A1 & A1 \\
\hline 067 & $\operatorname{mar} / 16$ & Pilar do Sul - SP & $23^{\circ} 47^{\prime} 57,59^{\prime \prime} \mathrm{S}$ & $47^{\circ} 35^{\prime} 29,38^{\prime \prime} \mathrm{W}$ & $881 \mathrm{~m}$ & Batata / Agata & A1 & $\mathrm{A} 1$ \\
\hline 068 & $\operatorname{mar} / 16$ & Pilar do Sul - SP & $23^{\circ} 47^{\prime} 57,59^{\prime \prime} \mathrm{S}$ & $47^{\circ} 35^{\prime} 29,38^{\prime \prime} \mathrm{W}$ & $881 \mathrm{~m}$ & Batata / Agata & A1 & A1 \\
\hline 069 & $\mathrm{mar} / 16$ & Pilar do Sul-SP & $23^{\circ} 47^{\prime} 57,59^{\prime \prime} \mathrm{S}$ & $47^{\circ} 35^{\prime} 29,38^{\prime \prime} \mathrm{W}$ & $881 \mathrm{~m}$ & Batata / Agata & A1 & $\mathrm{A} 1$ \\
\hline 070 & $\operatorname{mar} / 16$ & Pilar do Sul - SP & $23^{\circ} 47^{\prime} 57,59^{\prime \prime} \mathrm{S}$ & $47^{\circ} 35^{\prime} 29,38^{\prime \prime} \mathrm{W}$ & $881 \mathrm{~m}$ & Batata / Agata & A1 & A1 \\
\hline
\end{tabular}




\begin{tabular}{|c|c|c|c|c|c|c|c|c|}
\hline 071 & $\operatorname{mar} / 16$ & Pilar do Sul - SP & $23^{\circ} 47^{\prime} 57,59^{\prime \prime} \mathrm{S}$ & $47^{\circ} 35^{\prime} 29,38^{\prime \prime} \mathrm{W}$ & $881 \mathrm{~m}$ & Batata / Agata & A1 & A1 \\
\hline 072 & $\operatorname{mar} / 16$ & Pilar do Sul - SP & $23^{\circ} 47^{\prime} 57,59^{\prime \prime} \mathrm{S}$ & $47^{\circ} 35^{\prime} 29,38^{\prime \prime} \mathrm{W}$ & $881 \mathrm{~m}$ & Batata / Agata & A1 & A1 \\
\hline 073 & $\operatorname{mar} / 16$ & Pilar do Sul - SP & $23^{\circ} 47^{\prime} 57,59^{\prime \prime} \mathrm{S}$ & $47^{\circ} 35^{\prime} 29,38^{\prime \prime} \mathrm{W}$ & $881 \mathrm{~m}$ & Batata / Agata & A1 & A1 \\
\hline 074 & jul/16 & Vargem Grande do Sul - SP & $21^{\circ} 45^{\prime} 51^{\prime \prime} \mathrm{S}$ & $46^{\circ} 58^{\prime} 34^{\prime \prime} \mathrm{W}$ & $658,5 \mathrm{~m}$ & Batata / Atlantic & A1 & $\mathrm{A} 1$ \\
\hline 075 & $\mathrm{jul} / 16$ & Vargem Grande do Sul - SP & $21^{\circ} 45^{\prime} 41^{\prime \prime} \mathrm{S}$ & $46^{\circ} 58^{\prime} 29^{\prime \prime} \mathrm{W}$ & $660,5 \mathrm{~m}$ & Batata / Atlantic & A1 & A1 \\
\hline 076 & jul/16 & Vargem Grande do Sul - SP & $21^{\circ} 45^{\prime} 42^{\prime \prime} \mathrm{S}$ & $46^{\circ} 58^{\prime} 29^{\prime \prime} \mathrm{W}$ & $659,5 \mathrm{~m}$ & Batata / FL 1867 & A1 & A1 \\
\hline 077 & $\mathrm{jul} / 16$ & Vargem Grande do Sul - SP & $21^{\circ} 45^{\prime} 42^{\prime \prime} \mathrm{S}$ & $46^{\circ} 58^{\prime} 29^{\prime \prime} \mathrm{W}$ & $659,5 \mathrm{~m}$ & Batata / FL 1867 & A1 & A1 \\
\hline 078 & $\mathrm{jul} / 16$ & Vargem Grande do Sul - SP & $21^{\circ} 41^{\prime} 40^{\prime \prime} \mathrm{S}$ & $46^{\circ} 59^{\prime} 28^{\prime \prime} \mathrm{W}$ & $671,5 \mathrm{~m}$ & Batata / Orchestra & A1 & A1 \\
\hline 079 & $\operatorname{mar} / 15$ & Mogi Mirim - SP & $22^{\circ} 25^{\prime} 23,36^{\prime \prime} \mathrm{S}$ & $46^{\circ} 57^{\prime} 29,70^{\prime \prime} \mathrm{W}$ & $642 \mathrm{~m}$ & Tomate / - & $\mathrm{NA}$ & A1 \\
\hline 080 & nov/15 & Cordeirópolis - SP & $22^{\circ} 28^{\prime} 4,7^{\prime \prime} \mathrm{S}$ & $47^{\circ} 24^{\prime} 29,7^{\prime \prime} \mathrm{W}$ & $720,5 \mathrm{~m}$ & Tomate / - & $\mathrm{NA}$ & A1 \\
\hline 081 & nov/15 & Boa Vista - RR & $2^{\circ} 49^{\prime} 24.63^{\prime \prime} \mathrm{N}$ & $60^{\circ} 40^{\prime} 33^{\prime \prime} \mathrm{W}$ & $82 \mathrm{~m}$ & Tomate / - & $\mathrm{NA}$ & A1 \\
\hline 082 & out $/ 15$ & Divinolândia - SP & $23^{\circ} 47^{\prime} 57,59^{\prime \prime} \mathrm{S}$ & $47^{\circ} 35^{\prime} 29,38^{\prime \prime} \mathrm{W}$ & $881 \mathrm{~m}$ & Batata / Agata & A1 & A1 \\
\hline 083 & out/15 & Pilar do Sul - SP & $21^{\circ} 45^{\prime} 14,65^{\prime} \mathrm{S}$ & $46^{\circ} 37 ” 50,06 ” \mathrm{~W}$ & $1.354,5 \mathrm{~m}$ & Batata / Agata & A1 & A1 \\
\hline 084 & out $/ 15$ & Pilar do Sul - SP & $21^{\circ} 45^{\prime} 14,65^{\prime \prime} \mathrm{S}$ & $46^{\circ} 37 " 50,06^{\prime \prime} \mathrm{W}$ & $1.354,5 \mathrm{~m}$ & Batata / Agata & A1 & $\mathrm{A} 1$ \\
\hline 085 & mai/16 & São Miguel Arcanjo - SP & $23^{\circ} 52^{\prime} 43.27^{\prime \prime} \mathrm{S}$ & $23^{\circ} 52^{\prime} 43.27^{\prime \prime} \mathrm{S}$ & $661 \mathrm{~m}$ & Batata / - & A1 & A1 \\
\hline 086 & mai/16 & São Miguel Arcanjo - SP & $23^{\circ} 52^{\prime} 43.27^{\prime \prime} \mathrm{S}$ & $23^{\circ} 52^{\prime} 43.27^{\prime \prime} \mathrm{S}$ & $661 \mathrm{~m}$ & Batata / - & A1 & $\mathrm{A} 1$ \\
\hline 087 & mai/16 & São Paulo - SP & - & - & - & Batata / - & A1 & A1 \\
\hline 088 & mai/16 & São Paulo - SP & - & - & - & Batata / - & A1 & A1 \\
\hline 089 & out/15 & Lavras - MG & $21^{\circ} 14^{\prime} 54,43 " \mathrm{~S}$ & $45^{\circ} 0^{\prime} 5.01 " \mathrm{~W}$ & $928 \mathrm{~m}$ & Batata / - & A1 & A1 \\
\hline 090 & mai/16 & Campestre - MG & $21^{\circ} 42^{\prime} 36.50^{\prime \prime} \mathrm{S}$ & $46^{\circ} 14^{\prime} 56.35^{\prime \prime} \mathrm{W}$ & $650 \mathrm{~m}$ & Batata/BRS-Bel & A1 & A1 \\
\hline 091 & mai/16 & Campestre - MG & $21^{\circ} 42^{\prime} 36.50^{\prime \prime} \mathrm{S}$ & $46^{\circ} 14^{\prime} 56.35^{\prime \prime} \mathrm{W}$ & $650 \mathrm{~m}$ & Batata/BRS-Bel & A1 & A1 \\
\hline 092 & $\mathrm{jan} / 15$ & Ponta Grossa - PR & $25^{\circ} 4^{\prime} 13.25^{\prime \prime} \mathrm{S}$ & $50^{\circ} 17^{\prime} 47.61^{\prime \prime} \mathrm{W}$ & $938 \mathrm{~m}$ & Batata / - & $\mathrm{A} 1$ & $\mathrm{~A} 1$ \\
\hline
\end{tabular}




\begin{tabular}{|c|c|c|c|c|c|c|c|c|}
\hline 093 & out/15 & Ponta Grossa - PR & $25^{\circ} 4^{\prime} 13.25^{\prime \prime} \mathrm{S}$ & $50^{\circ} 17^{\prime} 47.61^{\prime \prime} \mathrm{W}$ & $938 \mathrm{~m}$ & Batata / - & A1 & A1 \\
\hline 094 & out/15 & Ponta Grossa - PR & $25^{\circ} 4^{\prime} 13.25^{\prime \prime} \mathrm{S}$ & $50^{\circ} 17^{\prime} 47.61^{\prime \prime} \mathrm{W}$ & $938 \mathrm{~m}$ & Batata / - & $\mathrm{A} 1$ & NIM \\
\hline 095 & out/15 & Lapa - PR & $25^{\circ} 38^{\prime} 39^{\prime \prime} \mathrm{S}$ & $49^{\circ} 49^{\prime} 59^{\prime \prime} \mathrm{W}$ & $905,0 \mathrm{~m}$ & Batata / - & $\mathrm{A} 1$ & A1 \\
\hline 096 & out/15 & Lapa - PR & $25^{\circ} 38^{\prime} 39^{\prime \prime} \mathrm{S}$ & $49^{\circ} 49^{\prime} 59^{\prime \prime} \mathrm{W}$ & $905,0 \mathrm{~m}$ & Batata / - & $\mathrm{A} 1$ & A1 \\
\hline 097 & mai/16 & Ibiraiaras - RS & $28^{\circ} 22^{\prime} 17.28^{\prime \prime} \mathrm{S}$ & $51^{\circ} 31^{\prime} 47.33^{\prime \prime} \mathrm{W}$ & $796 \mathrm{~m}$ & Batata / Agata & $\mathrm{A} 1$ & A1 \\
\hline 098 & $\mathrm{mai} / 16$ & Ibiraiaras - RS & $28^{\circ} 22^{\prime} 17.28^{\prime \prime} \mathrm{S}$ & $51^{\circ} 31^{\prime} 47.33^{\prime \prime} \mathrm{W}$ & $796 \mathrm{~m}$ & Batata / Agata & A1 & A1 \\
\hline 099 & mai/16 & Ibiraiaras - RS & $28^{\circ} 22^{\prime} 17.28^{\prime \prime} \mathrm{S}$ & $51^{\circ} 31^{\prime} 47.33^{\prime \prime} \mathrm{W}$ & $796 \mathrm{~m}$ & Batata / Agata & A1 & A1 \\
\hline 100 & mai/16 & Lagoa Vermelha-RS & $28^{\circ} 12^{\prime} 34.41^{\prime \prime} \mathrm{S}$ & $51^{\circ} 31^{\prime} 47.33^{\prime \prime} \mathrm{W}$ & $792 \mathrm{~m}$ & Batata / Agata & $\mathrm{A} 1$ & A1 \\
\hline 101 & $\mathrm{jul} / 16$ & Vargem Grande do Sul - SP & $21^{\circ} 55^{\prime} 38^{\prime \prime} \mathrm{S}$ & $47^{\circ} 07^{\prime} 32^{\prime \prime} \mathrm{W}$ & $644,0 \mathrm{~m}$ & Batata / Atlantic & $\mathrm{A} 1$ & A1 \\
\hline 102 & $\mathrm{jul} / 16$ & Vargem Grande do Sul - SP & $21^{\circ} 46^{\prime} 03^{\prime \prime} \mathrm{S}$ & $46^{\circ} 58^{\prime} 41^{\prime \prime} \mathrm{W}$ & $645,5 \mathrm{~m}$ & Batata / FL 1867 & $\mathrm{~A} 1$ & A1 \\
\hline 103 & jul/16 & Vargem Grande do Sul - SP & $21^{\circ} 51^{\prime} 28^{\prime \prime} \mathrm{S}$ & $46^{\circ} 59^{\prime} 58^{\prime \prime} \mathrm{W}$ & $719,0 \mathrm{~m}$ & Batata / FL 1867 & A1 & A1 \\
\hline 104 & set/16 & Ponta Grossa - PR & $25^{\circ} 09^{\prime} 23.92^{\prime \prime} \mathrm{S}$ & $50^{\circ} 08^{\prime} 38.92^{\prime \prime} \mathrm{W}$ & $830,0 \mathrm{~m}$ & Batata / Agata & $\mathrm{A} 1$ & A1 \\
\hline 105 & set/16 & Ponta Grossa - PR & $25^{\circ} 09^{\prime} 23.92^{\prime \prime} \mathrm{S}$ & $50^{\circ} 08^{\prime} 38.92^{\prime \prime} \mathrm{W}$ & $830,0 \mathrm{~m}$ & Batata / Agata & $\mathrm{A} 1$ & A1 \\
\hline 106 & set/16 & Ponta Grossa - PR & $25^{\circ} 09^{\prime} 23.92^{\prime \prime} \mathrm{S}$ & $50^{\circ} 08^{\prime} 38.92^{\prime \prime} \mathrm{W}$ & $830,0 \mathrm{~m}$ & Batata / Agata & $\mathrm{A} 1$ & A1 \\
\hline 107 & set/16 & Ponta Grossa - PR & $25^{\circ} 09^{\prime} 23.92^{\prime \prime} \mathrm{S}$ & $50^{\circ} 08^{\prime} 38.92^{\prime \prime} \mathrm{W}$ & $830,0 \mathrm{~m}$ & Batata / Agata & $\mathrm{A} 1$ & A1 \\
\hline 108 & set/16 & Ponta Grossa - PR & $25^{\circ} 09^{\prime} 23.92 ” \mathrm{~S}$ & $50^{\circ} 08^{\prime} 38.92^{\prime \prime} \mathrm{W}$ & $830,0 \mathrm{~m}$ & Batata / Agata & $\mathrm{A} 2$ & NIM \\
\hline 109 & set/16 & Ponta Grossa - PR & $25^{\circ} 09^{\prime} 23.92 ” \mathrm{~S}$ & $50^{\circ} 08^{\prime} 38.92^{\prime \prime} \mathrm{W}$ & $830,0 \mathrm{~m}$ & Batata / Agata & $\mathrm{A} 2$ & NIM \\
\hline 110 & $\mathrm{dez} / 16$ & Paraná - PR & $25^{\circ} 15^{\prime} 7.52^{\prime \prime} \mathrm{S}$ & $52^{\circ} 1^{\prime} 17.55^{\prime \prime} \mathrm{W}$ & $765 \mathrm{~m}$ & Batata / - & A1 & A1 \\
\hline 111 & $\operatorname{dez} / 16$ & Bom Jesus - RS & $28^{\circ} 42^{\prime} 44,4^{\prime \prime} \mathrm{S}$ & $50^{\circ} 18^{\prime} 32,1^{\prime \prime} \mathrm{W}$ & $1.098 \mathrm{~m}$ & Batata / Atlantic & A1 & A1 \\
\hline 112 & $\mathrm{dez} / 16$ & Bom Jesus - RS & $28^{\circ} 42^{\prime} 56,0^{\prime \prime} \mathrm{S}$ & $50^{\circ} 18^{\prime} 05,6^{\prime \prime} \mathrm{W}$ & $1.132 \mathrm{~m}$ & Batata / Atlantic & A1 & A1 \\
\hline 113 & $\mathrm{dez} / 16$ & Bom Jesus - RS & $28^{\circ} 43^{\prime} 09,8^{\prime \prime} \mathrm{S}$ & $50^{\circ} 18^{\prime} 13,9^{\prime \prime} \mathrm{W}$ & $1.109 \mathrm{~m}$ & Batata / Atlantic & $\mathrm{A} 1$ & A1 \\
\hline 114 & $\mathrm{jan} / 17$ & Lapa - PR & $25^{\circ} 38^{\prime} 35^{\prime \prime} \mathrm{S}$ & $49^{\circ} 49^{\prime} 53,98^{\prime \prime} \mathrm{W}$ & $926 \mathrm{~m}$ & Batata / Manitou & A1 & A1 \\
\hline
\end{tabular}




\begin{tabular}{|c|c|c|c|c|c|c|c|c|}
\hline 115 & $\mathrm{jan} / 17$ & Lapa - PR & $25^{\circ} 38^{\prime} 35^{\prime \prime} \mathrm{S}$ & $49^{\circ} 49^{\prime} 53,98^{\prime \prime} \mathrm{W}$ & $926 \mathrm{~m}$ & Batata / Romeo & A1 & A1 \\
\hline 116 & fev/17 & Lapa - PR & $25^{\circ} 38^{\prime} 35^{\prime \prime} \mathrm{S}$ & $49^{\circ} 49^{\prime} 53,98^{\prime \prime} \mathrm{W}$ & $926 \mathrm{~m}$ & Batata / Manitou & A1 & $\mathrm{A} 1$ \\
\hline 117 & fev/17 & Lapa - PR & $25^{\circ} 38^{\prime} 35^{\prime \prime} \mathrm{S}$ & $49^{\circ} 49^{\prime} 53,98^{\prime \prime} \mathrm{W}$ & $926 \mathrm{~m}$ & Batata / Atlantic & A1 & A1 \\
\hline 118 & $\mathrm{abr} / 17$ & Água-Doce - PR & $26^{\circ} 34^{\prime} 40^{\prime \prime} \mathrm{S}$ & $51^{\circ} 48^{\prime} 28^{\prime \prime} \mathrm{W}$ & $1.234 \mathrm{~m}$ & Batata / Agata & A1 & A1 \\
\hline 119 & $\mathrm{abr} / 17$ & Lagoa Seca - PR & $25^{\circ} 30^{\prime} 51^{\prime \prime} \mathrm{S}$ & $51^{\circ} 52^{\prime} 25^{\prime \prime} \mathrm{W}$ & $946 \mathrm{~m}$ & Batata / - & A1 & A1 \\
\hline 120 & $\mathrm{abr} / 17$ & Lagoa Seca - PR & $25^{\circ} 30^{\prime} 52^{\prime \prime} \mathrm{S}$ & $51^{\circ} 52^{\prime} 25^{\prime \prime} \mathrm{W}$ & $943 \mathrm{~m}$ & Batata / - & A1 & A1 \\
\hline 121 & $\mathrm{abr} / 17$ & Castrolanda - PR & $24^{\circ} 49^{\prime} 25^{\prime \prime} \mathrm{S}$ & $49^{\circ} 53^{\prime} 22^{\prime \prime} \mathrm{W}$ & $1.017 \mathrm{~m}$ & Batata / Agata & A1 & A1 \\
\hline 122 & jun/17 & Tapira - MG & $19^{\circ} 58^{\prime} 05,9^{\prime \prime}$ & $46^{\circ} 37^{\prime} 34,5^{\prime \prime} \mathrm{W}$ & $1.231,5 \mathrm{~m}$ & Batata / Atlantic & A1 & $\mathrm{A} 1$ \\
\hline 123 & jun/17 & Tapira - MG & $19^{\circ} 58^{\prime} 05,9^{\prime \prime}$ & $46^{\circ} 37^{\prime} 34,5^{\prime \prime} \mathrm{W}$ & $1.231,5 \mathrm{~m}$ & Batata / Atlantic & A1 & $\mathrm{A} 1$ \\
\hline 124 & jun/17 & Bom Repouso - MG & $22^{\circ} 28^{\prime} 3.28^{\prime \prime} \mathrm{S}$ & $46^{\circ} 9^{\prime} 0.587^{\prime \prime} \mathrm{W}$ & $1.388 \mathrm{~m}$ & Batata / Agata & A1 & A1 \\
\hline 125 & jun/17 & Itapetininga $-\mathrm{SP}$ & $23^{\circ} 31^{\prime} 47,58^{\prime \prime} \mathrm{S}$ & $48^{\circ} 4^{\prime} 53,85^{\prime \prime} \mathrm{W}$ & $723 \mathrm{~m}$ & Batata / Atlantic & A1 & $\mathrm{A} 1$ \\
\hline 126 & jun/17 & Santa Juliana - MG & $19^{\circ} 21^{\prime} 2,74^{\prime \prime} \mathrm{S}$ & $47^{\circ} 21^{\prime} 25,67^{\prime \prime} \mathrm{W}$ & $1.072 \mathrm{~m}$ & Batata / Asterix & A1 & A1 \\
\hline 127 & jun/17 & Santa Juliana - MG & $19^{\circ} 20^{\prime} 30,45^{\prime \prime} \mathrm{S}$ & $47^{\circ} 22^{\prime} 4,6^{\prime \prime} \mathrm{W}$ & $1.064 \mathrm{~m}$ & Batata / Asterix & A1 & $\mathrm{A} 1$ \\
\hline 128 & jun/17 & Santa Juliana - MG & $19^{\circ} 17^{\prime} 33,99^{\prime \prime} \mathrm{S}$ & $47^{\circ} 25^{\prime} 56,35^{\prime \prime} \mathrm{W}$ & $1.028 \mathrm{~m}$ & Batata / Asterix & A1 & $\mathrm{A} 1$ \\
\hline 129 & jun/17 & Vargem Grande do Sul - SP & $21^{\circ} 47^{\prime} 11,03^{\prime \prime} \mathrm{S}$ & $46^{\circ} 58^{\prime} 9,75^{\prime \prime} \mathrm{W}$ & $705 \mathrm{~m}$ & Batata / FL 1867 & A1 & A1 \\
\hline 130 & jun/17 & Vargem Grande do Sul - SP & $21^{\circ} 47^{\prime} 11,05^{\prime \prime} \mathrm{S}$ & $46^{\circ} 58^{\prime} 9,83^{\prime \prime} \mathrm{W}$ & $705 \mathrm{~m}$ & Batata / FL 1867 & A1 & A1 \\
\hline 131 & jun/17 & Vargem Grande do Sul - SP & $21^{\circ} 45^{\prime} 45,57^{\prime \prime} \mathrm{S}$ & $46^{\circ} 58^{\prime} 22,81^{\prime \prime} \mathrm{W}$ & $667 \mathrm{~m}$ & Batata / FL 1867 & A1 & A1 \\
\hline 132 & jun/17 & Taquarituba $-\mathrm{SP}$ & $23^{\circ} 43^{\prime} 58,68^{\prime \prime} \mathrm{S}$ & $49^{\circ} 7$ ' 24,16" W & $669 \mathrm{~m}$ & Batata / Atlantic & A1 & A1 \\
\hline 133 & jun/17 & Taquarituba $-\mathrm{SP}$ & $23^{\circ} 43^{\prime} 58,68^{\prime \prime} \mathrm{S}$ & $49^{\circ} 7^{\prime} 24,16^{\prime \prime} \mathrm{W}$ & $669 \mathrm{~m}$ & Batata / Atlantic & A1 & A1 \\
\hline 134 & jun/17 & Itapetininga $-\mathrm{SP}$ & $23^{\circ} 31^{\prime} 47,58^{\prime \prime} \mathrm{S}$ & $48^{\circ} 4^{\prime} 53,85^{\prime \prime} \mathrm{W}$ & $723 \mathrm{~m}$ & Batata / Atlantic & A1 & $\mathrm{A} 1$ \\
\hline 135 & jun/17 & Itapetininga $-\mathrm{SP}$ & $23^{\circ} 31^{\prime} 47,58^{\prime \prime} \mathrm{S}$ & $48^{\circ} 4^{\prime} 53,85^{\prime \prime} \mathrm{W}$ & $723 \mathrm{~m}$ & Batata / Atlantic & A1 & $\mathrm{A} 1$ \\
\hline 136 & jun/17 & Itapetininga $-\mathrm{SP}$ & $23^{\circ} 31^{\prime} 58,75^{\prime \prime} \mathrm{S}$ & $48^{\circ} 5^{\prime} 11,37^{\prime \prime} \mathrm{W}$ & $711 \mathrm{~m}$ & Batata / Romeo & A1 & A1 \\
\hline
\end{tabular}




\begin{tabular}{|c|c|c|c|c|c|c|c|c|}
\hline 137 & jun/17 & Itapetininga - SP & $23^{\circ} 31^{\prime} 19,95^{\prime \prime} \mathrm{S}$ & $48^{\circ} 9^{\prime} 22,7^{\prime \prime} \mathrm{W}$ & $751 \mathrm{~m}$ & Batata / Infinity & $\mathrm{A} 1$ & A1 \\
\hline 138 & jun/17 & Itapetininga - SP & $23^{\circ} 31^{\prime} 19,95^{\prime \prime} \mathrm{S}$ & $48^{\circ} 9^{\prime} 22,7^{\prime \prime} \mathrm{W}$ & $751 \mathrm{~m}$ & Batata / Atlantic & $\mathrm{A} 1$ & $\mathrm{~A} 1$ \\
\hline 139 & jun/17 & Sorocaba - SP & $23^{\circ} 31^{\prime} 23,23^{\prime \prime} \mathrm{S}$ & $48^{\circ} 9^{\prime} 23,19^{\prime \prime} \mathrm{W}$ & $764 \mathrm{~m}$ & Batata / Agata & $\mathrm{A} 1$ & A1 \\
\hline 141 & jul/17 & Pouso Alegre - MG & $22^{\circ} 14^{\prime} 52.93 " \mathrm{~S}$ & $45^{\circ} 56^{\prime} 31.24^{\prime \prime} \mathrm{W}$ & $816 \mathrm{~m}$ & Batata / - & $\mathrm{A} 1$ & $\mathrm{~A} 1$ \\
\hline 142 & ago/17 & Itobi - SP & $21^{\circ} 42^{\prime} 12,8^{\prime \prime} \mathrm{S}$ & $46^{\circ} 59^{\prime} 20,81^{\prime \prime} \mathrm{W}$ & $711 \mathrm{~m}$ & Batata / Markies & $\mathrm{AF}$ & A1 \\
\hline CRI-2 & $\begin{array}{c}\text { Isolado } \\
\text { padrão A1 }\end{array}$ & Cristal / RS & - & - & - & Batata / - & A2 & NIM \\
\hline PRT & $\begin{array}{c}\text { Isolado } \\
\text { padrão A1 }\end{array}$ & & - & - & - & Tomate / - & A1 & $\mathrm{A} 1$ \\
\hline
\end{tabular}

A1= Grupo de compatibilidade A1; A2 = Grupo de compatibilidade A2; AF = Isolado autofértil; NA = não avaliado; NIM - não identificado molecularmente. 
Em Mogi Mirim-SP e em Ponta Grossa- PR os dois grupos de compatibilidade foram observadas em uma mesma localidade

Tabela 6. Número de isolados de Phytophthora infestans pertencentes a cada Grupo de Compatibilidade quando avaliados pelo método de pareamento "in vitro" e pelos métodos moleculares.

\begin{tabular}{c|c|c}
\hline \multirow{2}{*}{$\begin{array}{c}\text { Grupo de } \\
\text { Compatibilidade }\end{array}$} & $\begin{array}{c}\text { Pareamento "in vitro" } \\
\mathbf{N}^{\mathbf{0}} \text { de A1 ou A2 / No total de } \\
\text { isolados (\%) }\end{array}$ & $\begin{array}{c}\text { Moleculares } \\
\mathbf{N}^{\mathbf{0}} \text { de A1 ou A2 / No total de } \\
\text { isolados (\%) }\end{array}$ \\
\hline A1 & $129 / 146(88,36 \%)$ & $142 / 146(97,26 \%)$ \\
\hline A2 & $04 / 146(2,74 \%)$ & $04 / 146(2,74 \%)$ \\
\hline Autofértil & $13 / 146(8,90 \%)$ & - \\
\hline
\end{tabular}

Segundo Suassuna e colaboradores (2001), a alta especificidade por hospedeiro fazia com que isolados A1 fossem associados ao tomateiro, enquanto isolados A2 à batata. Porém, o cenário observado no presente estudo mostrou que, isolados de $P$. infestans do grupo de compatibilidade A1 predominam em batata. Entretanto, não se sabe qual grupo de compatibilidade predomina atualmente em tomate no Brasil, pois foram avaliadas poucas amostras desta cultura.

Em 2006, Reis, Ribeiro e Mizubuti identificaram 78 isolados de P. infestans oriundos de tomate, proveniente do Distrito Federal e Goiás, como pertencentes ao grupo de compatibilidade A1 e 45 isolados de batata como pertencentes ao grupo de compatibilidade A2. Casa-Coila (2014) identificou ambos os grupos de compatibilidade em plantações de batata na região Sul do Brasil, com 20 isolados pertencentes ao grupo de compatibilidade A1, 54 isolados ao grupo de compatibilidade A2 e 27 isolados caracterizados como autoférteis. Portanto, a sequência de estudos mostra uma rápida desalojamento das linhagens do grupo A2, então predominantes em batata, pelas linhagens do grupo A1.

Alguns isolados brasileiros foram submetidos à amplificação com os iniciadores W16-1 e W16-2, e apresentaram um fragmento de aproximadamente $600 \mathrm{pb}$. As sequências destes fragmentos foram analisadas e em seus eletroferogramas foi observado polimorfismo para os isolados A1, que são heterozigotos para esta região do genoma, o mesmo estando ausente nos isolados A2, que são homozigotos (Figuras 11.a e 11.b). 
As diferenças entre os grupos de compatibilidade A1 e A2 utilizando os iniciadores moleculares W16-1 e W16-2, foram evidenciadas também por Mazakova e colaboradores (2010) que ao digerirem o fragmento amplificado com os iniciadores moleculares, aproximadamente 557 pb de seus isolados, com a enzima de restrição Hae III (BsuRI) (reconhece a sequência GGCC), detectaram que os produtos derivados de isolados pertencentes ao grupo de compatibilidade A1 apresentaram três fragmentos com tamanhos de aproximadamente 557, 457 e $100 \mathrm{pb}$ e os pertencentes ao grupo de compatibilidade A2 apresentaram dois fragmentos de 457 e $100 \mathrm{pb}$.

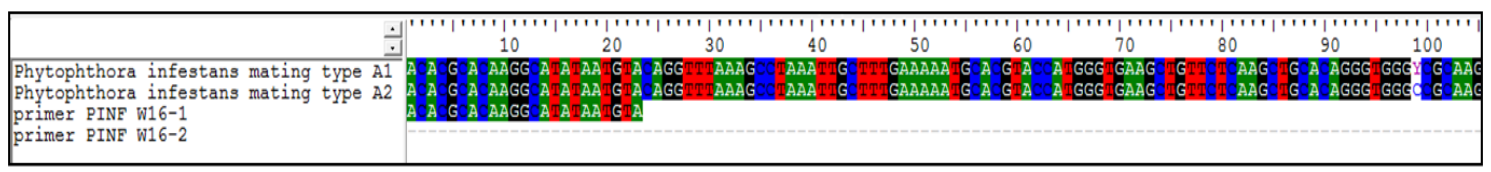

Figura 11.a. Sequências de fragmentos de DNA de isolados de Phytophthora infestans pertencentes ao grupo de compatibilidade A1 e A2, amplificados com iniciadores W161 e W16-2.

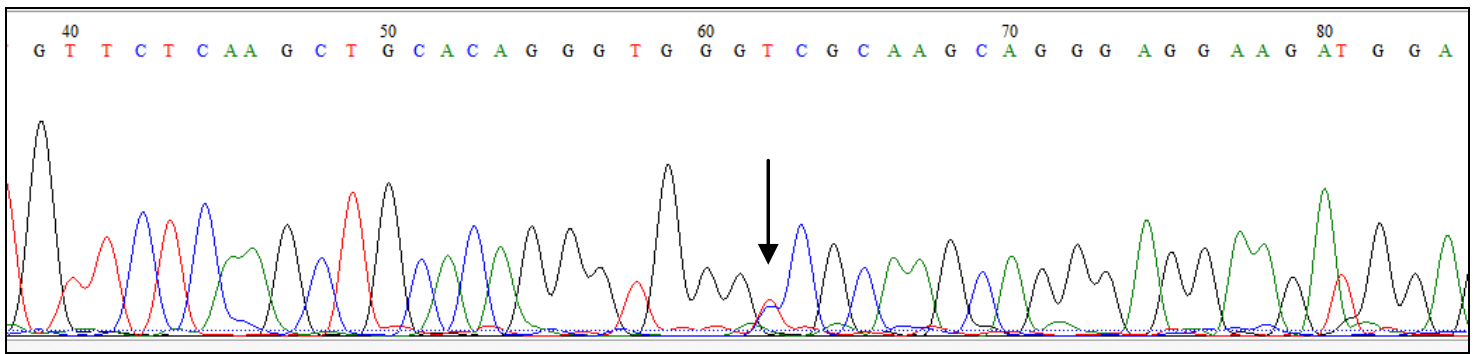

Figura 11.b. Polimorfismo encontrado em eletroferograma de um isolado pertencente ao grupo de compatibilidade A1. A seta indica a sobreposição de picos das bases $\mathrm{C}$ e $\mathrm{T}$.

Ao correlacionar os resultados do pareamento in vitro com os obtidos por amplificação por PCR utilizando os iniciadores S1, PHYB e W16 podemos concluir que os marcadores moleculares foram uma ferramenta útil para a determinação do grupo de compatibilidade, mesmo quando o patógeno não foi isolado da planta hospedeira.

Mazakova e colaboradores (2010) ao estudarem a população de $P$. infestans na República Checa quanto aos grupos de compatibilidade, não detectaram diferenças entre os resultados quando comparados os testes de pareamento in vitro e de amplificação por PCR utilizando os iniciadores W16-1 e W16-2, e digestão com a enzima de restrição Hae III (BsuRI). Por outro lado, Beketova e colaboradores (2014), ao determinarem o grupo de compatibilidade de isolados da Rússia utilizando a mesma metodologia observaram uma diferença de $10 \%$ entre os resultados dos testes in vitro e molecular. Em 2015, na Índia, Chowdappa e colaboradores observaram que 
todos os 157 isolados testados eram do tipo de acasalamento A2 e os resultados de ambos os testes foram consistentes.

Wang, Han e Guo (2016) ao compararem os resultados obtidos no teste de pareamento in vitro com os de amplificação por PCR utilizando os iniciadores S1, LB e W16, relataram que os iniciadores moleculares estudados não foram eficazes na identificação do grupo de compatibilidade. O melhor resultado apresentado foi com os iniciadores específicos S1-F e S1-R (ZHANG et al., 2006) com a eficiência de 81,53\%, seguido pelos iniciadores LB-1F e LB-1R descritos por Judelson (1996) com 73,84\% e os iniciadores W16-F e W16-R (JUDELSON; SPIELMAN; SHATTOCK, 1995) com $67,69 \%$.

Na Polônia em 2018, Brylinska e colaboradores com o objetivo de validar os iniciadores moleculares W16, S1 e PHYB para a identificação do grupo de compatibilidade de $P$. infestans, obtiveram 10\% (15 isolados) de discrepância nos resultados na determinação do tipo de acasalamento dos isolados quando comparados os resultados entre os iniciadores.

Vale ressaltar que os iniciadores moleculares descritos por Kim e Lee (2002) assim como os descritos por Judelson, Spielman e Shattock, 1995, para a identificação de grupo de compatibilidade de isolados de $P$. infestans ainda não tinham sido utilizados no Brasil e que nenhum dos métodos moleculares pode identificar isolados autoférteis.

\subsection{Caracterização molecular por microssatélite (SSR)}

Para a caracterização molecular via SSR foram utilizados 12 pares de marcadores microssatélites que apresentaram perfis polimórficos (Figura 12) para os 155 isolados de Phytophthora infestans utilizados neste estudo (153 coletados neste estudo e 2 padrões). 


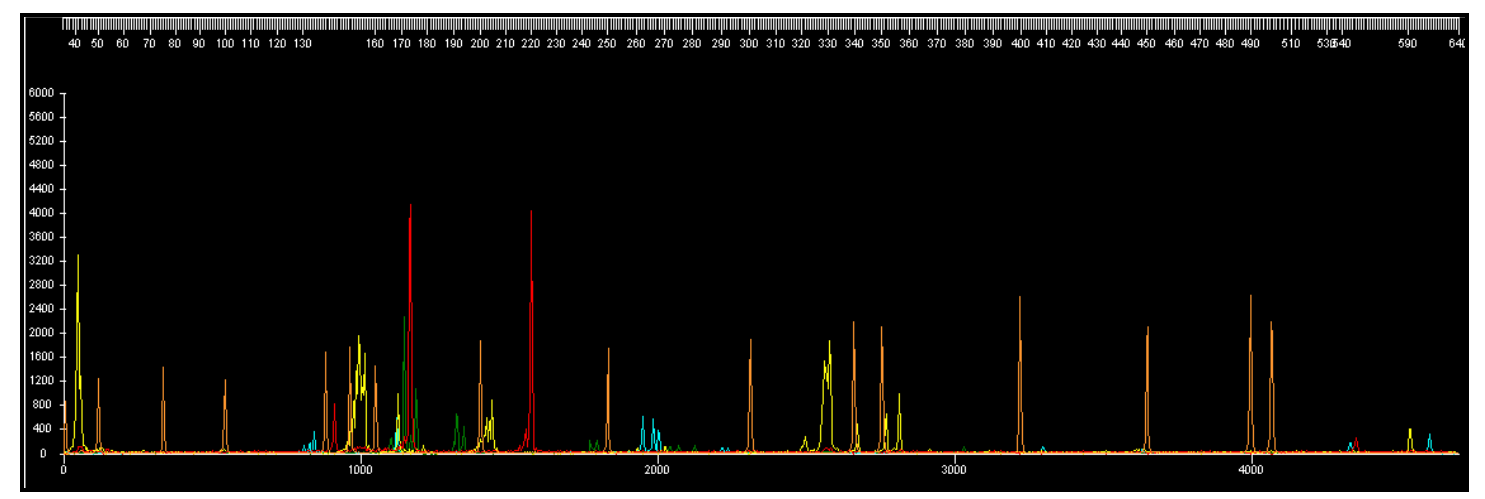

Figura 12. Perfil de um isolado de Phytophthora infestans obtido com os 12 pares de marcadores microssatélites.

Foram detectados no total, 42 alelos (Tabela 7), nos 12 lócus analisados. O lócus PiG11 foi o que mais apresentou alelos, com seis, e os lócus SSR2 e SSR6 foram os que apresentaram menos alelos, com dois alelos cada.

Tabela 7. Número de alelos existentes mundialmente para Phytophthora infestans e número de alelos detectado por lócus nos isolados presente estudo

\begin{tabular}{|c|c|c|}
\hline Lócus & $\begin{array}{l}N^{\circ} \text { de alelos existentes / } \\
N^{\circ} \text { de alelos detectados }\end{array}$ & Alelos detectados \\
\hline D13 & $28 / 04$ & $136 / 140 / 142 / 166$ \\
\hline Pi04 & $05 / 04$ & $160 / 166 / 168 / 170$ \\
\hline Pi4B & $08 / 03$ & $213 / 219 / 297$ \\
\hline Pi63 & $03 / 03$ & $270 / 273 / 279$ \\
\hline Pi70 & $03 / 03$ & 189 / 192 / 195 \\
\hline PiG11 & $28 / 06$ & $150 / 152$ / 154 / $200 / 204 / 206$ \\
\hline PinfSSR2 & $03 / 02$ & $173 / 177$ \\
\hline PinfSSR3 & $06 / 04$ & 264 / 266 / 268 / 270 \\
\hline PinfSSR4 & $08 / 05$ & 285 / 287 / 289 / 291 / 293 \\
\hline PinfSSR6 & $04 / 02$ & $242 / 244$ \\
\hline PinfSSR8 & $03 / 03$ & $260 / 264 / 266$ \\
\hline PinfSSR11 & $03 / 03$ & $330 / 340 / 356$ \\
\hline
\end{tabular}

As frequências dos alelos encontrados nos 155 isolados estudados variaram de 100 a 0,65\% (Tabela 8). No lócus D13 foram encontrados quatro alelos apresentando frequências distintas: o alelo 136 teve frequência de 99,35\% nos isolados analisados, o 
alelo 140 teve $3,25 \%$, o 142 teve $1,30 \%$ e o 166 teve $0,65 \%$. Em 95,45\% dos isolados o lócus foi homozigoto com o alelo 136.

No lócus Pi04 foram encontrados também quatro alelos: os alelos 160, 166 e 170 com frequência de 99,35\% e o alelo 168 com $1,30 \%$.

No lócus Pi4B foram encontrados três alelos: os alelos 213 e 297 tiveram a frequência de 0,65\% e o alelo 219 apresentou frequência de 99,35\%. O lócus foi homozigoto para dois alelos, o 219 em 99,35\% dos isolados e 297 em 0,65\%.

No lócus Pi63 encontramos três alelos: os alelos 270 e 273 tiveram a frequência de $98,70 \%$ e o alelo 279 apresentou frequência um pouco menor, de 98,70\%. Em 1,30\% dos isolados o lócus foi homozigoto com o alelo 270.

No lócus Pi70 foram encontrados novamente três alelos, 189, 192 e 195 com as frequências de $0,65 \%, 100 \%$ e $99,35 \%$ respectivamente.

No lócus G11, foi encontrado o maior número de alelos, seis: os alelos 150 e 200 tiveram frequências de 0,65\%, o alelo 204 de 11,04\%, o 206 apresentou frequência de $88,31 \%, 154$ teve $99,35 \%$ e o $152100 \%$.

No lócus SSR2 foram encontrados apenas dois alelos: o alelo 173 teve frequência de $100 \%$ nos isolados analisados e o alelo 177 que teve 1,30\%. Neste lócus, 98,70\% dos isolados foram homozigotos para o alelo 173.

No lócus SSR3 foram encontrados quatro alelos com frequências distintas: o alelo 264 com $0,65 \%$, o 266 com 1,30\%, o 268 com 98,05\% e o 270 com 99,35\%.

No lócus SSR4 encontramos cinco alelos: os alelos 285 e 287 com a frequência de $0,65 \%$, o alelo 289 com 88,31\% de frequência, o 291 com 99,35\% e o 293 com $100 \%$.

O lócus SSR6 apresentou dois alelos, um com 100\% de frequência, 242 e o outro com 99,35\%. Em 0,65\% dos isolados o lócus apresentou-se homozigoto para o alelo 242 .

Nos dois últimos lócus analisados, SSR8 e SSR11, foram encontrados três alelos. No primeiro, os três alelos, 260, 264 e 266 apresentaram a mesma frequência de 99,35\%, sendo que em $0,65 \%$ dos isolados o lócus foi homozigoto com o alelo 266. Já no lócus SSR11 os alelos 340 e 356 tiveram a frequência de 100\% nos isolados analisados e o alelo 330 teve $6,49 \%$.

Segundo Rupp (2008) são chamados de lócus homozigoto aqueles que apresentam o mesmo número de repetições em ambos os cromossomos homólogos. Lócus heterozigoto apresentam um número diferente de repetições para cada alelo. 
Entretanto, no mesmo lócus a população ao todo contém geralmente diversos alelos, cada um com um número diferente de repetições. Isso significa que os marcadores de microssatélites (SSR) são úteis para discriminar indivíduos diferentes.

Tabela 8. Frequência dos alelos no estudo molecular por SSR nos isolados de Phytophthora infestans do presente estudo

\begin{tabular}{|c|c|c|c|}
\hline Lócus & Alelos & $\mathbf{N}^{0}$ de Isolados & Frequência $(\%)$ \\
\hline \multirow{4}{*}{ D13 } & 136 & 154 & $99,35 \%$ \\
\hline & 140 & 5 & $3,22 \%$ \\
\hline & 142 & 2 & $1,29 \%$ \\
\hline & 166 & 1 & $0,64 \%$ \\
\hline \multirow{4}{*}{ Pi04 } & 160 & 154 & $99,35 \%$ \\
\hline & 166 & 154 & $99,35 \%$ \\
\hline & 168 & 2 & $1,29 \%$ \\
\hline & 170 & 154 & $99,35 \%$ \\
\hline \multirow{3}{*}{$\mathrm{Pi} 4 \mathrm{~B}$} & 213 & 1 & $0,64 \%$ \\
\hline & 219 & 154 & $99,35 \%$ \\
\hline & 297 & 1 & $0,64 \%$ \\
\hline \multirow{3}{*}{ Pi63 } & 270 & 155 & $100 \%$ \\
\hline & 273 & 153 & $98,70 \%$ \\
\hline & 279 & 153 & $98,70 \%$ \\
\hline \multirow{3}{*}{ Pi70 } & 189 & 1 & $0,64 \%$ \\
\hline & 192 & 155 & $100 \%$ \\
\hline & 195 & 154 & $99,35 \%$ \\
\hline \multirow{6}{*}{ G11 } & 150 & 1 & $0,64 \%$ \\
\hline & 152 & 155 & $100 \%$ \\
\hline & 154 & 154 & $99,35 \%$ \\
\hline & 200 & 1 & $0,64 \%$ \\
\hline & 204 & 17 & $10,96 \%$ \\
\hline & 206 & 136 & $87,74 \%$ \\
\hline \multirow{2}{*}{ SSR2 } & 173 & 155 & $100 \%$ \\
\hline & 177 & 2 & $1,29 \%$ \\
\hline \multirow{2}{*}{ SSR3 } & 264 & 1 & $0,64 \%$ \\
\hline & 266 & 2 & $1,29 \%$ \\
\hline
\end{tabular}




\begin{tabular}{cccc}
268 & 152 & $98,06 \%$ \\
& 270 & 154 & $99,35 \%$ \\
\hline \multirow{2}{*}{ SSR4 } & 285 & 1 & $0,64 \%$ \\
& 289 & 1 & $0,64 \%$ \\
& 291 & 136 & $87,74 \%$ \\
& 293 & 154 & $99,35 \%$ \\
SSR6 & 242 & 155 & $100 \%$ \\
\hline \multirow{2}{*}{ SSR8 } & 244 & 155 & $100 \%$ \\
& 260 & 154 & $99,35 \%$ \\
\hline \multirow{2}{*}{ SSR11 } & 264 & 154 & $99,35 \%$ \\
& 266 & 154 & $99,35 \%$ \\
& 330 & 154 & $99,35 \%$ \\
\hline 340 & 10 & $6,45 \%$ \\
& 356 & 155 & $100 \%$ \\
& & 155 & $100 \%$ \\
\hline
\end{tabular}

Analisando os 155 perfis polimórficos obtidos dos isolados de $P$. infestans neste estudo, foram encontradas 16 variações (Tabela 9). 
Tabela 9. Variações encontradas entre os perfis polimórficos obtidos com os marcadores microssatélites (SSR) dos isolados Phytophthora infestans do presente estudo

\begin{tabular}{|c|c|c|c|c|c|c|c|c|c|c|c|c|c|c|c|c|c|c|c|c|c|c|c|c|c|c|c|c|c|c|c|c|c|c|c|c|}
\hline \multirow{2}{*}{$\begin{array}{c}\text { Varia- } \\
\text { ção }\end{array}$} & \multicolumn{3}{|c|}{ D13 } & \multicolumn{3}{|c|}{ Pi04 } & \multicolumn{3}{|c|}{ Pi4B } & \multicolumn{3}{|c|}{ Pi63 } & \multicolumn{3}{|c|}{ Pi70 } & \multicolumn{3}{|c|}{ G11 } & \multicolumn{3}{|c|}{ SSR2 } & \multicolumn{3}{|c|}{ SSR3 } & \multicolumn{3}{|c|}{ SSR4 } & \multicolumn{3}{|c|}{ SSR6 } & \multicolumn{3}{|c|}{ SSR8 } & \multicolumn{3}{|c|}{ SSR11 } \\
\hline & Al. & Al. & Al. & 1. & Al. & Al. & Al. & Al. & Al. & Al. & Al. & Al. & 1. & Al. & 1. & 1. & 1. & Al. & l. & Al. & Il. & Al. & 1. & 1. & I. & Al. & I. & Al. & Al. & l. & Al. & Al. & Al. & Al. & Al. & Al. \\
\hline 01 & 136 & 140 & 0 & 160 & 166 & 168 & 219 & 219 & 0 & 270 & 273 & 279 & 192 & 195 & 0 & 152 & 154 & 206 & 173 & 173 & 0 & 268 & 270 & 0 & 289 & 291 & 293 & 242 & 244 & 0 & 260 & 264 & 266 & 340 & 356 & 0 \\
\hline 02 & 136 & 136 & 0 & 60 & 66 & 70 & 219 & 219 & 0 & 270 & 73 & 70 & 2 & 25 & 0 & 52 & 154 & 204 & 173 & 173 & O & 268 & 270 & 0 & 289 & 291 & 293 & 242 & 244 & 0 & 260 & 264 & 266 & 340 & 356 & 0 \\
\hline 03 & 136 & 136 & 0 & 160 & 166 & 170 & 219 & 219 & 0 & 270 & 273 & 279 & 192 & 195 & 0 & 152 & 154 & 206 & 173 & 173 & 0 & 268 & 270 & 0 & 289 & 291 & 293 & 242 & 244 & 0 & 260 & 264 & 266 & 330 & 340 & 356 \\
\hline 04 & 136 & 36 & 0 & 160 & 166 & 170 & 219 & 219 & 0 & 270 & 273 & 279 & 92 & 95 & 0 & 152 & 154 & 206 & 173 & 173 & 0 & 268 & 270 & 0 & 289 & 291 & 293 & 242 & 244 & 0 & 260 & 264 & 266 & 340 & 356 & 0 \\
\hline 05 & 136 & 1 & 0 & 160 & 166 & 170 & 219 & 219 & 0 & 270 & 273 & 279 & 2 & 195 & 0 & 2 & 154 & 206 & 173 & 173 & 0 & 270 & 270 & 0 & 291 & 293 & 0 & 242 & 244 & 0 & 260 & 264 & 266 & 340 & 356 & 0 \\
\hline 06 & 136 & 136 & 0 & 160 & 166 & 170 & 219 & 219 & 0 & 273 & 279 & 0 & 192 & 195 & 0 & 152 & 154 & 206 & 173 & 173 & 0 & 268 & 270 & 0 & 289 & 291 & 293 & 242 & 244 & 0 & 260 & 264 & 266 & 340 & 356 & 0 \\
\hline 07 & 136 & 6 & 0 & 0 & 166 & 170 & 219 & 219 & 0 & 270 & 273 & 279 & 2 & 5 & 0 & 2 & 154 & 206 & 173 & 173 & 0 & 268 & \begin{tabular}{|l}
270 \\
\end{tabular} & 0 & 291 & 293 & 0 & 242 & 244 & 0 & 260 & 264 & 266 & 340 & 356 & 0 \\
\hline 08 & 136 & 136 & 0 & 160 & 166 & 170 & 219 & 219 & 0 & 270 & 273 & 279 & 192 & 195 & 0 & 152 & 154 & 204 & 173 & 173 & 0 & 268 & 270 & 0 & 289 & 291 & 293 & 242 & 244 & 0 & 260 & 264 & 266 & 330 & 340 & 356 \\
\hline 09 & 136 & 140 & 0 & 160 & 166 & 170 & 219 & 219 & 0 & 270 & 273 & 279 & 192 & 195 & U & 152 & 154 & 206 & 173 & 173 & 0 & 268 & 270 & 0 & 289 & 291 & 293 & 242 & 244 & 0 & 260 & 264 & 266 & 330 & 340 & 356 \\
\hline 10 & 136 & 136 & 0 & 160 & 166 & 170 & 297 & 297 & 0 & 270 & 270 & 0 & 192 & 195 & 0 & 152 & 154 & 204 & 173 & 173 & 0 & 266 & 270 & 0 & 289 & 291 & 293 & 242 & 244 & 0 & 260 & 264 & 266 & 330 & 340 & 356 \\
\hline 11 & 136 & 142 & 0 & 160 & 168 & 170 & 213 & 219 & 0 & 270 & 273 & 279 & 189 & 192 & 0 & 150 & 152 & 200 & 173 & 177 & 0 & 264 & 266 & 268 & 285 & 287 & 293 & 242 & 244 & 0 & 266 & 266 & 0 & 340 & 356 & 0 \\
\hline 12 & 136 & 136 & 0 & 160 & 166 & 170 & 219 & 219 & 0 & 270 & 273 & 279 & 192 & 1 & 0 & 52 & 154 & 206 & 173 & 1 & 0 & 268 & 27 & 0 & 291 & 293 & 0 & 242 & 242 & 0 & 260 & 264 & 266 & 340 & 356 & 0 \\
\hline 13 & 136 & 140 & 0 & 160 & 166 & 170 & 219 & 219 & 0 & 270 & 273 & 279 & 192 & 195 & 0 & 152 & 154 & 206 & 173 & 173 & 0 & 268 & 270 & 0 & 289 & 291 & 293 & 242 & 244 & 0 & 260 & 264 & 266 & 340 & 356 & 0 \\
\hline 14 & 136 & 136 & 0 & 166 & 170 & 0 & 219 & 219 & 0 & 270 & 273 & 279 & 192 & 193 & 0 & 152 & 154 & 206 & 173 & 173 & 0 & 268 & 270 & 0 & 291 & 293 & 0 & 242 & 244 & 0 & 260 & 264 & 266 & 340 & 356 & 0 \\
\hline 15 & 142 & 166 & 0 & 160 & 166 & 170 & 219 & 219 & 0 & 270 & 270 & 0 & 192 & 195 & 0 & 152 & 154 & 206 & 173 & 173 & 0 & 268 & 270 & 0 & 291 & 293 & 0 & 242 & 244 & 0 & 260 & 264 & 0 & 330 & 340 & 356 \\
\hline 16 & 136 & 140 & 0 & 160 & 166 & 170 & 219 & 219 & 0 & 270 & 273 & 279 & 192 & 195 & 0 & 152 & 154 & 206 & 173 & 177 & 0 & 268 & 270 & 0 & 291 & 293 & 0 & 242 & 244 & 0 & 260 & 264 & 266 & 330 & 340 & 356 \\
\hline
\end{tabular}


Dentre as 16 variações encontradas, a variação 04 foi a mais abundante neste estudo. Dos 155 isolados analisados, $111(71,6 \%)$ foram identificados como pertencente a essa variação. A variação 02 foi a segunda variação mais abundante neste estudo, com 14 representantes $(9,0 \%)$, seguida da variação 07 , com 11 representantes $(7,1 \%)$. As demais variações apresentaram três (variação 03) representantes, dois (variações 05, 08 e 09) e um (variações $01,06,10,11,12,13,14,15$ e 16), sendo estas as menos abundantes neste estudo.

Estas variações foram comparadas aos perfis polimórficos de isolados de $P$. infestans do banco de dados da EuroBlight e da Tizón Latino, redes internacionais que estudam $P$. infestans. As variações 02, 03, 04, 06, 07, 08, 09, 12, 13 e 14 foram identificadas como pertencentes à linhagem EU_2_A1 (ou simplesmente 2_A1), e a variação 11 pertencente a linhagem US-1.

A linhagem EU_2_A1 é uma linhagem originária na Europa (NJOROGE et al., 2019) e a linhagem US-1 foi descrita pela primeira vez por Goodwin, Cohen e Fry em 1994 nos Estados Unidos e Canadá.

Segundo Saville, Martin e Ristaino (2016), a linhagem US-1 foi disseminada mundialmente em meados do século 20. Legard, Lee e Fry (1995) detectaram a linhagem US-1 de P. infestans em tomate e em batata nos Estados Unidos.

As variações encontradas neste estudo também foram comparadas aos perfis polimórficos descritos por $\mathrm{Li}$ (2012), onde foram encontrados 2 isolados com alta similaridade polimórfica com variações encontradas neste estudo (Tabela 10). As variações 02, 03, 04, 06, 07, 08, 09, 12, 13 e 14 deste estudo apresentaram alta similaridade com o perfil polimórfico do isolado VK98014 descrito por Li (2012), a similaridade destas variações oscilaram entre $86,11 \%$ e $80,55 \%$. O isolado VK98014 é de origem Holandesa (1998), foi isolado de Solanum tuberosum e pertence à linhagem clonal 2_A1 (LI, 2012).

A variação 11 apresentou aproximadamente $66,67 \%$ de similaridade com o perfil polimórfico do isolado VK1_4 descrito por Li (2012). Este isolado é de origem Holandesa (1958), foi isolado de Solanum tuberosum, classificado como pertencente ao grupo de compatibilidade A1 e pertencente à linhagem US-1 (Li, 2012).

Reis e colaboradores (2003) relataram a existência das linhagens clonais US-1 e BR-1 no Brasil, sendo cada linhagem altamente específica a seu hospedeiro: os isolados US-1 estão associados com tomate, enquanto os isolados BR-1 foram encontrados em batata. Estes resultados foram confirmados por Suassuna e colaboradores (2004). 
Os isolados da linhagem BR-1, foram sempre associados à batata, enquanto os da linhagem US-1 foram mais comumente associados ao tomate (GOODWIN; COHEN; FRY, 1994).

Lucca e colaboradores (2018) identificaram as linhagens 2_A1 e US-1 em uma análise preliminar de isolados de $P$. infestans do presente estudo. No mesmo ano, Lucca e Restrepo (2018), relataram que os isolados de P. infestans analisados do Chile e da Argentina pertenciam à linhagem 2_A1 e os isolados analisados do Brasil pertenciam às linhagens 2_A1 e US-1.

Acuña e colaboradores (2016) relataram que no Chile, entre 2003 e 2005, a linhagem de $P$. infestans predominante era a US-1, e de 2006 a 2016 a linhagem 2_A1 passou a ser o predominante no país.

No Peru, Gamboa e colaboradores (2018) relataram a existência de quatro linhagens EC-1 e US-1 em batata e PE-3 e PE-7 em variedades nativas ou espécies silvestres. A linhagem EC-1 foi predominante no estudo.

Vargas e colaboradores (2009) relataram as linhagens EC-1 e US-7 na Colômbia, entretanto Gilchrist Ramelli e colaboradores (2009) relataram a presença das linhagens EC-1 e US-1 em Antioquia, Colômbia. 
Tabela 10. Comparação dos perfis polimórficos das variações 04 e 11 deste trabalho, com os perfis polimórficos encontrados por Li (2012).

\begin{tabular}{|c|c|c|c|c|c|c|c|c|c|c|c|c|c|c|c|c|c|c|c|c|c|c|c|c|c|c|c|c|c|c|c|c|c|c|c|c|}
\hline \multirow{2}{*}{ Variação } & \multicolumn{3}{|c|}{ D13 } & \multicolumn{3}{|c|}{ Pi04 } & \multicolumn{3}{|c|}{ Pi4B } & \multicolumn{3}{|c|}{ Pi63 } & \multicolumn{3}{|c|}{ Pi70 } & \multicolumn{3}{|c|}{ G11 } & \multicolumn{3}{|c|}{ SSR2 } & \multicolumn{3}{|c|}{ SSR3 } & \multicolumn{3}{|c|}{ SSR4 } & \multicolumn{3}{|c|}{ SSR6 } & \multicolumn{3}{|c|}{ SSR8 } & \multicolumn{3}{|c|}{ SSR1 } \\
\hline & Al. & Al. & 1. & l. & Al. & Al. & Il. & Al. & Al. & Al. & Al. & Al. & 1. & Al. & l. & Al. & Al. & l. & II. & Al. & Al. & Il. & Al. & Al. & Il. & Al. & Al. & Al. & Al. & Al. & I. & Al. & Al. & Al. & Al. & Al. \\
\hline $\begin{array}{c}\text { Variação } \\
02\end{array}$ & 136 & 36 & 0 & 60 & 166 & 170 & 19 & 219 & 0 & 270 & 273 & 79 & 192 & 195 & 0 & 152 & 154 & 204 & 173 & 173 & 0 & 268 & 270 & 0 & 89 & 291 & 293 & 242 & 244 & 0 & 260 & 264 & 266 & 340 & 356 & 0 \\
\hline $\begin{array}{l}\text { Variação } \\
03\end{array}$ & 136 & 136 & 0 & 160 & 166 & 170 & 219 & 219 & 0 & 270 & 273 & 279 & 192 & 195 & 0 & 152 & 154 & 206 & 173 & 173 & 0 & 268 & 270 & 0 & 289 & 291 & 293 & 242 & 244 & 0 & 260 & 264 & 266 & 330 & 340 & 356 \\
\hline $\begin{array}{c}\text { Variação } \\
04\end{array}$ & 136 & 136 & 0 & 160 & 166 & 170 & 219 & 219 & 0 & 270 & 273 & 279 & 192 & 195 & 0 & 152 & 154 & 206 & 173 & 173 & 0 & 268 & 270 & 0 & 289 & 291 & 293 & 242 & 244 & 0 & 260 & 264 & 266 & 340 & 356 & 0 \\
\hline $\begin{array}{c}\text { Variação } \\
06\end{array}$ & 36 & 36 & 0 & 160 & 166 & 170 & 219 & 219 & 0 & 273 & 279 & 0 & 192 & 195 & 0 & 152 & 154 & 206 & 173 & 173 & 0 & 268 & 270 & 0 & 289 & 291 & 293 & 242 & 244 & 0 & 260 & 264 & 266 & 340 & 356 & 0 \\
\hline $\begin{array}{c}\text { Variação } \\
07\end{array}$ & 136 & 136 & 0 & 160 & 166 & 170 & 219 & 219 & 0 & 270 & 273 & 279 & 192 & 195 & 0 & 152 & 154 & 206 & 173 & 173 & 0 & 268 & 270 & 0 & 291 & 293 & 0 & 242 & 244 & 0 & 260 & 264 & 266 & 340 & 356 & 0 \\
\hline $\begin{array}{c}\text { Variação } \\
08\end{array}$ & 136 & 136 & 0 & 160 & 166 & 170 & 219 & 219 & 0 & 270 & 273 & 279 & 192 & 195 & 0 & 152 & 154 & 204 & 173 & 173 & 0 & 268 & 270 & 0 & 289 & 291 & 293 & 242 & 244 & 0 & 260 & 264 & 266 & 330 & 340 & 356 \\
\hline $\begin{array}{c}\text { Variação } \\
09\end{array}$ & 136 & 40 & 0 & 160 & 166 & 170 & 19 & 219 & 0 & 27 & 27 & 27 & 192 & 195 & 0 & 152 & 154 & 206 & 173 & 17 & 0 & 268 & 270 & 0 & 289 & 291 & 293 & 242 & 244 & 0 & 260 & 264 & 266 & 330 & 340 & 356 \\
\hline $\begin{array}{c}\text { Variação } \\
12\end{array}$ & 136 & 136 & 0 & 160 & 166 & 170 & 219 & 219 & 0 & 2 & 273 & 2 & 192 & 195 & 0 & 152 & 154 & 206 & 173 & 17 & 0 & 268 & 270 & 0 & 291 & 293 & 0 & 242 & 242 & 0 & 260 & 264 & 266 & 340 & 356 & 0 \\
\hline $\begin{array}{c}\text { Variação } \\
14 \\
\end{array}$ & 136 & 136 & 0 & 166 & 170 & 0 & 19 & 219 & 0 & 270 & 27 & 279 & 192 & 195 & 0 & 152 & 154 & 206 & 173 & 173 & 0 & 268 & 270 & 0 & 291 & 293 & 0 & 242 & 244 & 0 & 260 & 264 & 266 & 340 & 356 & 0 \\
\hline VK98014 & 136 & 136 & 0 & 166 & 170 & 0 & 217 & 217 & 0 & $* 148$ & $* 151$ & *157 & 192 & 195 & 0 & 154 & 156 & 206 & 173 & 173 & 0 & 258 & 268 & 0 & 288 & 290 & 292 & 242 & 244 & 0 & 260 & 264 & 266 & 341 & 356 & 0 \\
\hline $\begin{array}{c}\text { Variação } \\
11 \\
\end{array}$ & 136 & 142 & 0 & 160 & 168 & 170 & 213 & 219 & 0 & 270 & 273 & 279 & 189 & 192 & 0 & 150 & 152 & 200 & 173 & 177 & 0 & 264 & 266 & 268 & 285 & 287 & 293 & 242 & 244 & 0 & 266 & 266 & 0 & 340 & 356 & 0 \\
\hline VK1_4 & 140 & 140 & 0 & 166 & 170 & 0 & 213 & 217 & 0 & $* 148$ & $* 151$ & $* 157$ & 189 & 192 & 0 & 152 & 156 & 200 & 173 & 177 & 0 & 266 & 266 & 0 & 288 & 290 & 0 & 244 & 244 & 0 & 266 & 266 & 0 & 341 & 356 & 0 \\
\hline
\end{tabular}

*No estudo de Li (2012) o lócus Pi63 está com a nomenclatura 148/151/157 que segundo a Lista de alelos e tamanhos de produtos dos 12 marcadores (SSR) cedidos pela Eurobligth (Anexos 1 e 2) correspondem atualmente aos alelos 270/273/279. 
Na França, em 2001, a linhagem predominante era a 2_A1 com 60\% de frequência, em 2006 a mesma linhagem permaneceu como predominante, porém sua frequência foi mais baixa (40\%). Já nos anos de 2007 e 2008 a linhagem 13_A2 (Blue 13) foi a predominante com $80 \%$ de frequência (MARIETTE et al., 2014).

Em levantamento feito por Alor-Romero (2015) na Espanha, a linhagem mais frequente foi a 2_A1 (42,30\%), seguida pelas linhagens 3_A2, 13_A2y, Misc A1 e Misc A2.

Rekad e colaboradores (2017) realizaram a caracterização da população de $P$. infestans no noroeste da Argélia entre 2008-2014 por análise genotípica (SSR) e o resultado mostrou baixa diversidade. A linhagem predominante foi a 13_A2 (67\%), seguida pela linhagem 2_A1 e 23_A1 com 21 e 5\% respectivamente.

No Quênia e Uganda todos os isolados coletados por Vega-Sanchez e colaboradores (2000) pertenciam à linhagem US-1. Posteriormente, Were e colaboradores (2013) detectaram no Quênia as linhagens 2_A1 e US-1 em frequência de 52,27 e 47,73\% respectivamente. Recentemente, no leste da África (Quênia, Uganda, Tanzânia, Burundi e Ruanda), Njoroge e colaboradores (2019) constataram a predominância das linhagens 2_A1 em batata e US-1 em tomate (exceto no Quênia, onde a linhagem 2_A1 predominou em tomate também). Os isolados da linhagem 2_A1 foram significativamente mais agressivos que os isolados da linhagem US-1 em ambas cultivares de batata avaliadas (cultivar Sarpo Mira e cultivar Kachpot-1). Os isolados da linhagem 2_A1 foram significativamente mais agressivos na batata do que no tomate. Nota-se que, de maneira similar ao que o presente estudo revela ter acontecido em batata no Brasil, no leste da África a linhagem 2_A1 suplantou rapidamente a linhagem anteriormente predominante (BR-1 no Brasil e US-1 na África).

Saville e colaboradores (2016) utilizaram os mesmos marcadores microssatélites para o estudo molecular de isolados de P. infestans pelo mundo. Dentre os 183 isolados analisados, foram incluídos quatro da linhagem BR-1 provenientes do Brasil, isolados em 1998 e cedidos pelo Dr. Eduardo Mizubuti (Tabela 11). Ao compararmos os perfis polimórficos dos isolados da linhagem BR-1 com as variações encontradas no presente trabalho, podemos observar que os isolados atuais pertencem a linhagens marcadamente distintas da anteriormente presente no Brasil.

Árvore de distância genética construída com os dados dos microssatélites dos isolados do presente estudo com os de outras linhagens mundiais, mostra que as linhagens brasileiras atuais formam um ramo junto à linhagem 2_A1 (Figura 13). 
Observa-se também que a linhagem BR-1 se aproxima da linhagem AR4 da Argentina. A variação 11 se assemelha à linhagem US-1, conforme já discutido anteriormente.

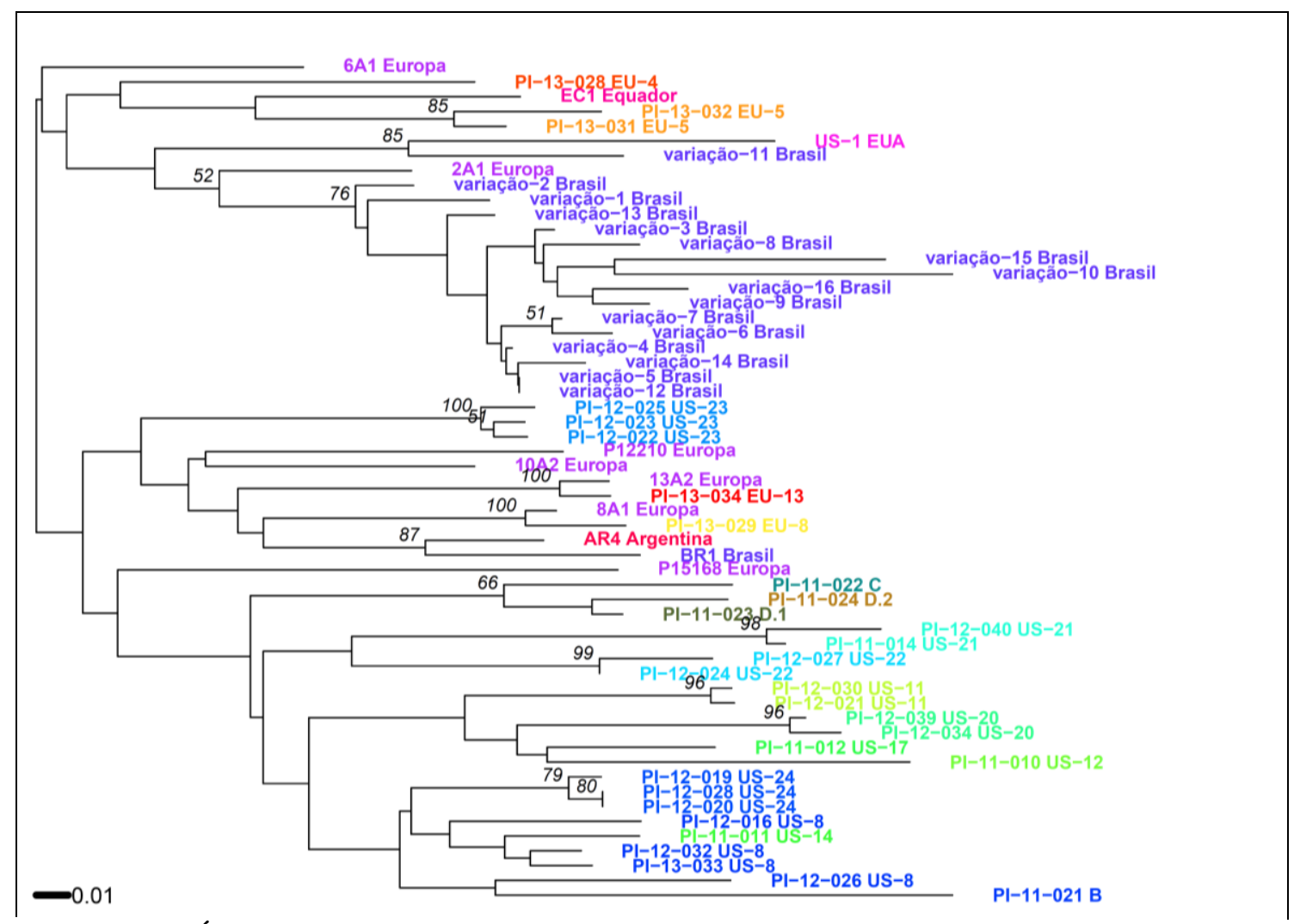

Figura 13. Árvore de distância genética construída pelo método de Neighbor Joining com os dados de microssatélites dos isolados de Phytophthora infestans do presente estudo e de outras linhagens mundiais.

O gráfico de rede de extensão mínima (minimum spanning network) confirma o agrupamento das variações do presente estudo com a linhagem 2_A1 (Figura 14). 


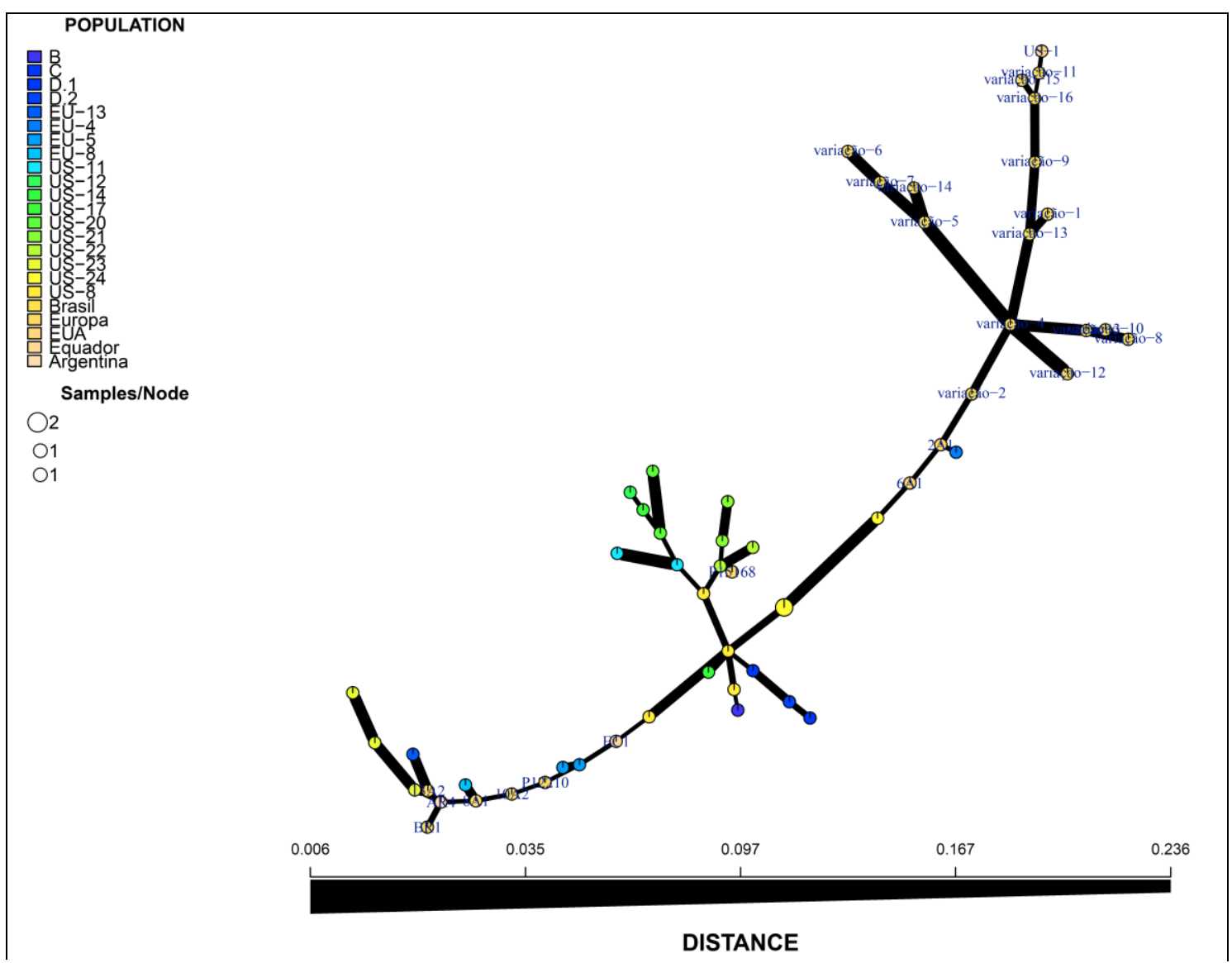

Figura 14. Gráfico da rede de extensão mínima (minimum spanning network) construído com os dados de microssatélites de isolados de Phytophthora infestans do presente estudo e de outras linhagens mundiais. 
Tabela 11. Perfis polimórficos dos isolados brasileiros estudados por Saville e colaboradores (2016), pertencentes à linhagem BR-1.

\begin{tabular}{|c|c|c|c|c|c|c|c|c|c|c|c|c|c|c|c|c|c|c|c|c|c|c|c|c|c|c|c|c|c|c|c|c|c|c|c|c|c|}
\hline \multirow{2}{*}{$\begin{array}{l}\text { Iso- } \\
\text { lado }\end{array}$} & \multirow{2}{*}{$\begin{array}{l}\text { Genó } \\
\text {-tipo }\end{array}$} & \multicolumn{3}{|c|}{ D13 } & \multicolumn{3}{|c|}{ Pi04 } & \multicolumn{3}{|c|}{ Pi4B } & \multicolumn{3}{|c|}{ Pi63 } & \multicolumn{3}{|c|}{ Pi70 } & \multicolumn{3}{|c|}{ G11 } & \multicolumn{3}{|c|}{ SSR2 } & \multicolumn{3}{|c|}{ SSR3 } & \multicolumn{3}{|c|}{ SSR4 } & \multicolumn{3}{|c|}{ SSR6 } & \multicolumn{3}{|c|}{ SSR8 } & \multicolumn{3}{|c|}{ SSR11 } \\
\hline & & Al. & Al. & Al. & Al. & Al. & Al. & Al. & Al. & Al. & Al. & Al. & Al. & Al. & Al. & Al. & Al. & Al. & Al. & Al. & Al. & Al. & Al. & Al. & Al. & Al. & Al. & Al. & Al. & Al. & Al. & Al. & Al. & Al. & Al. & Al. & Al. \\
\hline B219 & BR1 & 140 & 140 & 0 & 160 & 160 & 0 & 205 & 213 & 243 & 279 & 279 & 0 & 192 & 192 & 0 & 160 & 162 & 0 & 173 & 173 & 0 & 266 & 268 & 0 & 285 & 293 & 0 & 244 & 244 & 0 & 260 & 266 & 0 & 330 & 340 & 0 \\
\hline B217 & BR1 & 140 & 140 & 0 & 170 & 10 & 0 & 205 & 213 & 243 & 270 & 279 & 0 & 192 & 192 & 0 & 164 & 164 & 0 & 173 & 173 & 0 & 266 & 268 & 0 & 285 & 297 & 0 & 244 & 244 & 0 & 260 & 266 & 0 & 330 & 340 & 0 \\
\hline B189 & BR1 & \begin{tabular}{|l|l}
136 \\
\end{tabular} & 136 & 0 & 170 & 170 & 0 & 205 & 213 & \begin{tabular}{|l|l}
243 \\
\end{tabular} & 270 & 279 & 0 & 192 & 192 & 0 & 162 & \begin{tabular}{|l|l|}
164 \\
\end{tabular} & 0 & 173 & 173 & 0 & 266 & 268 & 0 & 285 & 293 & 0 & 244 & 244 & 0 & 260 & 266 & 0 & \begin{tabular}{|l}
330 \\
\end{tabular} & 340 & 0 \\
\hline B193 & BR1 & $\mid 140$ & 140 & 0 & 170 & 170 & 0 & 205 & 213 & 243 & 270 & 279 & 0 & 192 & 192 & 0 & 162 & \begin{tabular}{|l|l}
164 \\
\end{tabular} & 0 & 173 & 173 & 0 & 266 & 268 & 0 & 285 & \begin{tabular}{|l|}
293 \\
\end{tabular} & 0 & 244 & 244 & 0 & 260 & 266 & 0 & \begin{tabular}{|l}
330 \\
\end{tabular} & 340 & 0 \\
\hline
\end{tabular}

Tabela 12. Comparação dos perfis polimórficos dos isolados autoférteis encontrados neste estudo, com os perfis polimórficos dos isolados autoférteis encontrados por Casa-Coila e colaboradores (2017).

\begin{tabular}{|c|c|c|c|c|c|c|c|c|c|c|c|c|c|c|c|c|c|c|c|c|c|c|c|c|c|c|c|c|c|c|c|c|c|c|c|c|c|c|c|}
\hline \multirow{2}{*}{$\begin{array}{c}\text { Variaçã } \\
\text { o }\end{array}$} & \multirow{2}{*}{$\begin{array}{c}\text { solad } \\
\text { o }\end{array}$} & \multicolumn{3}{|c|}{ D13 } & \multicolumn{3}{|c|}{ Pi04 } & \multicolumn{3}{|c|}{ Pi4B } & \multicolumn{3}{|c|}{ Pi63 } & \multicolumn{3}{|c|}{ Pi70 } & \multicolumn{3}{|c|}{ G11 } & \multicolumn{3}{|c|}{ SSR2 } & \multicolumn{3}{|c|}{ SSR3 } & \multicolumn{3}{|c|}{ SSR4 } & \multicolumn{4}{|c|}{ SSR6 } & \multicolumn{4}{|c|}{ SSR8 } & \multicolumn{3}{|c|}{ SSR11 } \\
\hline & & Al. & Al. & Al. & Al. & Al. & Al. & Al. & Al. & Al. & Al. & Al. & Al. & Al. & Al. & Al. & Al. & Al. & Al. & Al. & Al. & Al. & Al. & Al. & Al. & Al. & Al. & Al & & Al. & Al. & Al. & Al. & Al. & & & Al. & Al. & Al. \\
\hline 02 & 011A & 136 & 136 & 0 & 0 & 166 & 170 & 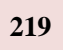 & 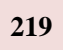 & 0 & 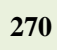 & 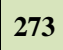 & 279 & 2 & 195 & 0 & 152 & 4 & 4 & 73 & \begin{tabular}{|l|}
173 \\
\end{tabular} & 0 & 268 & 270 & 0 & 9 & 291 & 20 & & 42 & 244 & 0 & 60 & 54 & & & 40 & 356 & $\mathbf{0}$ \\
\hline 0 & ID & & 136 & 0 & 0 & 166 & & 9 & 219 & 0 & & 273 & 9 & 2 & 195 & 0 & 52 & 4 & 4 & 73 & 173 & $\mathbf{0}$ & 268 & 270 & 0 & 39 & 291 & 29. & & 12 & 244 & & 60 & 64 & & & 10 & 56 & 0 \\
\hline 02 & $2 A$ & 5 & 136 & 0 & ) & 166 & 170 & 219 & 9 & 0 & 0 & 273 & 9 & 2 & 5 & 0 & 2 & 4 & 4 & 73 & \begin{tabular}{|l|}
173 \\
\end{tabular} & 0 & 2 & 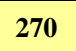 & O & 39 & 291 & 29. & & 242 & 244 & 0 & 60 & 64 & & & 40 & 56 & O \\
\hline 04 & $2 \mathrm{~B}$ & & & 0 & 160 & 166 & & 219 & 219 & 0 & 70 & 273 & 9 & 2 & 195 & 0 & 2 & 4 & 06 & 3 & 173 & 0 & 2 & 270 & o & 39 & 29 & 2 & & 242 & 244 & 0 & 60 & 264 & & & 40 & 356 & $\mathbf{0}$ \\
\hline 07 & $012 \mathrm{C}$ & 136 & 136 & 0 & 160 & 166 & 0 & 219 & 219 & 0 & 0 & 273 & 9 & 192 & 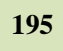 & 0 & 52 & 154 & 206 & 173 & 173 & 0 & 2 & 27 & 0 & 291 & 2 & & & 242 & 244 & c & 260 & 64 & 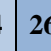 & & 340 & 356 & 0 \\
\hline 04 & 2D & 6 & 136 & 0 & 0 & 166 & 170 & 9 & 219 & 0 & 270 & 3 & 9 & 2 & 195 & 0 & 2 & 4 & 06 & 3 & 173 & $\mathbf{0}$ & 268 & 270 & 0 & 89 & 29 & 29. & & 42 & 2 & 0 & 60 & 64 & & & 10 & 356 & $\mathbf{0}$ \\
\hline 04 & $012 E$ & 136 & $13 t$ & 0 & 160 & 166 & 70 & 219 & 219 & 0 & 0 & 273 & 279 & 192 & 19 & $\mathbf{0}$ & 152 & 154 & 206 & 173 & 173 & $\mathbf{0}$ & 268 & 270 & 0 & 289 & 291 & 29 & & 242 & 244 & 0 & 260 & 264 & 26 & & 340 & 356 & 0 \\
\hline 1 & 035A & 136 & 140 & 0 & 160 & 1 & 170 & 9 & 219 & 0 & 270 & 273 & 270 & 192 & & 0 & 152 & 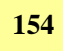 & 6 & 3 & 1 & 0 & 268 & 270 & 0 & 289 & 291 & 20 & & 242 & 244 & 0 & 60 & 264 & 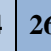 & & 340 & 356 & 0 \\
\hline 02 & 035B & 136 & 136 & 0 & 160 & 166 & 170 & 219 & 219 & 0 & 70 & 273 & 279 & 192 & 95 & $\mathbf{0}$ & 52 & 154 & 204 & 173 & \begin{tabular}{|l|}
173 \\
\end{tabular} & 0 & 268 & 270 & 0 & 289 & 291 & 29 & & 242 & 244 & 0 & 260 & 64 & 26 & & 340 & 356 & $\mathbf{0}$ \\
\hline 04 & $035 \mathrm{C}$ & 6 & 136 & 0 & 60 & 166 & 170 & 219 & 2 & 0 & 70 & 273 & 279 & 192 & 195 & 0 & 2 & 154 & 06 & 73 & 173 & 0 & 26 & 270 & 0 & 289 & 291 & 29. & & 242 & 244 & 0 & 60 & 64 & 26 & & 340 & 356 & 0 \\
\hline 04 & 035D & 0 & 136 & 0 & 0 & 166 & 170 & 219 & 219 & 0 & 0 & 273 & 9 & 2 & 195 & 0 & 2 & 154 & 6 & 3 & 173 & $\mathbf{0}$ & 2 & 270 & 0 & 9 & 291 & 29. & & 242 & 2 & 0 & 60 & 64 & 26 & & 40 & 356 & 0 \\
\hline 04 & $035 E$ & 136 & 136 & 0 & 160 & 166 & 70 & 219 & 219 & 0 & 0 & 273 & 79 & 192 & 5 & $\mathbf{0}$ & 52 & 154 & 206 & 173 & 173 & 0 & $2 \theta$ & 270 & 0 & 289 & 291 & 29. & & 242 & 244 & 0 & 260 & 64 & 26 & & 340 & 356 & $\mathbf{0}$ \\
\hline 04 & 142 & 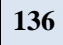 & 36 & 0 & 0 & 166 & 0 & 219 & 219 & 0 & 770 & 273 & 99 & 192 & 80 & 0 & 2 & 4 & 06 & 173 & 173 & 0 & 268 & 270 & o & 39 & 291 & 2 & & 242 & 244 & 0 & 260 & 64 & 20 & & 40 & 356 & 0 \\
\hline & - & 8 & 40 & 0 & 168 & 168 & 0 & & - & - & & & & & . & - & 158 & 158 & 0 & 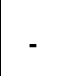 & - & - & $146 /$ & $\begin{array}{l}160 / \\
266\end{array}$ & $\mathbf{0}$ & & & & & & - & - & & & & & $\begin{array}{c}* \\
200\end{array}$ & $\begin{array}{c}* \\
203\end{array}$ & $\begin{array}{l}* \\
0\end{array}$ \\
\hline
\end{tabular}

*Alelos encontrados no lócus Pi33 que não foi utilizado neste estudo. 
Em 2017 Casa-Coila e colaboradores realizaram o primeiro relato de isolados autoférteis de $P$. infestans no Brasil. Foram encontrados três isolados no Estado do Paraná (Ponta Grossa, Contenda e Castro) para os quais foi realizado o estudo molecular por SSR utilizando nove pares de iniciadores (SSR), alguns iguais ao utilizados neste estudo. Os perfis polimórficos dos isolados foram obtidos com os marcadores microssatélites: G11, Pi02, Pi89, Pi04, Pi70, Pi56 (Long), Pi63 (Long), Pi33 e D13. Ao compararmos os isolados autoférteis relatados por Casa-Coila e colaboradores (2017), com os isolados obtidos neste estudo, observamos tratar de perfis distintos (Tabela 12).

5.5. Teste de sensibilidade in vitro de isolados de Phytophthora infestans aos fungicidas ciazofamida, clorotalonil, dimetomorfe e propamocarbe

Os 17 isolados de $P$. infestans utilizados, representativos de 6 variações genotípicas, apresentaram sensibilidade variável aos princípios ativos analisados (ciazofamida, clorotalonil, dimetomorfe e propamocarbe). 


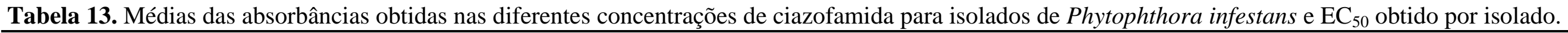

\begin{tabular}{|c|c|c|c|c|c|c|c|c|c|c|c|c|c|c|c|c|c|}
\hline \multirow{2}{*}{$\begin{array}{c}\text { Concentraçãa } \\
{\left[\mu \mathrm{g} \mathrm{mL}^{-1}\right]}\end{array}$} & \multicolumn{17}{|c|}{ Isolados de Phytophthora infestans } \\
\hline & 151 & PRT & CRI-2 & 006 & $012 \mathrm{C}$ & 023 & 035B & 042 & 051 & 061 & 064 & 077 & 093 & 109 & 117 & 136 & 140 \\
\hline 0 & $0,1173 \mathrm{a}$ & $0,1244 \mathrm{a}$ & $0,7757 \mathrm{a}$ & $0,7609 \mathrm{a}$ & $0,6393 \mathrm{a}$ & $0,1088 \mathrm{a}$ & $0,2757 \mathrm{a}$ & $1491 \mathrm{a}$ & $6275 \mathrm{a}$ & $0,5663 \mathrm{a}$ & $0,7097 \mathrm{a}$ & $0,3742 \mathrm{a}$ & $0,6919 \mathrm{a}$ & $0,7943 \mathrm{a}$ & $0,7578 \mathrm{a}$ & $0,1103 \mathrm{a}$ & $0,2804 \mathrm{a}$ \\
\hline 0,01 & $\underline{0,0458 \mathrm{~b}}$ & $0,1033 \mathrm{~b}$ & $0,6745 \mathrm{~b}$ & $0,6457 \mathrm{ab}$ & $\underline{0,3749 \mathrm{~b}}$ & $0,0600 \mathrm{~b}$ & $\underline{0,1341 \mathrm{~b}}$ &, $1079 \mathrm{~b}$ & $0,3309 \mathrm{~b}$ & $\underline{0,3853 \mathrm{a}}$ & $0,6314 \mathrm{ab}$ & $\underline{0,1567 \mathrm{~b}}$ & $0,6175 \mathrm{~b}$ & $0,6485 \mathrm{~b}$ & $0,6785 \mathrm{a}$ & $0,0704 \mathrm{~b}$ & $\underline{0,1422 \mathrm{~b}}$ \\
\hline 0,03 & $\overline{0,0363 \mathrm{c}}$ & $0,0431 \mathrm{c}$ & $0,6558 \mathrm{bc}$ & $0,6141 \mathrm{bc}$ & $\overline{0,3018 \mathrm{~b}}$ & $\underline{0,0449 \mathrm{bc}}$ & $\overline{0,0834}$ bc & $0,0942 \mathrm{bc}$ & $\underline{0,3317 \mathrm{~b}}$ & $\overline{\mathbf{0 , 1 0 3 7 ~ b}}$ & 0,4282 abc & $\overline{0,1100 ~ b c}$ & $0,5806 \mathrm{~b}$ & $0,5409 \mathrm{c}$ & $0,5498 \mathrm{ab}$ & $0,0615 b c$ & $\overline{0,1016 b c}$ \\
\hline 0,1 & $0,0339 \mathrm{~cd}$ & $0,0400 \mathrm{c}$ & $0,6505 \mathrm{bc}$ & 0,5902 bed & $0,1275 \mathrm{c}$ & $\overline{0,0417 \mathrm{bcd}}$ & 0,0764 bc & $0,0923 \mathrm{bcd}$ & $\overline{0,1736 c}$ & 0,0766 b & 0,3650 abc & 0,1058 bc & $0,5006 \mathrm{c}$ & $\underline{0,2285 \mathrm{~d}}$ & 0,3403 bc & $0,0490 \mathrm{bcd}$ & 0,0875 bc \\
\hline 0,3 & $0,0285 \mathrm{de}$ & $\overline{0,0320 \mathrm{~cd}}$ & $0,6376 \mathrm{bc}$ & 0,5779 bcd & $0,0975 \mathrm{c}$ & $0,0376 \mathrm{~cd}$ & 0,0717 bc & $\underline{0,0771 \mathrm{bcd}}$ & $0,1510 \mathrm{c}$ & 0,0650 b & 0,2065 bc & 0,0880 bc & $\underline{0,0959 \mathrm{~d}}$ & $\overline{0,1670 \mathrm{de}}$ & $\underline{0,2994}$ bc & $\overline{0,0410 \mathrm{cde}}$ & 0,0779 bc \\
\hline 1 & $0,0237 \mathrm{e}$ & $0,0265 \mathrm{de}$ & 0,5927 bcd & 0,5686 bcd & 0,0783 c & $0,0298 \mathrm{~cd}$ & 0,0678 bc & $\overline{0,0649 \text { cde }}$ & 0,1497 c & 0,0568 b & $\overline{0,0912 \mathrm{c}}$ & 0,0768 bc & $\overline{0,0943 \mathrm{~d}}$ & $0,1608 \mathrm{de}$ & $\overline{0,1114 c}$ & $0,0366 \mathrm{de}$ & 0,0702 bc \\
\hline 3 & $0,0155 \mathrm{f}$ & $0,0168 \mathrm{e}$ & $0,5697 \mathrm{~cd}$ & $0,4863 \mathrm{~d}$ & 0,0638 c & 0,0238 de & 0,0584 bc & $0,0490 \mathrm{de}$ & $0,0973 \mathrm{c}$ & 0,0412 b & 0,0537 c & 0,0529 c & $0,0608 \mathrm{~d}$ & 0,0925 ef & $0,0951 \mathrm{c}$ & 0,0262 ef & 0,0624 bc \\
\hline 10 & $0,0146 \mathrm{f}$ & $0,0014 \mathrm{f}$ & $0,5088 \mathrm{~d}$ & $0,4950 \mathrm{~cd}$ & 0,0379 c & 0,0052 e & 0,0344 c & 0,0307 e & $0,0771 \mathrm{c}$ & 0,0232 b & $0,0200 \mathrm{c}$ & $0,0301 \mathrm{c}$ & $0,0306 \mathrm{~d}$ & $0,0591 \mathrm{f}$ & $0,0508 \mathrm{c}$ & 0,0122 f & $0,0418 \mathrm{c}$ \\
\hline $\mathrm{CV} \%$ & 6,27 & 8,62 & 5,07 & 7,58 & 27,59 & 15,41 & 28,15 & 15,08 & 20,97 & 54,59 & 49,76 & 26,44 & 11,25 & 8,45 & 29,52 & 15,6 & 28,13 \\
\hline $\mathrm{EC}_{50}$ & 0,000369 & 0,036492 & 1779,664 & 1260,723 & 0,009659 & 0,016987 & 0,000995 & 0,249111 & 0,012018 & 0,003042 & 0,101859 & 0,000752 & 0,163704 & 0,069486 & 0,136544 & 0,069766 & 0,00304 \\
\hline
\end{tabular}

$\mathrm{CV} \%=$ Coeficiente de variação em \%; $\mathrm{EC}_{50}=$ Concentração do fungicida capaz de reduzir 50\% do crescimento micelial do patógeno.

Tabela 14. Médias das absorbâncias obtidas nas diferentes concentrações de clorotalonil para isolados de Phytophthora infestans e EC 50 obtido por isolado.

\begin{tabular}{|c|c|c|c|c|c|c|c|c|c|c|c|c|c|c|c|c|c|}
\hline \multirow{2}{*}{$\begin{array}{c}\text { Concentração } \\
{\left[\mu \mathrm{gL} \mathrm{m}^{-1}\right]}\end{array}$} & \multicolumn{17}{|c|}{ Isolados de Phytophthora infestans } \\
\hline & 151 & PRT & CRI-2 & 006 & $012 \mathrm{C}$ & 023 & 035B & 042 & 051 & 061 & 064 & 077 & 093 & 109 & 117 & 136 & 140 \\
\hline 0 & $0,1116 \mathrm{a}$ & 0,1388 a & $0,5390 \mathrm{a}$ & $0,5734 \mathrm{a}$ & $0,1492 \mathrm{a}$ & $0,0969 \mathrm{a}$ & $0,2017 \mathrm{a}$ & $0,1414 \mathrm{a}$ & $0,1246 \mathrm{a}$ & $0,5350 \mathrm{a}$ & 0,6007 a & $0,2629 \mathrm{a}$ & $0,1440 \mathrm{a}$ & $0,2843 \mathrm{a}$ & $0,5559 \mathrm{a}$ & $0,0585 \mathrm{a}$ & $2,1889 \mathrm{a}$ \\
\hline 0,01 & $\underline{0,0320 \mathrm{~b}}$ & $0,0921 \mathrm{~b}$ & 0,5297 a & 0,5471 a & $0,1094 \mathrm{ab}$ & $0,0466 \mathrm{~b}$ & $0,2487 \mathrm{a}$ & $0,1047 \mathrm{ab}$ & 0,1165 a & $\underline{0,2888 \mathrm{~b}}$ & $0,3753 \mathrm{~b}$ & $0,1621 \mathrm{ab}$ & $0,1268 \mathrm{~b}$ & 0,2476 a & $\underline{0,1697 b}$ & $0,0338 \mathrm{~b}$ & $1,2512 \mathrm{~b}$ \\
\hline 0,03 & $\overline{0,0288 \mathrm{~b}}$ & $0,0703 \mathrm{bc}$ & $0,5172 \mathrm{a}$ & 0,5886 a & $0,0801 \mathrm{bc}$ & $\overline{0,0339 \mathrm{~b}}$ & $0,0596 \mathrm{a}$ & $\underline{0,0630}$ bc & $0,1097 \mathrm{a}$ & $\overline{0,1702 \mathrm{bc}}$ & $0,3150 \mathrm{bc}$ & $\underline{0,1406 \mathrm{bc}}$ & $0,1034 \mathrm{c}$ & $0,2040 \mathrm{~b}$ & $\overline{\mathbf{0 , 0 8 0 3 ~ c}}$ & $0,0336 \mathrm{~b}$ & $\overline{1,0064 \mathrm{c}}$ \\
\hline 0,3 & $0,0318 \mathrm{~b}$ & $0,0607 \mathrm{~cd}$ & $0,5088 \mathrm{a}$ & 0,6062 a & $\overline{0,0549 \mathrm{~cd}}$ & $0,0291 \mathrm{bc}$ & $\overline{0,0557 \mathrm{a}}$ & $0,0225 \mathrm{c}$ & $0,0772 \mathrm{a}$ & 0,0541 c & $\overline{0,2428 \mathrm{~d}}$ & 0,0667 bcd & $0,0676 \mathrm{de}$ & $0,1508 \mathrm{~cd}$ & 0,0666 c & $0,0314 \mathrm{bc}$ & $0,8568 \mathrm{~cd}$ \\
\hline 1 & 0,0121 bc & $\underline{0,0395 \mathrm{de}}$ & $0,4955 \mathrm{a}$ & 0,6043 a & $0,0495 \mathrm{~cd}$ & $0,0094 \mathrm{~cd}$ & $0,0533 \mathrm{a}$ & $0,0070 \mathrm{c}$ & $0,0704 \mathrm{a}$ & 0,0357 c & $0,1648 \mathrm{e}$ & $0,0381 \mathrm{~cd}$ & $\underline{0,0567 \mathrm{e}}$ & $\underline{0,1256 \mathrm{de}}$ & 0,0629 c & $\overline{0,0236 \mathrm{~cd}}$ & $0,8190 \mathrm{de}$ \\
\hline 3 & 0,0026 c & $\overline{0,0212 \text { ef }}$ & $0,4855 \mathrm{a}$ & 0,6355 a & $0,0310 \mathrm{~cd}$ & $0,0064 \mathrm{~d}$ & $0,0450 \mathrm{a}$ & 0,0078 c & $0,0570 \mathrm{a}$ & 0,0349 c & $0,0719 \mathrm{f}$ & $0,0324 \mathrm{~cd}$ & & 4 ef & 0,0611 c & $0,0211 \mathrm{~d}$ & 0,6750 ef \\
\hline 10 & 0,0011 c & $0,0062 \mathrm{f}$ & $0,4863 \mathrm{a}$ & $0,6206 \mathrm{a}$ & $0,0252 \mathrm{~d}$ & $0,0035 \mathrm{~d}$ & $0,0320 \mathrm{a}$ & 0,0059 c & $\underline{0,0482 \mathrm{a}}$ & 0,0224 c & $0,0329 \mathrm{f}$ & $0,0068 \mathrm{~d}$ & $0,0306 \mathrm{f}$ & 0,0853 f & 0,0604 c & $0,0193 \mathrm{~d}$ & $0,6278 \mathrm{f}$ \\
\hline $\mathrm{EC}_{50}$ & $2,84 \times 10^{-5}$ & 0,043919 & $5,24 \times 10^{21}$ & Resistente & 0,05247 & 0,001633 & 0,037449 & 0,012593 & 4,690103 & 0,000418 & 0,032502 & 0,020731 & 0,399073 & 0,946099 & $1,4 \times 10^{-11}$ & 0,168819 & 0,009281 \\
\hline
\end{tabular}

$\mathrm{CV} \%$ = Coeficiente de variação em \%; $\mathrm{EC}_{50}=$ Concentração do fungicida capaz de reduzir $50 \%$ do crescimento micelial do patógeno. 
Tabela 15. Médias das absorbâncias obtidas nas diferentes concentrações de dimetomorfe para isolados de Phytophthora infestans e EC 50 obtido por isolado.

\begin{tabular}{|c|c|c|c|c|c|c|c|c|c|c|c|c|c|c|c|c|c|}
\hline \multirow{2}{*}{$\begin{array}{c}\text { Concentração } \\
{\left[\mu \mathrm{g} \mathrm{mL}^{-1}\right]}\end{array}$} & \multicolumn{17}{|c|}{ Isolados de Phytophthora infestans } \\
\hline & 151 & PRT & CRI-2 & 006 & $012 \mathrm{C}$ & 023 & 035B & 042 & 051 & 061 & 064 & 077 & 093 & 109 & 117 & 136 & 140 \\
\hline 0 & $0,0467 \mathrm{a}$ & $0,0497 \mathrm{a}$ & $0,7142 \mathrm{a}$ & $0,7021 \mathrm{a}$ & $0,1500 \mathrm{a}$ & $0,0994 \mathrm{a}$ & $0,2285 \mathrm{a}$ & $0,1861 \mathrm{a}$ & $0,3358 \mathrm{a}$ & $0,5433 \mathrm{a}$ & $0,5310 \mathrm{a}$ & $0,2919 \mathrm{a}$ & $0,5264 \mathrm{a}$ & $0,6416 \mathrm{a}$ & $0,7226 \mathrm{a}$ & $0,0911 \mathrm{a}$ & $0,2127 \mathrm{a}$ \\
\hline 0,01 & $0,0407 \mathrm{ab}$ & $0,0422 \mathrm{ab}$ & $0,6964 \mathrm{ab}$ & $0,6602 \mathrm{ab}$ & $0,1327 \mathrm{ab}$ & $0,0865 \mathrm{ab}$ & $0,1746 \mathrm{~b}$ & $0,1589 \mathrm{a}$ & $0,2563 \mathrm{~b}$ & 0,3892 ab & $0,1542 \mathrm{~b}$ & $0,2548 \mathrm{ab}$ & $0,2383 \mathrm{~b}$ & $0,4827 \mathrm{~b}$ & $0,4890 \mathrm{~b}$ & $0,0847 \mathrm{ab}$ & $0,1331 \mathrm{~b}$ \\
\hline 0,03 & $0,0367 \mathrm{ab}$ & $0,0379 \mathrm{abc}$ & 0,6646 abc & $0,6493 \mathrm{ab}$ & $0,1186 b c$ & $0,0702 \mathrm{abc}$ & $\underline{0,0866 \mathrm{c}}$ & $\underline{0,1118 \mathrm{~b}}$ & $0,2378 \mathrm{bc}$ & 0,3702 ab & $\overline{0,1163 \mathrm{c}}$ & 0,1920 abc & $\overline{0,1270 \mathrm{c}}$ & $0,4044 b c$ & $0,3936 \mathrm{bc}$ & $0,0727 \mathrm{abc}$ & $\overline{0,0956 \mathrm{c}}$ \\
\hline 0,1 & $0,0339 \mathrm{bc}$ & $0,0370 \mathrm{abc}$ & 0,6490 abc & $0,6153 \mathrm{abc}$ & $0,1076 \mathrm{bcd}$ & 0,0563 bed & $\overline{0,0681 \mathrm{c}}$ & 0,1031 bc & $0,1961 \mathrm{bcd}$ & 0,2301 ab & $0,0768 \mathrm{~d}$ & 0,1454 bc & $0,1173 \mathrm{~cd}$ & $\underline{0,3030 \mathrm{~cd}}$ & $0,2713 \mathrm{~cd}$ & 0,0557 bed & $0,0786 \mathrm{~cd}$ \\
\hline 0,3 & 0,0310 bed & $0,0348 \mathrm{abc}$ & 0,6454 abc & $0,6130 \mathrm{abc}$ & 0,0932 cde & $0,0473 \mathrm{~cd}$ & $0,0598 \mathrm{c}$ & 0,0853 bc & 0,1683 cde & $0,2045 a b$ & 0,0696 de & $\underline{0,1140 \mathrm{c}}$ & $0,1020 \mathrm{de}$ & $\overline{0,2007 \text { de }}$ & 0,1669 de & $\underline{0,0485 \mathrm{~cd}}$ & 0,0641 cde \\
\hline 1 & 0,0283 bcd & $0,0305 \mathrm{bc}$ & 0,6154 abc & $\begin{array}{c}0,5692 \\
\text { bed }\end{array}$ & 0,0779 de & $\underline{0,0444 c d}$ & $0,0562 \mathrm{c}$ & 0,0796 bc & 0,1612 de & $\underline{0,0670 \mathrm{ab}}$ & 0,0651 de & $0,1045 \mathrm{c}$ & 0,0861ef & $0,1556 \mathrm{e}$ & 0,1118 e & $0,0418 \mathrm{~cd}$ & 0,0593 de \\
\hline 3 & $0,0211 \mathrm{~d}$ & $0,0261 \mathrm{~cd}$ & 0,5686 bc & $0,5412 \mathrm{~cd}$ & 0,0716 e & $0,0379 \mathrm{~d}$ & 0,0527 c & 0,0717 bc & $\underline{0,1503 \mathrm{de}}$ & 0,0502 ab & $0,0633 \mathrm{de}$ & 0,08 & $0,0765 f$ & 0,1328 e & 0,0843 e & $3 \mathrm{~d}$ & 0,0551 de \\
\hline 10 & $\underline{0,0218 \mathrm{~cd}}$ & $\underline{\mathbf{0 , 0 1 5 8 d}}$ & 0,5399 c & $0,4932 \mathrm{~d}$ & $\underline{0,0668 \mathrm{e}}$ & $0,0379 \mathrm{~d}$ & 0,0437 c & 0,0586 c & $0,1144 \mathrm{e}$ & $\mathbf{0 , 0 3 5 1 ~ b ~}$ & 0,0555 e & $0,0718 \mathrm{c}$ & $0,0723 \mathrm{f}$ & 0,0898 e & 0,0763 e & $\mathbf{0 , 0 2 8 6} \mathrm{d}$ & $0,0403 \mathrm{e}$ \\
\hline $\mathrm{CV} \%$ & 13,73 & 14,19 & 7,36 & 5,7 & 10,49 & 18,55 & 16,53 & 15,07 & 13,11 & 74,15 & 4,08 & 27,08 & 4,05 & 16,25 & 18,52 & 20,79 & 13,4 \\
\hline $\mathrm{EC}_{50}$ & 6,849307 & 7,894986 & 15953607 & 588376,5 & 7,08912 & 0,948592 & 0,011926 & 0,012593 & 1,208674 & 0,058881 & $1,27 \times 10^{-9}$ & 0,261414 & $1,16 \times 10^{-5}$ & 0,077496 & 0,020134 & 0,168819 & 0,009677 \\
\hline
\end{tabular}

$\mathrm{CV} \%=$ Coeficiente de variação em \%; $\mathrm{EC}_{50}=$ Concentração do fungicida capaz de reduzir $50 \%$ do crescimento micelial do patógeno

Tabela 16. Médias das absorbâncias obtidas nas diferentes concentrações de propamocarbe para isolados de Phytophthora infestans e EC E $_{50}$ obtido por isolado.

\begin{tabular}{|c|c|c|c|c|c|c|c|c|c|c|c|c|c|c|c|c|c|}
\hline \multirow{2}{*}{$\begin{array}{c}\text { Concentração } \\
{\left[\mu \mathrm{gL}^{-1}\right]}\end{array}$} & \multicolumn{17}{|c|}{ Isolados de Phytophthora infestans } \\
\hline & 151 & PRT & CRI-2 & 006 & $012 \mathrm{C}$ & 023 & 035B & 042 & 051 & 061 & 064 & 077 & 093 & 109 & 117 & 136 & 140 \\
\hline 0 & $0,0484 \mathrm{a}$ & $0,0536 \mathrm{a}$ & $0,6942 \mathrm{a}$ & $0,6254 \mathrm{a}$ & $0,1294 \mathrm{a}$ & $0,0738 \mathrm{a}$ & $0,3474 \mathrm{a}$ & $0,1596 \mathrm{a}$ & $0,2009 \mathrm{a}$ & $0,6840 \mathrm{a}$ & $0,5796 \mathrm{a}$ & $0,4191 \mathrm{a}$ & $0,5820 \mathrm{a}$ & $0,7334 \mathrm{a}$ & $0,8792 \mathrm{a}$ & $0,0758 \mathrm{a}$ & $0,4378 \mathrm{a}$ \\
\hline 0,01 & $0,0404 \mathrm{ab}$ & $0,0441 \mathrm{ab}$ & $0,6519 \mathrm{ab}$ & $0,5962 \mathrm{ab}$ & $0,1130 \mathrm{~b}$ & $0,0649 \mathrm{~b}$ & $0,2796 \mathrm{ab}$ & $0,1137 \mathrm{~b}$ & $\underline{0,1718 \mathrm{ab}}$ & 0,4232 ab & $0,4323 \mathrm{~b}$ & $0,2867 \mathrm{~b}$ & $\underline{0,3248 \mathrm{~b}}$ & $0,5164 \mathrm{~b}$ & $0,7287 \mathrm{ab}$ & $0,0680 \mathrm{ab}$ & $0,3633 \mathrm{ab}$ \\
\hline 0,03 & $0,0374 a b c$ & $0,0402 a b c$ & $0,6397 \mathrm{bc}$ & $0,5881 \mathrm{abc}$ & $0,0983 \mathrm{c}$ & $0,0603 \mathrm{bc}$ & $0,2578 a b c$ & $0,1060 \mathrm{~b}$ & $0,1588 \mathrm{abc}$ & $\underline{0,3852 \text { ab }}$ & $0,3017 \mathrm{c}$ & $0,2659 \mathrm{~b}$ & $\overline{0,2977 \mathrm{c}}$ & $0,4006 \mathrm{c}$ & $0,6756 \mathrm{~b}$ & $0,0610 \mathrm{bc}$ & $0,2884 \mathrm{bc}$ \\
\hline 0,1 & $0,0347 \mathrm{bcd}$ & $0,0369 \mathrm{bc}$ & $0,6267 \mathrm{bcd}$ & $0,5698 \mathrm{bc}$ & $0,0945 \mathrm{~cd}$ & $0,0561 \mathrm{~cd}$ & $0,2180 \mathrm{bcd}$ & $0,0931 \mathrm{bc}$ & 0,1422 bcd & $\overline{0,2720 \mathrm{ab}}$ & $\underline{0,2615 \mathrm{~cd}}$ & $0,2466 \mathrm{bc}$ & $0,2025 \mathrm{~d}$ & $\underline{0,3190 \mathrm{~d}}$ & $0,5719 \mathrm{bc}$ & $0,0570 \mathrm{~cd}$ & $0,2636 \mathrm{~cd}$ \\
\hline 0,3 & $0,0324 \mathrm{bcd}$ & 0,0349 bed & $0,6154 \mathrm{bcd}$ & $0,5667 \mathrm{bc}$ & $0,0874 \mathrm{cde}$ & $0,0532 \mathrm{cde}$ & $0,1786 \mathrm{~cd}$ & $0,0923 \mathrm{bc}$ & 0,1308 bcd & $0,0869 b$ & $\overline{0,2207 \mathrm{~cd}}$ & 0,2135 bcd & $0,1714 \mathrm{e}$ & $\overline{0,2852 \mathrm{de}}$ & $0,4849 \mathrm{c}$ & $0,0536 \mathrm{cde}$ & 0,2119 cde \\
\hline 1 & 0,0271 cde & $0,0296 \mathrm{~cd}$ & 0,5962 cde & $0,5473 \mathrm{bc}$ & $0,0833 \mathrm{de}$ & $0,0498 \mathrm{de}$ & $\underline{0,1364 \mathrm{de}}$ & $0,0910 \mathrm{bc}$ & 0,1188 bcd & 0,0736 b & 0,1733 de & 0,2120 bcd & $0,1390 \mathrm{f}$ & 0,2271 ef & $0,4325 \mathrm{~cd}$ & $0,0514 \mathrm{de}$ & $\underline{0,1813 \mathrm{e}}$ \\
\hline 3 & 0,0248 de & $0,0271 \mathrm{~cd}$ & 0,5884 de & $0,5382 \mathrm{~cd}$ & 0,0763 ef & $0,0452 \mathrm{e}$ & $\overline{0,0639}$ ef & $0,0750 \mathrm{~cd}$ & $0,1071 \mathrm{~cd}$ & 0,0608 b & 0,0981 e & $\overline{0,1524 \mathrm{~cd}}$ & $0,0984 \mathrm{~g}$ & $0,1690 \mathrm{f}$ & $0,4025 \mathrm{~cd}$ & $0,0475 \mathrm{e}$ & $\overline{0,1151 \mathrm{f}}$ \\
\hline 10 & $\underline{0,0185 \text { e }}$ & $\underline{0,0226 \mathrm{~d}}$ & 0,5662 e & $0,4886 \mathrm{~d}$ & 0,0672 f & $0,0323 \mathrm{f}$ & 0,0380 f & $\underline{0,0635 d}$ & $0,0864 \mathrm{~d}$ & $0,0556 \mathrm{~b}$ & $0,0615 \mathrm{e}$ & $0,1473 \mathrm{~d}$ & 0,0652 h & $0,0842 \mathrm{~g}$ & $\overline{\mathbf{0 , 3 0 3 4 d}}$ & $0,0338 \mathrm{f}$ & $0,0483 \mathrm{~g}$ \\
\hline $\mathrm{CV} \%$ & 13,47 & 13,96 & 2,55 & 3,24 & 5,31 & 5,65 & 17,6 & 8,53 & 14,32 & 62,2 & 15,3 & 13,94 & 2,9 & 7,49 & 10,93 & 5,65 & 14,59 \\
\hline $\mathrm{EC}_{50}$ & 8,102545 & 9,393238 & $7,66 \times 10^{12}$ & $2,1 \times 10^{10}$ & 107,1952 & 57,83516 & 0,315768 & 3,977605 & 0,004263 & 0,013058 & 0,058646 & 0,69023 & 0,008698 & 0,056091 & 2,222396 & 65,4758 & 0,301488 \\
\hline
\end{tabular}

$\mathrm{CV} \%=$ Coeficiente de variação em \%; $\mathrm{EC}_{50}=$ Concentração do fungicida capaz de reduzir $50 \%$ do crescimento micelial do patógeno. 
No experimento com o principio ativo ciazofamida (Tabela 13), todos os isolados apresentaram sensibilidade. Observamos que todos os isolados apresentaram menor absorbância na concentração a $10 \mu \mathrm{g} \mathrm{mL} \mathrm{m}^{-1}$, no entanto, a análise estatística mostrou que alguns isolados apresentaram comportamentos similares ao apresentado na concentração de $10 \mu \mathrm{g} \mathrm{mL}^{-1}$ quando em menores concentrações.

A análise estatística mostrou que os isolados 035B, 061, 064, 077 e 140 apresentaram resultados similares ao da concentração de $10 \mu \mathrm{g} \mathrm{mL}^{-1}$, na concentração de $0,03 \mu \mathrm{g} \mathrm{mL}^{-1}$, os isolados $006,012 \mathrm{C}, 051$ e 117 na concentração $0,1 \mu \mathrm{g} \mathrm{mL} \mathrm{m}^{-1}$, o isolado 093 na concentração na concentração $0,3 \mu \mathrm{g} \mathrm{mL}^{-1}$, os isolados CRI-2 e 042 na concentração $1 \mu \mathrm{g} \mathrm{mL}^{-1}$, os isolados 023,109 e 136 na concentração $3 \mu \mathrm{g} \mathrm{mL}{ }^{-1}$. Já o isolado PRT, mostrou menor absorção somente a $10 \mu \mathrm{g} \mathrm{mL}^{-1}$ (Tabela 13).

Ao correlacionar o $\mathrm{EC}_{50}$ dos isolados para ciazofamida com as concentrações utilizadas no experimento (Tabela 13) observamos que seis isolados (151, 012C, 035B, 061, 077 e 140) apresentaram o EC50 na concentração de $0,01 \mu \mathrm{g} \mathrm{mL} \mathrm{m}^{-1}$, dois isolados (023 e 051) na concentração $0,03 \mu \mathrm{g} \mathrm{mL}^{-1}$, três isolados (PRT, 109 e 136) na concentração de $0,1 \mu \mathrm{g} \mathrm{mL}^{-1}$ e quatro isolados $(042,064,093$ e 117) na concentração de $0,3 \mu \mathrm{g} \mathrm{mL} \mathrm{m}^{-1}$. Os $\mathrm{EC}_{50}$ dos isolados CRI-2 e 006 não foram encontrados nas concentrações utilizadas no experimento.

No experimento com clorotalonil (Tabela 14), com excessão dos isolados CRI-2 e 006, todos os demais isolados apresentaram sensibilidade ao fungicida. Os isolados CRI-2, 006, 035B e 051 não apresentaram diferença estatística quando comparados entre as concentração do princípio ativo. No entanto, entre os isolados que apresentaram sensibilidade, observamos que a análise estatística mostrou que todos os isolados apresentaram comportamentos similares ao de $10 \mu \mathrm{g} \mathrm{mL} \mathrm{m}^{-1}$.quando em menores concentrações.

A análise estatística mostrou que os isolados 042 e 117 apresentaram resultados similares ao da concentração de $10 \mu \mathrm{g} \mathrm{mL}^{-1}$, na concentração de $0,03 \mu \mathrm{g} \mathrm{mL}^{-1}$, o isolado

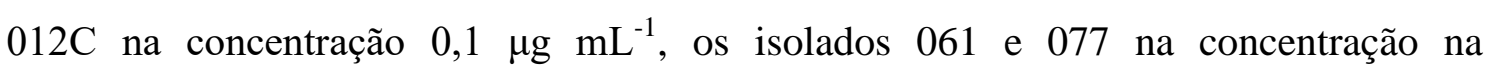
concentração $0,3 \mu \mathrm{g} \mathrm{mL}^{-1}$, os isolados 151,023 e 136 na concentração $1 \mu \mathrm{g} \mathrm{mL}^{-1}$ e os isolados PRT, 064, 093, 109 e 140 na concentração $3 \mu \mathrm{g} \mathrm{mL}^{-1}$ (Tabela 14).

Comparando o $\mathrm{EC}_{50}$ obtido dos isolados, com as concentrações utilizadas no experimento com clorotalonil (Tabela 14), podemos observar que cinco isolados (151, 023, 061, 117 e 140) obtiveram o $\mathrm{EC}_{50}$ na concentração $0,01 \mu \mathrm{g} \mathrm{mL}^{-1}$, dois isolados (042 e 077) na concentração $0,03 \mu \mathrm{g} \mathrm{mL}^{-1}$, três isolados $(012 \mathrm{C}, 035 \mathrm{~B}$ e 064) na 
concentração $0,1 \mu \mathrm{g} \mathrm{mL} \mathrm{m}^{-1}$, um isolado (136) na concentração $0,3 \mu \mathrm{g} \mathrm{mL} \mathrm{m}^{-1}$, três isolados (PRT, 093 e 109) na concentração $1,0 \mu \mathrm{g} \mathrm{mL}^{-1}$ e um isolado (051) na concentração 10,0 $\mu \mathrm{g} \mathrm{mL}{ }^{-1}$. Novamente, os $\mathrm{EC}_{50}$ dos isolados CRI-2 e 006 não foram encontrados nas concentrações utilizadas no experimento.

No experimento com o dimetomorfe (Tabela 15), com excessão dos isolados CRI-2 e 006, os demais também todos os isolados apresentaram sensibilidade. Novamente, todos os isolados apresentaram menor absorbância na concentração a $10 \mu \mathrm{g}$ $\mathrm{mL}^{-1}$, porém neste, a análise estatística mostrou que todos isolados apresentaram comportamentos similares a maior concentração quando em menores concentrações.

O isolado 061 apresentou resultado similar ao da concentração de $10 \mu \mathrm{g} \mathrm{mL}{ }^{-1}$, na concentração de $0,01 \mu \mathrm{g} \mathrm{mL} \mathrm{m}^{-1}$, os isolados CRI-2, 035B e 077 na concentração $0,03 \mu \mathrm{g}$ $\mathrm{mL}^{-1}$, os isolados 023,042 e 136 na concentração na concentração $0,1 \mu \mathrm{g} \mathrm{mL} \mathrm{m}^{-1}$, os isolados $151,012 \mathrm{C}, 051,064,109,117$ e 140 na concentração $0,3 \mu \mathrm{g} \mathrm{mL} \mathrm{mL}^{-1}$, os isolados 006 e 093 na concentração $1 \mu \mathrm{g} \mathrm{mL}^{-1}$ e o isolado PRT na concentração $3 \mu \mathrm{g} \mathrm{mL}^{-1}$ (Tabela 15).

Ao correlacionar o $\mathrm{EC}_{50} \mathrm{com}$ as concentrações utilizadas no experimento com dimetomorfe (Tabela 15), observamos que três isolados (064, 093 e 140) tem o EC50 na concentração de $0,01 \mu \mathrm{g} \mathrm{mL} \mathrm{m}^{-1}$, um isolado (117) na concentração $0,03 \mu \mathrm{g} \mathrm{mL}^{-1}$, um isolado (109) na concentração de $0,1 \mu \mathrm{g} \mathrm{mL}^{-1}$, quatro isolados $(035 \mathrm{~B}, 042,077$ e 136) na concentração de $0,3 \mu \mathrm{g} \mathrm{mL}^{-1}$, dois isolados (023 e 061) na concentração de $1 \mu \mathrm{g} \mathrm{mL}^{-}$ 1, um isolado (051) na concentração de $3,0 \mu \mathrm{g} \mathrm{mL}^{-1}$ e três isolados (151, PRT e 012C) na concentração de $10,0 \mu \mathrm{g} \mathrm{mL} \mathrm{m}^{-1}$.

No experimento com propamocarbe, igual aos experimentos anteriores, todos os isolados apresentaram sensibilidade (Tabela 16). Observamos que todos os isolados apresentaram menor absorção na concentração a $10 \mu \mathrm{g} \mathrm{mL} \mathrm{m}^{-1}$, no entanto, a análise estatística mostrou que alguns isolados apresentaram comportamentos similares ao de $10 \mu \mathrm{g} \mathrm{mL}^{-1}$ quando em menores concentrações.

A análise estatística (Tabela 16) mostrou que o isolado 061 apresentou comportamento similar ao da concentração de $10 \mu \mathrm{g} \mathrm{mL}^{-1}$, na concentração de $0,01 \mu \mathrm{g}$ $\mathrm{mL}^{-1}$, o isolado 051 na concentração $0,1 \mu \mathrm{g} \mathrm{mL}^{-1}$, os isolados 151 , CRI-2, 064 e 117 na concentração na concentração $1 \mu \mathrm{g} \mathrm{mL} \mathrm{m}^{-1}$, os isolados 006, 012C, 035B e 042 na concentração $3 \mu \mathrm{g} \mathrm{mL}^{-1}$. Os demais isolados 023, 093, 109, 136 e 140, mostraram menor absorção somente a $10 \mu \mathrm{g} \mathrm{mL}^{-1}$. 
E no experimento com propamocarbe, comparando o $\mathrm{EC}_{50}$ obtido, com as concentrações utilizadas(Tabela 16), observamos que dois isolados (051 e 093) obtiveram o $\mathrm{EC}_{50}$ na concentração $0,01 \mu \mathrm{g} \mathrm{mL}^{-1}$, um isolado (061) na concentração 0,03 $\mu \mathrm{g} \mathrm{mL} \mathrm{mL}^{-1}$, dois (064 e 109) na concentração de $0,1 \mu \mathrm{g} \mathrm{mL} \mathrm{m}^{-1}$, três $(035 \mathrm{~B}, 077$ e 140$)$ na concentração de $1 \mu \mathrm{g} \mathrm{mL} \mathrm{mL}^{-1}$, um isolado (117) na concentração de $3 \mu \mathrm{g} \mathrm{mL} \mathrm{m}^{-1}$ e três isolados (151, PRT e 042) na concentração de $10 \mu \mathrm{g} \mathrm{mL}^{-1}$. Os $\mathrm{EC}_{50}$ dos isolados CRI-2, 006, 012C, 023 e 136 não foram encontrados nas concentrações utilizadas no experimento.

Tabela 17. Valores de EC50 $\left(\mu \mathrm{g} \mathrm{mL}^{-1}\right)$ para os 17 isolados de Phytophthora infestans para os fungicidas ciazofamida, clorotalonil, dimetomorfe e propamocarbe.

\begin{tabular}{|c|c|c|c|c|}
\hline \multirow{2}{*}{ Isolado } & Ciazofamida & Clorotalonil & Dimetomorfe & Propamocarbe \\
\hline & $\mathrm{EC}_{50}\left(\mu \mathrm{g} \mathrm{mL} \mathrm{L}^{-1}\right)$ & $\mathrm{EC}_{50}\left(\mu \mathrm{g} \mathrm{mL} \mathrm{L}^{-1}\right)$ & $\mathrm{EC}_{50}\left(\mu \mathrm{g} \mathrm{mL}^{-1}\right)$ & $\mathrm{EC}_{50}\left(\mu \mathrm{g} \mathrm{mL}^{-1}\right)$ \\
\hline 151 & 0,000369 & $2,84 \times 10^{-5}$ & 6,849307 & 8,102545 \\
\hline PRT & 0,036492 & 0,043919 & 7,894986 & 9,393238 \\
\hline CRI-2 & 1779,664 & Resistente* & Resistente* & Resistente* \\
\hline 006 & 1260,723 & Resistente* & Resistente* & Resistente* \\
\hline 012C & 0,009659 & 0,05247 & 7,08912 & 107,1952 \\
\hline 023 & 0,016987 & 0,001633 & 0,948592 & 57,83516 \\
\hline 035B & 0,000995 & 0,037449 & 0,011926 & 0,315768 \\
\hline 042 & 0,249111 & 0,012593 & 0,012593 & 3,977605 \\
\hline 051 & 0,012018 & 4,690103 & 1,208674 & 0,004263 \\
\hline 061 & 0,003042 & 0,000418 & 0,058881 & 0,013058 \\
\hline 064 & 0,101859 & 0,032502 & $1,27 \times 10^{-9}$ & 0,058646 \\
\hline 077 & 0,000752 & 0,020731 & 0,261414 & 0,69023 \\
\hline 093 & 0,163704 & 0,399073 & $1,16 \times 10^{-5}$ & 0,008698 \\
\hline 109 & 0,069486 & 0,946099 & 0,077496 & 0,056091 \\
\hline 117 & 0,136544 & $1,4 \times 10^{-11}$ & 0,020134 & 2,222396 \\
\hline 136 & 0,069766 & 0,168819 & 0,168819 & 65,4758 \\
\hline 140 & 0,00304 & 0,009281 & 0,009677 & 0,301488 \\
\hline
\end{tabular}

$*$ Resistente $=\mathrm{EC}_{50}>10000 \mu \mathrm{g} \mathrm{mL}$

Ao analisarmos a Tabela 17, observamos os maiores e menores EC50 por princípio ativo. Para todos os princípios ativos, os maiores valores de $\mathrm{EC}_{50}$ foram do isolado CRI-2. Os menores valores de $\mathrm{EC}_{50}$ para ciazofamida e clorotalonil foram do 
isolado 151, para dimetomorfe foi do isolado 064 e para propamocarbe foi do isolado 051.

Ao compararmos os valores de $\mathrm{EC}_{50}$ dos isolados por princípio ativo observamos que oito isolados (PRT, CRI-2, 006, 012C, 035B, 077, 136 e 140) apresentaram menor $\mathrm{EC}_{50}$ com o tratamento com ciazofamida, cinco isolados $(151,023,042,061$ e 117) com clorotalonil, três isolados (042, 064 e 093) com dimetomorfe e dois isolados (051 e 109) com propamocarbe.

Os valores $\mathrm{de}_{0} \mathrm{EC}_{50}$ máximo e mínimo para cada princípio ativo apresentaram ampla variação entre os isolados avaliados .

Isolados pertencentes à mesma variação também apresentaram grande amplitude na sensibilidade aos princípios ativos, não sendo possível associar fenótipo ao genótipo (Tabelas 18 e 19). A insensibilidade para os diferentes princípios ativos observada para os isolados CRI-2 e 006 precisará ser confirmada pelo método de inibição de crescimento em meio de cultura sólido pois é possível que algum fator desconhecido tenha afetado a absorbância no ensaio em placa de microtitulação.

Os valores elevados de EC50 de propamocarbe obtidos para alguns isolados pode ser um artefato da técnica de microtitulação. Este fungicida é eficaz na inibição da germinação de esporos porém tem pouco efeito na inibição do crescimento micelial. Caso os esporângios da suspensão utilizada no experimento já tenham iniciado a germinação, ou se a suspensão apresentar hifas do fungo, o fungicida não é capaz de impedir o crescimento micelial (HU et al., 2007).

Tabela 18. Valores de EC50 para os 17 isolados subdivididos por variações dos genótipos, para ciazofamida, clorotalonil, dimetomorfe e propamocarbe.

\begin{tabular}{cccccc}
\hline \multirow{2}{*}{ Variação } & Isolado & Ciazofamida & Clorotalonil & Dimetomorfe & Propamocarbe \\
\cline { 3 - 6 } & & $\mathrm{CE}_{50}\left(\mu \mathrm{g} \mathrm{mL}^{-1}\right)$ & $\mathrm{CE}_{50}\left(\mu \mathrm{g} \mathrm{mL}^{-1}\right)$ & $\mathrm{CE}_{50}\left(\mu \mathrm{g} \mathrm{mL}^{-1}\right)$ & $\mathrm{CE}_{50}\left(\mu \mathrm{gL}^{-1}\right)$ \\
\hline \multirow{2}{*}{$\mathbf{0 2}$} & $\mathbf{0 3 5 B}$ & 0,000995 & 0,037449 & 0,011926 & 0,315768 \\
& $\mathbf{0 6 1}$ & 0,003042 & 0,000418 & 0,058881 & 0,013058 \\
\hline & $\mathbf{C R I}-2$ & 1779,664 & Resistente* & Resistente* & Resistente* \\
& $\mathbf{0 0 6}$ & 1260,723 & Resistente* & Resistente* & Resistente* \\
\multirow{204}{*}{} & $\mathbf{0 7 7}$ & 0,000752 & 0,020731 & 0,261414 & 0,69023 \\
& $\mathbf{0 9 3}$ & 0,163704 & 0,399073 & $1,16 \times 10^{-5}$ & 0,008698 \\
& $\mathbf{1 0 9}$ & 0,069486 & 0,946099 & 0,077496 & 0,056091 \\
& $\mathbf{1 1 7}$ & 0,136544 & $1,4 \times 10^{-11}$ & 0,020134 & 2,222396
\end{tabular}




\begin{tabular}{cccccc} 
& $\mathbf{1 3 6}$ & 0,069766 & 0,168819 & 0,168819 & 65,4758 \\
& $\mathbf{1 4 0}$ & 0,00304 & 0,009281 & 0,009677 & 0,301488 \\
\hline \multirow{2}{*}{$\mathbf{0 7}$} & $\mathbf{0 1 2 C}$ & 0,009659 & 0,05247 & 7,08912 & 107,1952 \\
& $\mathbf{0 4 2}$ & 0,249111 & 0,012593 & 0,012593 & 3,977605 \\
& $\mathbf{0 5 1}$ & 0,012018 & 4,690103 & 1,208674 & 0,004263 \\
\hline
\end{tabular}

Tabela 19. Valores de EC50 máximo e mínimo entre as variações de Phytophthora infestans para ciazofamida, clorotalonil, dimetomorfe e propamocarbe

\begin{tabular}{cccc}
\hline Variação & Fungicida & EC50 max & EC50 min \\
\hline $\mathbf{0 2}$ & Ciazofamida & $0,003042 \mu \mathrm{g} \mathrm{mL}^{-1}$ & $0,000995 \mu \mathrm{g} \mathrm{mL}^{-1}$ \\
& Clorotalonil & $0,037449 \mu \mathrm{g} \mathrm{mL}^{-1}$ & $0,000418 \mu \mathrm{g} \mathrm{mL}^{-1}$ \\
& Dimetomorfe & $0,058881 \mu \mathrm{g} \mathrm{mL}^{-1}$ & $0,011926 \mu \mathrm{g} \mathrm{mL}^{-1}$ \\
& Propamocarbe & $0,315768 \mu \mathrm{g} \mathrm{mL}^{-1}$ & $0,013058 \mu \mathrm{g} \mathrm{mL}^{-1}$ \\
$\mathbf{0 4}$ & Ciazofamida & $1779,664 \mu \mathrm{g} \mathrm{mL}^{-1}$ & $0,000752 \mu \mathrm{g} \mathrm{mL}^{-1}$ \\
& Clorotalonil & $>1000 \mu \mathrm{g} \mathrm{m}^{-1}$ & $1,4 \times 10^{-11} \mu \mathrm{g} \mathrm{mL}^{-1}$ \\
& Dimetomorfe & $>1000 \mu \mathrm{g} \mathrm{m}^{-1}$ & $1,16 \times 10^{-5} \mu \mathrm{g} \mathrm{mL}^{-1}$ \\
& Propamocarbe & $>1000 \mu \mathrm{g} \mathrm{mL}^{-1}$ & $0,008698 \mu \mathrm{g} \mathrm{mL}^{-1}$ \\
& Ciazofamida & $0,249111 \mu \mathrm{g} \mathrm{mL}^{-1}$ & $0,009659 \mu \mathrm{g} \mathrm{mL}^{-1}$ \\
& Clorotalonil & $4,690103 \mu \mathrm{g} \mathrm{mL}^{-1}$ & $0,012593 \mu \mathrm{g} \mathrm{mL}^{-1}$ \\
& Dimetomorfe & $7,08912 \mu \mathrm{g} \mathrm{m}^{-1}$ & $0,012593 \mu \mathrm{g} \mathrm{mL}^{-1}$ \\
& Propamocarbe & $107,1952 \mu \mathrm{g} \mathrm{mL}^{-1}$ & $0,004263 \mu \mathrm{g} \mathrm{mL}^{-1}$ \\
\hline
\end{tabular}

Kato e colaboradores (1997) em experimento utilizando isolados dos EUA de 4 linhagens clonais (US-1, US-6, US-7 e US-8) e o princípio ativo clorotalonil, através da metodologia de inibição do crescimento micelial, encontraram EC50 que variou entre 0,21 e $1,47 \mu \mathrm{g} \mathrm{mL}{ }^{-1}$.

Mitani e colaboradores (2002) utilizando metodologia de inibição do crescimento micelial em meio de cultura, encontraram para ciazofamida, EC50 mínimo de 0,006 e máximo de $0,03 \mathrm{mg} / \mathrm{mL}$ para isolados de $P$. infestans do Japão.

Oliveira (2010) realizou experimentos com seis princípios ativos e 62 isolados brasileiros de $P$. infestans. Para clorotalonil e propamocarbe com a metodologia de inibição do crescimento micelial da colônia em meio de cultura (ICM), os valores de EC50 variaram entre 0,20 e $8,16 \mu \mathrm{g} \mathrm{mL}^{-1}$ com clorotalonil e de 0,1 e $34,10 \mu \mathrm{g} \mathrm{mL}^{-1}$ com propamocarbe. Para dimetomorfe a metodologia utilizada foi a de microtitulação colorimétrica e o $\mathrm{EC}_{50}$ variou entre 0,03 e $1,46 \mu \mathrm{g} \mathrm{mL}^{-1}$. 
Na Sérvia, Rekanović e colaboradores (2011) determinaram o $\mathrm{EC}_{50}$ de 14 isolados de $P$. infestans para o princípio ativo propamocarbe, encontrando valores que variaram de 12,1 a $31,1 \mathrm{mg} \mathrm{L}^{-1}$.

Em 2014, Casa-Coila, utilizando a metodologia de inibição do crescimento micelial da colônia em meio de cultura (ICM), avaliou 131 isolados de P. infestans quanto à sensibilidade a clorotalonil, encontrando $\mathrm{EC}_{50}$ mínimo de 0,01 e máximo de $4,67 \mu \mathrm{g} / \mathrm{mL}$.

Saville e colaboradores (2015) avaliaram a sensibilidade à ciazofamida para isolados de sete linhagens clonais diferentes (US-8, US-11, US-20, US-21, US-22, US23 e US-24) e não encontraram nenhum isolado insensível ao princípio ativo.

De maneira geral, os valores do $\mathrm{EC}_{50}$ obtidos pelo método de microtitulação colorimétrica são inferiores aos valores de $\mathrm{EC}_{50}$ obtidos pelo método de inibição do crescimento micelial da colônia em meio de cultura (ICM). Isso se deve ao fato de o método de microtitulação utilizar meio de cultura líquido, por aumentar a superfície de contato entre este e o esporângio do patógeno, o que pode interferir na relação doseresposta entre oomiceto e a concentração do fungicida. Outro possível motivo seria o fato dos esporos/esporângios ficarem submersos na solução com o principio ativo na microtitulação, ao contrário do método de inibição do crescimento micelial da colônia em meio de cultura (ICM), onde parte da colônia do fungo fica sobre o meio de cultura (que neste método é solido) com fungicida (RAPOSO, et al., 2015; VALENCIO, 2017). 
6. CONCLUSÕES 
O grupo de compatibilidade de Phytophthora infestans predominante nos isolados brasileiros coletados neste trabalho foi o A1.

A reprodução sexuada de isolados autoférteis de Phytophthora infestans foi detectada no Estados de São Paulo, nas cidades de Divinolândia e Itobi; no Paraná, em Campo do Tenente; e em Minas Gerais, em Serra do Salitre/MG.

Foram detectados, no total, 42 alelos nos 12 lócus de microssatélites estudados nos 155 isolados de Phytophthora infestans deste estudo.

Foram encontradas 16 variações de perfis polimórficos, sendo a variação 4 a mais abundante (71,6\% dos isolados), seguida pelas variações 2 e $7(9,0 \%$ e $7,1 \%$ dos isolados, respectivamente).

Foram identificadas duas linhagens clonais de Phytophthora infestans entre os isolados brasileiros do presente estudo, a linhagem 2_A1 e a linhagem US-1.

A linhagem 2_A1está amplamente disseminada nas áreas produtoras de batata das regiões Sul e Sudeste, tendo desalojado linhagens anteriormente dominantes como a BR-1.

A maioria dos isolados apresentaram alta sensibilidade aos princípios ativos ciazofamida, clorotalonil, dimetomorfe e propamocarbe. 
7. REFERÊNCIAS BIBLIOGRÁFICAS 
ABAD, Z. G.; ABAD, J. A. Another look at the origin of late blight of potatoes, tomatoes, and pear melon in the Andes of South America. Plant Disease, Saint. Paul, v. 81, n. 6, p. 682-688, 1997.

ACUÑA, I. et al. Genotipificación y determinación de EC50 para los principales ingredientes activos en las poblaciones de Phytophthora infestans del sur de Chile. In: ACUÑA, I., RESTREPO, S., GABRIEL, J. (Eds). Resúmenes del Segundo Taller de la red de Cooperación Latinoamericana sobre el estudio del tizón tardío de las solanáceas. Revista Latinoamericana de la papa, v. 20, n. 1, p. 45-64. Apresentação no Segunda Taller Tizón Latino, Panamá, 2016.

AGRIOS, G.N. Plant pathology. 5. ed. Amsterdam: Elsevier Academic Press, 2005. 919 p.

ALOR-ROMERO, N. A. Caracterización de Phytophthora infestans y mejora genética para la resistencia en patata. 2015. 165f. Tese (Doutorado) Departamento de Producción y Protección Vegetal de Neiker, Universidad de Lleida \& Neiker-Tecnalia. 2015.

AMES, M.; SPOONER, D. M. DNA from herbarium specimens settles a controversy about origins of the European potato. American Journal Of Botany, v. 95, n. 2, p. 252-257, 2008. Disponível em: https://doi.org/10.3732/ajb.95.2.252. Acesso em: 13 nov. 2018.

AZEVEDO, L.A.S. Fungicidas sistêmicos: prática e teoria. Campinas: O Autor, 2007. $290 \mathrm{p}$.

BARBOZA, E. A. Ocorrência e diversidade de Pythium e Phytophthora em fontes de água utilizada para irrigação na Região do Distrito Federal. 2014. 119 f. Dissertação (Mestrado em Fitopatologia) - Universidade de Brasília, Brasília, 2014.

BEKETOVA, M. P. et al. On molecular identification of Phytophthora infestans genotypes. Russian Agricultural Sciences, v. 40, n. 6, p. 435-438. 2014. Disponível em: https://doi.org/10.3103/S1068367414060068. Acesso em: 05 dez. 2018.

BELABID, L. et al. Pathogenic and genetic characterization of Algerian isolates of Fusarium oxysporum f. sp. lentis by RAPD and AFLP analysis. African Journal of Biotechnology, Kenya, v. 3, n. 1, p. 25-31, 2004. 
BLUM, M. M. C. Sensibilidade de Phakopsora pachyrhizi a fungicidas. 2009. $174 \mathrm{f}$. Tese de doutorado em fitopatologia, Universidade de Passo Fundo, Passo Fundo, 2009 .

BODKER, L.; NIELSEN, B.J. Preventive and curative effect of fungicides against potato late blight under field conditions. PPV-Special Report, v.7, p.261-264, 2001 .

BODKER, L.; NIELSEN, B.J. Field Experiments with preventive and curative control of potato late blight. PPO-Special Report, v.8, p.211-215, 2002.

BOSCO, L. C. et al. Sistema de previsão de requeima em cultivos de batata em santa Maria, RS. Bragantia, Campinas, v. 69, n. 3, p. 649-660, 2010.

BRADSHAW, N.J.; SCHEPERS, H.T.A.M. Experiences with RH-117281 (zoxamide) - a new fungicide for the control of potato blight. PPV-Special Report, v. 7, p. 173- 183, 2001.

BRENT, K. J.; HOLLOMON, D. W. Fungicide resistance in crop pathogens: How can it be managed. FRAC monograph. 2. ed. rev. Brussels, v.1, p. 1-60, 2007.

BROMMONSCHENKEL, S.H. Patogenicidade, compatibilidade, citogenética e padrões isoenzimáticos de isolados de Phytophthora infestans (Mont.) De Bary do Brasil. (Tese de Mestrado). Viçosa, Universidade Federal de Viçosa. 1988.

BRYLIŃSKA, M. et al. Evaluation of PCR markers for Phytophthora infestansmating type determination. European Journal of Plant Pathology, v. 152, n. 1, p. 3344, 2018. Disponível em : https://doi.org/10.1007/s10658-018-1445-4 Acesso em: 21 dez. 2018.

CASA-COILA, V. H. et al. First Report of Phytophthora infestans Self-Fertile Genotypes in Southern Brazil. Plant Disease, Saint Paul, v. 101, n. 9, p. 1682$1682,2017$.

CASA-COILA, V.H. Caracterização de isolados de Phytophthora infestans (Mont.) De Bary provenientes de batata do Sul do Brasil associada ao estudo da resistência em Solanum spp. 2014. 126f. Tese (Doutorado em Agronomia) Universidade Federal de Pelotas, Pelotas, 2014.

CAVALIER-SMITH, T. A revised six-kingdom system of life. Biological Reviews, v. 73, n. 3, p. 203-266, 1998. Disponível em: https://doi.org/10.1111/j.1469185X.1998.tb00030.x Acesso em: 21 nov. 2018. 
CENTER FOR AGRICULTURE AND BIOSCIENCES INTERNATIONAL (CABI), 2019. Disponível em: https://www.cabi.org/isc/datasheet/40970. Acesso em: 14 janeiro 2019.

CERQUEIRA, A. O. Caracterização, distribuição e Genética populacional de Phytophthora capsici em Hevea brasiliensis na Bahia, Brasil. 2014. 82f. Tese de Doutorado. Universidade Estadual de Santa Cruz, Iheus, Bahia, 2014.

CHAVES, S.C. Genotypes Shape the Population Structure of Phytophthora infestans in the Central Region of Colombia. Phytopathology, Saint Paul, v. 109, n. 1, p. , 2019.

CHOWDAPPA, P. et al. Severe outbreaks of late blight on potato and tomato in South India caused by recent changes in the Phytophthora infestans population. Plant Pathology, Saint Paul, v. 64, n. 1, p. 191-199, 2015.

CLINTON, G. P. Oospores of potato blight. Science. v. 33, n. 854, p. 744-747, 1911. Disponível em: http://www.jstor.org/stable/1637606. Acesso em: 08 jan, 2018.

COOKE, D. E. L.; LEES, A. K. Markers, old and new, for examining Phytophthora infestans diversity. Plant Pathology. v. 53, p. 692-704, 2004.

CROSIER, W. Studies in the biology of Phytophthora infestans (Mont.) de Bary, Cornell University Agricultural Experiment Station, Memoir, Ithaca, n. 155, p. $1-40,1934$.

DAHLIN, P. Analysis of sterol metabolism in the pathogenic oomycetes Saprolegnia parasitica and Phytophthora infestans. 2016. 60f. Tese. Universidade de Estocolmo, Estocolmo, 2016.

DANIES, G. et al. Phenotypic characterization of recent clonal lineages of Phytophthora infestans in the United States. Plant Disease, Saint Paul, v.97, n. 7 p.873-881, 2013.

DAVIS, J. E.; KUBISIAK, T. L.; MILGROOM, M. G. Polymorphic sequencecharacterized codominant loci in the chestnut blight fungus, Cryphonectria parasitica. Molecular Ecology Notes, Oxford, v.5, n.2, p.195-197, 2005.

DE WEILLE, G.A. Forecasting crop infection by the potato blight fungus. A fundamental approach to the ecology of a parasite-host relationship. Koninklijk Nederlands Meteorologisch Instiuut, Mededelingen Verhandelingen, v. 82, p. 1144, 1964. 
DEKKER, J. How to detect and measure fungicide resistance. In: Experimental Techniques in Plant Disease Epidemioogy, 1987. 299 p.

DELGADO, R.A. et al. 2013. Large subclonal variation in Phytophthora infestans populations associated with Ecuadorian potato landraces. Plant Pathology, v. 62, n. 5, p. 1081-8, 2013.

DELLAPORTA, S. L.; WOOD, J.; HICKS, J. B. A plant DNA minipreparation: version II. Plant Molecular Biology Reporter, v. 1, n. 4, p. 19-21, 1983.

DOBROWOLSKI, M. P. et al. Three clonal lineages of Phytophthora cinnamomi in Australia revealed by microsatellites. Phytopathology, Saint Paul, v. 93, n. 6, p. 695-704, 2003.

EBERSOLD, D. Ranman, the new marathon fungicide. PPO-Special Report, Edinburgh, v.8, p.225-230, 2002

EDGINGTON, L. V.; KHEW, K. L.; BARRON, G. L. Fungitoxic Spectrum of Benzimidazole Compounds. Phytopathology, Saint Paul, v. 61, p. 42-44, 1971.

ERWIN, D. C.; RIBEIRO, O. K. Phytophthora diseases worldwide. American Phytopathological Society (APS Press), Saint Paul, 1996. 562 p.

EUROBLIGHT - A potato late blight network for Europe. Disponível em: http://agro.au.dk/forskning/internationale-

platforme/euroblight/currently/news/nyhed/artikel/results-of-the-euroblightpotato-late-blight-monitoring-in-2018/ Acesso em: 14 de julho de 2019.

FABRITIUS, A. L.; JUDELSON, H. S. Mating-type loci segregate aberrantly in Phytophthora infestans but normally in Phytophthora parasitica: Implications for models of mating-type determination. Current Genetics, v. 32, p. 60-65, 1997

FERNÁNDEZ- PAVÍA, S. P.; GRÜNWALD, N. J.; FRY, W. E. Formation of Phytophthora infestans oospores in nature on tubers in central Mexico. Plant Diseases, Saint Paul, v. 86, p. 73, 2002.

FILGUEIRA, F.A.R. Novo Manual de olericultura: agrotecnologia moderna na produção e comercialização de hortaliças. 3. ed. Viçosa: Universidade Federal de Viçosa, 2003. 412 p.

FLIER; W. G. et al. The population structure of Phytophthora infestans from de Toluca Vallery of central México suggests genetic differentiation between populations 
from cultivated potato and wild Solanum spp. Phytopathology, Saint Paul, v. 93, p. 382-390, 2003.

FLIER, W. G.; GRUNWALD, N. J.; FRY, W. E.; TURKENSTEEN, L. J. Formation, production and viability of oospores of Phytophthora infestans from potato and Solanum demissum in the Toluca Valley, central Mexico. Mycological Research, Inglaterra, v.105, n.8, p.998-1006, 2001.

FOOD AND AGRICULTURE ORGANIZATION OF THE UNITED NATIONS (FAO), Roma, 2019. Disponível em: http://www.fao.org/faostat/. Acesso em: 21 jan. 2019.

FORBES GA. Global overview of late blight. Proceedings Regional Workshop on Potato Late Blight for East and Southeast Asia and the Pacific. In: GLOBAL OVERVIEW OF LATE BLIGJT, Yezin Agricultural University, Myanmar, 2004. Disponível em: https://research.cip.cgiar.org/confluence/download/attachments/37192023/Procee dings_Gilb_final_completo.pdf?version=1\&modificationDate $=1273690250000$. Acesso em: 21 mar. 2016.

FORTES, G. R. L.; PEREIRA, J. E. S. Classificação e descrição botânica. IN: PEREIRA, S. A.; DANIELS, J. (Eds.). O cultivo da batata na região sul do Brasil. Brasília: Embrapa Informação Tecnológica, 2003. p. 69-79.

FRY LAB: Biology of Phytophthora infestans and Management of Late Blight Cornell University - Departament of Plant Pathology and Plant-Microbr Biology. 2014, Disponível em: http://www.plantpath.cornell.edu/Fry/ProtocolsCulture.html. Acesso em: 03 mar. 2014.

FRY, W. E. et al. Population genetics and intercontinental migrations of Phytophthora infestans. Annual Review of Phytopathology, Palo Alto, v. 30, p. 107-129, 1992.

FRY, W. E. et al. Population genetics and population diversity of Phytophthora infestans. In: LAMOUR, K. Kamoun, S. (Ed.). Oomycete Genetics and Genomics: Diversity, Interactions and Research Tools, Hoboken, New Jersey: Wiley-Blackwell, p. 139-164, 2009.

FRY, W. E.; GOODWIN, S. B. Resurgence of the Irish potato famine fungus. BioScience, Washington, v. 47, p. 363-371, 1997. 
FRY, W. E.; GRUNWALD, N. J. 2010. Introduction to Oomycetes. The Plant Health Instructor, Saint Paul, 2010. Disponível em: https://www.apsnet.org/edcenter/disandpath/oomycete/introduction/Pages/IntroOo mycetes.aspx. DOI: 10.1094/PHI-I-2010-1207-01. Acesso em: 21 mar. 2016.

FRY, W. E.; MIZUBUTI, E. S. Potato late blight. In: JONES, D. G. (Ed.). The Epidemiology of Plant Diseases. Dordrecht: Kluwer Academic Publishers, 1998. p. 371-388.

FRY, W. E. Phytophthora infestans: the plant (and R gene) destroyer. Molecular Plant Pathology, v. 9, p. 385-402, 2008.

FRY, W. E. Role of early and late blight suppression in potato pest management. In: ZENDER, G. W.; POWLESON, M. L.; JANSSON R. K.; RAMAN, K. V. Advances in potato pest: biology and management. Saint. Paul, 1994. p. 166177.

FYFE, A. M.; SHAW, D. S. An analysis of self-fertility in field isolates of Phytophthora infestans. Mycological Research, v. 96, n. 5, p. 390-394, 1992.

Fungicide Resistance Action Committee - FRAC, Disponível em: http://www.frac.info/resistance-overview/mechanisms-of-fungicide-resistance Acesso em: 04 dez. 2018.

Fungicide Resistance Action Committee - FRAC, Disponível em: http://www.frac.info/docs/default-source/monitoring-methods/approvedmethods/phytin-microtiter-method-sporangia-basf-2006v1.pdf?sfvrsn=479a419a_4 Acesso em: 17 out. 2017.

GALINDO, J.; GALLEGLY, M. E. The nature of sexuality in Phytophthora infestans. Phytopathology, Saint Paul, v. 50, p. 123 - 128, 1960.

GALlEGLY, M. E.; GALINDO, J. Mating types and oospores of Phytophthora infestans in nature in Mexico. Phytopathology, Saint Paul, v. 48, p. 274-277, 1958.

GAMBOA, S. et al. Análisis genético de la población actual de Phytophthora infestans en Perú / Genetic analysis of the current population of Phytophthora infestans in Peru. In: PEREZ, W., ANDRADE-PIEDRA, J.L., LUCCA, F., RESTREPO, S., Y ACUÑA, I. 2018. Memorias del 3er. Taller de la Red de Cooperación Latinoamericana sobre el estudio del Tizón Tardío de las Solanáceas (Tizón 
Latino). Cusco, Perú. 27 de Mayo del 2018. Centro Internacional de la Papa (CIP, Perú), Instituto de Investigaciones Agropecuarias (INIA, Chile), Instituto Nacional de Tecnología agropecuaria (INTA, Argentina) y Universidad de los Andes (UNIANDES, Colombia), 2018. 19 p.

GARCÍA, B. I. L. Risco climático de ocorrência da requeima da batata na região dos Andes, Venezuela. 2005. 132 f. Tese (Doutorado em Agronomia) - Escola Superior de Agricultura "Luiz de Queiroz” - USP, Piracicaba, 2005.

GARRY, G. at al. 2005. Genetic diversity and host differentiation among isolates of Phytophthora infestans from cultivated potato and wild Solanaceous hosts in Peru. Plant Pathology, v. 54, n. 6, p. 740- 8, 2005.

GENET, J.L. et al. Effect of temperature on the curative and anti-sporulant action of cymoxanil for control of Phytophthora infestans. Fifth Workshop of an European Network for development of an Integrated Control Strategy of potato late blight, Munich, p.107-117, 2000.

GEORGOPOULOS, S. G. Detection and measurement os fungicide resistance. In: DEKKER, J.; GEORGOPOULOS, S. G. Fungicide resistence in crop protection. Wageningen: Center for Agricultural Publishing and Documentation, 1982. p. 2431.

GOMEZ-ALPIZAR, L.; CARBONE, I.; RISTAINO, J. B. An Andean origin of Phytophthora infestans inferred from mitochondrial and nuclear gene genealogies. Proceedings of the National Academy of Sciences, USA, v. 104, n. 09, p. 3306 - 3311, 2007.

GOODWIN, S. B.;COHEN, B. A.; FRY, W. E. Panglobal distribution of a single clonal lineage of the Irish potato famine fungus. Proceedings of the National Academy of Science, v. 91, p. 591-11,595, 1994.

GOODWIN, S. B.; DRENTH, A.; FRY, W.E. Cloning and genetic analysis of two highly polymorphic, moderately repetitive nuclear DNAs from Phytophthora infestans. Current Genetics, v. 22, p. 107-15, 1992a.

GOODWIN, S. B. et al. Clonal diversity and genetic differentiation of Phytophthora infestans populations in northern and central Mexico. Phytopathology, Saint Paul, v. 82, p. 955-61, 1992b. 
GOSS, E. M. et al. The Irish potato famine pathogen Phytophthora infestans originated in central Mexico rather than the Andes. Proceedings of the National Academy of Sciences, Washington, v. 111, n. 24, p. 8791-8796, 2014.

GRÜNWALD, N. J. et al. Analysis of Genotypic Diversity Data for Populations of Microorganisms. Phytopathology, Saint Paul, v. 93, p. 738- 746, 2003.

GRUNWALD, N. J. et al. Population structure of Phytophthora infestans in the Toluca valley region of central Mexico. Phytopathology, Saint Paul, v. 91, n. 9, p. 882890, 2001.

GUO, J. et al. Phytophthora infestans isolates form Northern China show high virulence diversity but low genotypic diversity. Plant Biology. Stuttgart, v. 11, n. 1, p. 5767, 2009.

GILCHRIST RAMELLI, E. et al. Characterization of Phytophthora infestans populations in Antioquia, Colombia. Revista Facultad Nacional de Agronomía, Medellín , v. 62, n. 2, p. 5031-5037, 2009. Disponível em: http://www.scielo.org.co/scielo.php?script=sci_arttext\&pid=S0304$\underline{28472009000200001}$ Acesso em: 07 jul. 2017.

GOLD, R. et al. Initium ${ }^{\circledR}$ - An Innovative Fungicide of a New Chemical Class for the Control of Oomycetes. BCPC Congress, 2009.

HALL, T.A. BioEdit: a user-friendly biological sequence alignment editor and analysis program for Windows 95/98/NT. Nucleic Acids Symposium Series, n. 41, p. 9598, 1999.

HAMRICK, J. L. Plant population genetics and evolution. American Journal of Botany, Ohio, v.69, n.10, p.1685-1693, 1982.

HARRISON, J.G. Effects of the aerial environment on late blight of potato foliage - a review. Plant Pathology, v. 41, n. 4, p. 384-416, 1992.

HARRISON, J. G.; LOWE, R. Effects of humidity and air speed on sporulation of Phytophthora infestans on potato leaves. Plant Pathology, v. 38, n. 4, p. 585-591, 1989.

HARTILL, W.F.T. et al. Effects of temperature and Leaf wetness on the potato late blight. New Zealand Journal of Crop and Horticultural Science, v. 18, n. 4, p. 181-184, 1990. 
HAAS, B. J. et al. Genome sequence and analysis of the Irish potato famine pathogen Phytophthora infestans. Nature, London, v. 461, p. 393-398, 2009.

HENFLING, J. W. El tizón tardio de la papa: Phytophthora infestans. 2 ed. Lima: Centro Internacional de La Papa, 1987. 25 p.

HENSEN, I.; OBERPRIELER, C.; WESCHE, K. Genetic structure, population size, andseed production of Pulsatilla vulgaris Mill.(Ranunculaceae) in Central Germany. Flora, Jena, v. 200, n. 1, p. 3-14, 2005.

HERMANN, D.; BARLETT, D.W.; FISCHER, W.; KEMPF, H.J. The behavior of mandipropamid in plants. In: BCPC CROP SCIENCE \& TECHONOLOGY, 2005, Glasgow. Proceedings. Glasgow: BCPC, 2005. p. 93-98.

HIJMANS, R. J.; FORBES, G. A.; WALKER, T. S. Estimating the global severity of potato late blight with GIS-linked disease forecast models. Plant Pathology, v. 49, n. 6, p. 697-705, 2000.

HOOKER, W. J. Compendium of potato diseases. American Phytopathological Society, Saint Paul, Minnesota, USA. 1981. 125 p.

HU， J.H.; HONG， C.X.; STROMBERG， E.L.; MOORMAN， G.W, Effects of propamocarb hydrochloride on mycelial growth, sporulation, and infection by Phytophthora nicotianae isolates from Virginia nurseries. Plant Disease, v. 91, n. 4, p. 414- 420, 2007.

HUGGENBERGER, F.; KNAUF-BEITER, G. Mandipropamid a new fungicides for the control of late blight in potatoes. PPO-Special Report, v.12, p. 67-76, 2007.

INSTITUTO BRASILEIRO DE GEOGRAFIA E ESTATÍSTICA - IBGE. Disponível em: http://www.ibge.gov.br Acesso: 25 de jan. de 2019.

INTERNATIONAL POTATO CENTER - CIP. Lima, 2019. Disponível em: https://cipotato.org/crops/potato/. Acesso em: 22 janeiro 2019.

IVORS K. et al. Use of microsatellite markers derived from whole genome sequence data for identifying polymorphism in Phytophthora ramorum. In: FRANKEL, S. J.; SHEA, P. J.; HAVERTY, M.I., (Ed.). Proceedings of the sudden oak death second science symposium: the state of our knowledge. General Technical Report. Albany, CA: Pacific Southwest Research Station, Forest Service, U.S. Department of Agriculture, 2006a. 
IVORS K. et al. Microsatellite markers identify three lineages of Phytophthora ramorum in US nurseries, yet single lineages in US forest and European nursery populations. Molecular Ecology, v.15, p. 1493-1505, 2006 b.

JAMES, T. Y.; LIOU, S.-R.; VILGALYS, R. The genetic structure and diversity of the A and B mating-type genes from the tropical oyster mushroom, Pleurotus djamor. Fungal Genetics and Biology, Orlando, v.41, n.8, p.813-825, 2004.

JOHNSON, D.A.; CUMMINGS, T.F.; GEARY, B. Postinfection activity of selected late blight fungicides. Plant Disease, v. 84 n. 10, p. 1116 - 1120, 2000.

JONES, J. B.; JONES, J. P.; STALL, R. E.; ZITTER, T. A. (Ed.). Compendium of tomato diseases. Saint Paul: APS Press, 1991. 73 p.

JUDELSON, H. S. Chromosomal heteromorphism linked to the mating type locus of the oomycete Phytophthora infestans. Molecular and General Genetics, v. 252, v. 1-2, p. 155-161, 1996.

JUDELSON, H.S.; BLANCO, F.A. The spores of Phytophthora: Weapons of the plant destroyer. Nature Reviews Microbiology, v. 3, p. 47-58, 2005.

JUDELSON, H. S. et al. Metabolic adaptation of Phytophthora infestans during growth on leaves, tubers and artificial media. Molecular plant pathology, v. 10, n. 6, p. 843-855, 2009.

JUDELSON, H. S.; SPIELMAN, L. J.; SHATTOCK, R. C. Genetic mapping and nonMendelian segregation of mating type loci in the oomycete, Phytophthora infestans. Genetics, v. 141, n. 2, p. 503-512, 1995.

KAMOUN, S. et al. The Top 10 oomycete pathogens in molecular plant pathology. Molecular Plant Pathology, v. 16, n. 4, p. 413-34, 2015.

KAMOUN, S.; HUITEMA, E.; VLEESHOUWERS, V. G. A. A. Resistance to oomycetes: a general role for the hypersensitive response? Trends in Plant Science, v. 4, n. 5, p. 196-200, 1999.

KAMOUN, S. Molecular genetics of phytopathogenic oomycetes. Eukaryotic Cell, Washington, v.2, p.191-199, 2003.

KATO, M. et al. Sensitivity to protectant fungicides and pathogenic fitness of clonal lineages of Phytophthora infestans in the United States. Phytopathology, Saint Paul, v. 87, n. 09, p. 973-978, 1997. 
KNAPOVA G, GISI U. Phenotypic and genotypic structure of Phytophthora infestans populations on potato and tomato in France and Switzerland. Plant Pathology, v. 51, n. 05, p. 641- 653, 2002.

KANDEL, K. P. Transcriptomic studies of the early stages of potato infection by Phytophthora infestans. 2014. 245f. Tese (Doutorado). Universidade de Dudee, Dundee, Escócia, 2014.

KIM, K. J.; LEE, Y. S. Genetic DNA marker for A2 mating type in Phytophthora infestans. The Journal of Microbiology, v. 40, p. 254-259, 2002.

KIRK, W. W. et al. Evaluation of potato late blight management utilizing host plant resistance and reduced rates and frequencies of fungicide applications. Crop Protection, v. 24, n. 11, p. 961-970, 2005.

LATIJNHOUWERS, M.; DE WIT, P. J. G. M.; GOVERS, F. Oomycetes and fungi: similar weaponry to attack plants. Trends in Microbiology, Cambridge v. 11, n. 10, p. 462-469, 2003.

LATORSE, M.P. et al. Tuber blight control: effect of foliar applied fungicides such as Infinito on viability of sporangia of Phytophthora infestans. PPO-Special Report, v.12, p.37-47, 2007.

LEAL-BERTIOLI, S. C. M. O enfoque molecular na sistemática de fungos. Revisão Anual de Patologia de Plantas, Passo Fundo, v.6, p.197-230, 1998.

LEES, A. K. et al. Novel microsatellite markers for the analysis of Phytophthora infestans populations. Plant Pathology, v. 55, n. 3, p. 311-319, 2006.

LOPES, C. A.; SANTOS, J. R. M. Doenças do tomateiro. EMBRAPA-CNPH; EMBRAPA-SPI, 1994. 67 p.

LI, Y. et al. A new set of highly informative SSR markers for Phytophthora infestans population analysis assembled into an efficient multiplex. Molecular Ecology Resources, v. 10, p. 1098-1105, 2010.

LI, Y. 2012. Multiplex SSR analysis of Phytophthora infestans in different countries and the importance for potato breeding. Tese de Doutorado. Universidade de Wageningen, Wageningen, Holanda.

LI, Y., et al., 2013. Efficient multiplex simple sequence repeat genotyping of the oomycete plant pathogen Phytophthora infestans. Journal of Microbiological Methods, 92:316-322. DOI: Doi 10.1016/J.Mimet.2012.11.021. 
LEGARD, D. E.; LEE, T. Y.; FRY, W.E. Pathogenic specialization in Phytophthora infestans: aggressiveness on tomato. Phytopathology, Saint Paul, 85:1356-1361, 1995.

LUCCA, M. F.; RESTREPO, S.; ACUÑA, I.; ZANOTTA, S. Genotipificación de poblaciones de Phytophthora en Latino América / Genotyping of Phytophthora populations in Latin America. In: PEREZ, W., ANDRADE-PIEDRA, J.L., LUCCA, F., RESTREPO, S., Y ACUÑA, I. Memorias del 3er. Taller de la Red de Cooperación Latinoamericana sobre el estudio del Tizón Tardío de las Solanáceas (Tizón Latino). Cusco, Perú. 27 de Mayo del 2018. Centro Internacional de la Papa (CIP, Perú), Instituto de Investigaciones Agropecuarias (INIA, Chile), Instituto Nacional de Tecnología agropecuaria (INTA, Argentina) y Universidad de los Andes (UNIANDES, Colombia), 2018. 19 p.

LUCCA, M. F.; RESTREPO, S. Genetic population structure of Phytophthora spp. causing late blight on potato crops and Solanaceous hosts in Latin America. Apresentação no 10th World Potato Congress (WPC) / XXVIII Congreso de La Asociación Latino Americana de La Papa (ALAP), Cusco - Peru, 2018.

LOOMIS, T. A. Fundamentos de toxicologia. 3. Ed. Zaragoza: Acribia, 1995. p. 444.

LUDWIG, A. BOLLER, T. A method for the study of fungal growth inhibition by plant proteins. FEMS Microbiology Letters, v. 69, n. 1-2, p. 61-66, 1990.

MARIETTE, N. et al. Aggressiveness and genetic structure of french populations of Phytophthora infestans from 2001 to 2008. Are the most aggressive isolates the fittest? In: Book of acts of 19th Triennial Conference European Association for Potato Research (EAPR). Brussels (Belgium) 6-11 July, 2014. 52 p.

MARTIN, M.D. et al. 2013. Reconstructing genome evolution in historic samples of the Irish potato famine pathogen. Nature Communications. 4. Doi: 10.1038/ncomms3172. Acesso em: 14 de julho de 2019.

MARTIN, M. D. et al. Genomic characterization of a South American Phytophthora hybrid mandates reassessment of the geographic origins of Phytophthora infestans. Molecular Biology and Evolution. 33, 478-91, 2015.

MARTIN, E.A. 2019. The interplay of landscape composition and configuration: new pathways to manage functional biodiversity and agroecosystem services across Europe. Ecology Letters, v. 22, n. 7, p. 1083-1094. Doi: https://doi.org/10.1111/ele.13265. Acesso: 14 de julho de 2019. 
MAZÁKOVÁ, J. et al. Mating type distribution of Phytophthora infestans (Mont.) de Bary in the Czech Republic in 2007 and 2008. Plant Protection Science, Czech Republic, v. 46, n. 03, p. 89-97, 2010.

\section{MAZIERO, J. M. N. Influencia da temperatura e do tempo de molhamento foliar} nos componentes epidemiológicos de Phytophthora infestans e validação do simulador Blight no Brasil. 2001. 73f. Dissertação (Mestrado). Universidade Federal de Viçosa, Viçosa, MG, 2001.

MAYTON, H. et al. Oospore survival and pathogenicity of single oospore recombinant progeny from a cross involving US-17 and US-8 genotypes of Phytophthora infestans. Plant Disease, Saint Paul, v. 84, n, 11, p. 1190-1196, 2000.

MILLER, J. S.; HAMM, P. B.; JOHNSON, D. A. Characterization of the Phytophthora infestans population in the Columbia Basin of Oregon and Washington from 1992 to 1995. Phytopathology, Saint Paul, v. 87, n. 6, p. 656-660, 1997.

MILGROOM, M. G.; PEEVER, T. L. Population biology of plant pathogens - The synthesis of plant disease epidemiology and population genetics. Plant Disease, Saint Paul, v. 87, n. 06, p. 608-617, 2003.

MINOGUE, K. P.; FRY, W. E. Effects of temperature, relative humidity, and rehydration rate on germination of dried sporangia of Phytophthora infestans. Phytopathology, Saint Paul, v.71, p.1181-1184, 1981.

MITANI, S. et al. Biological properties of the novel fungicide cyazofamid against Phytophthora infestans on tomato and Pseudoperonospora cubenis on cucumber. Pest Management Science, v. 58, n. 2, p. 139-145, 2002.

MIYAKE Y. et al. Fungicidal activity of Benthiavalicarb-isopropyl against Phytophthora infestans and its controlling activity against late blight diseases. Journal Pesticide Science, v. 30, n. 04, p. 390-396, 2005.

MIZUBUTI, E. S. G.; FRY, W. E. Potato late blight. In: COOKE, B. M.; JONES, D. G.; KAYE, B. The epidemiology of plant diseases. Amsterdam: Springer, 2006. p. $445-471$.

MIZUBUTI, E. S. G.; FRY, W. E. Temperature effects on developmental stages of isolates from three clonal lineages of Phytophthora infestans. Phytopathology, Saint Paul, v. 88, n. 08, p. 837-843, 1998. 
MOSA, A. A. et al. Occurrence of the A2 mating type of Phytophthora infestans on potato in Japan. Japanese Journal oy Phytopathology, v. 55, n. 05, p. 615-620, 1989.

MOURA, R. M. Relembrando Anton de Bary e sua obra fitopatológica. Fitopatologia Brasileira, Brasília, v. 27, n. 4, p. 337-343, 2002.

MYCOBANK DATABASE, 2019. Disponível em: http://www.mycobank.org/BioloMICSDetails.aspx?Rec=21649. Acesso em: $10 \mathrm{de}$ julho de 2019.

NAZARENO, N. R. X.; JACCOUND FILHO, D. S. Doenças fúngicas. In: PEREIRA, A. S.; DANIELS, J. (Ed.). O cultivo da batata na região sul do Brasil. Embrapa Informação Tecnológica, Brasília, p. 239-276, 2003.

NAZARENO, N. R. X. et al. Controle da requeima da batata através do monitoramento das variáveis climáticas. Fitopatologia Brasileira, Brasília, v. 24, n. 2, p. 170174, 1999.

NIEDERHAUSER, J. S. Phytophthora infestans: The Mexican connection. In: LUCAS, J. A.; SHATTOCK, R. C.; SHAW, D. S.; COOKE, L. R. (Ed.) Phytophthora. Cambridge University Press, Cambridge, 1991. p. 25-45.

NJOROGE, A.W. et al. Genotyping of Phytophthora infestans in eastern-Africa reveals a dominating invasive European lineage. Phytopathology, v. 109, n. 04, p. 670680, 2019. Disponível em: https://apsjournals.apsnet.org/doi/full/10.1094/PHYTO-07-18-0234$\underline{\text { R?url_ver=Z39.88-2003\&rfr_id=ori:rid:crossref.org\&rfr_dat=cr_pub\%3dpubmed }}$ DOI: https://doi.org/10.1094/PHYTO-07-18-0234-R Acesso em: 11 mar. 2019.

OGA, S.; CAMARGO, M. M. A.; BATISTUZZO, J. A. O. Fundamentos de toxicología. 3. ed. São Paulo: Atheneu Editora, 2008. 704 p.

OGUNDIWIN, E.A. et al. Construction of 2 intraspecific linkage maps and identification of resistance QTLs for Phytophthora capsici root-rot and foliarblight diseases of pepper (Capsicum annuum L.). Genome, Ottawa, v. 48, n. 04, p. 698-711. 2005.

OLIVA, R. F. et al. Potential of sexual reproduction among host-adapted populations of Phytophthora infestans sensu lato in Ecuador. Plant Pathology, v. 51, n. 06, p. 710-719, 2002. 
OLIVEIRA, S. A. S. Genetic structure, aggressiveness and fungicide sensitivity of Phytophthora infestans populations from the south and southeast regions of Brazil. 2010. 96f. Tese (Doutorado). Universidade Federal de Viçosa, Viçosa, MG, 2010.

OYARZUN, P. J. et al. Host specificity of Phytophthora infestans on tomato and potato in Ecuador. Phytopathology, Saint Paul, v. 88, n. 03, p. 265-271, 1998.

PORTER, L. D.; DASGUPTA, N.; JOHNSON, D. A. Effects of tuber depth and soil moisture on infection of potato tubers in soil by Phytophthora infestans. Plant Disease, Saint Paul, v.89, n. 02, p.146-152, 2005.

PROSPERO, S.; BLACK, J. A.; WINTON, L. M. Isolation and characterization of microsatellite markers in Phytophthora ramorum, the causal agent of sudden oak death. Molecular Ecology, v. 04, n. 04, p. 672-674, 2004.

QI, J. Characterization of a Phytophthora mating hormone. Science, Washington v. 309, n. 5742, p. 1828-1828, 2005.

RAMPERSAR, S. N. A Rapid Colorimetric Microtiter Bioassay to Evaluate Fungicide Sensitivity Among Verticillium dahliae Isolates. Plant Disease, Saint Paul, v. 95, n. 03, p. 248-255, 2011.

RAPOSO, R. et al. Application of an Automated Quantitative Method to Determine Fungicide Resistance in Botrytis cinerea . Plant Disease, Saint Paul, v. 79, n. 03, p. 294-296, 2015.

REIMANN, S. et al. Initium ${ }^{\circledR}$ : a new fungicidal active ingredient for the control of Oomycetes. PPO-Special Report, v.14, p.89-94, 2010.

REIS, A. Caracterização das populações de Phytophthora infestans das regiões Sul e Sudeste do Brasil. 2001. 88f. (Tese de Doutorado). Viçosa, Universidade Federal de Viçosa. 2001.

REIS, A. et al. Characterization of isolates of Phytophthora infestans from southern and southeastern Brazil from 1998 to 2000. Plant Disease, Saint Paul, v. 87, n. 08, p. 896-900, 2003.

REIS, A. et al. Sensitivity of Brazilian isolates of Phytophthora infestans to commonly used fungicides in tomato and potato crops. Plant Disease, Saint Paul, v. 89, n. 12, p. 1279-1284, 2005. 
REIS, E. M.; REIS, A. C.; FORCELINI, C. A. Manual de fungicidas. Guia para o controle químico de doenças de plantas. Passo Fundo: Editora Universidade de Passo Fundo, 2007. 153 p.

REIS, A.; RIBEIRO, F. H. S.; MIZUBUTI, E. S. G. Caracterização de isolados de Phytophthora infestans do Distrito Federal e de Goiás. Fitopatologia Brasileira, Brasilia, v.31, n. 03, p. 270-276, 2006.

REKAD, F. Z. et al. Characterization of Phytophthora infestans populations in northwestern Algeria during 2008-2014, Fungal Biology, v. 121, n. 05, p. 467477, 2017.

REKANOVIC, E. et al. Sensitivity of Phytophthora infestans (Mont.) de Bary Isolates to Fluazinam, Fosetyl-Al and Propamocarb-hydrochloride. Journal Pesticides and Phytomedicine, Belgrade, v. 26, n. 02, p. 111-116, 2011.

RIBEIRO, O.K. A Historical Perspective of Phytophthora. In: Phytophthora: a global perspective (Lamour K, ed.): 1-10. Wallingford: CAB International, 2013.

RISTAINO, J. B.; GUMPERTZ, M. L. New frontiers in the study of dispersal and spatial analysis of epidemics caused by species in the genus Phytophthora. Annual Review of Phytopathology. v. 38, p. 541-5476, 2000.

RUPP, J. V. Diversidade genética em progênies de milho doce utilizando marcadores SSR. 2008. 38f. Dissertação (Mestrado). Universidade Estadual de Maringá, Maringá, PR, 2008.

RUSSELL, P.E. A century of fungicide evolution. Journal of Agricultural Science, Cambridge, v. 143, n. 01, p. 11-25, 2005.

RUSSEL, P. E. Sensitivity baselines in fungicide resistance researchand management. 2004. 60f. FRAC, Cambridge, 2004.

SALAMAN, R. N.; BURTON, W. G. The History and Social Influence of the Potato. Cambridge University Press, Cambridge, 1985. 599 p.

SANGER, F., et al. DNA sequencing with chain-terminating inhibitors. Proceedings of the National Academy of Sciences, v. 74, p. 5463-5467, 1977.

SANTANA, F. M. 2006. Distribuição e caracterização de isolados de Phytophthora infestans (Mont.) De Bary associados à batata (Solanum tuberosum L.) na região sul do Brasil. 2006. 76f. Tese (Doutorado). Universidade Federal de Pelotas, Pelotas, 2006. 
SANTANA, F. M.; GOMES, C. B.; ROMBALDI, C.; BIANCHI, V. J.; REIS, A. Characterization of Phytophthora infestans populations of southern Brazil in 2004 and 2005. Phytoparasitica, v.41, p.557-568, 2013.

SATO, N. Effect of sporulating temperature on the limit temperature of indirect germination of the sporangia of Phytophthora infestans. Annals of the Phytopathological Society of Japan, v. 60, p. 60-65, 1994a.

SATO, N. Effect of water temperature on direct germination of the sporangia of Phytophthora infestans. Annals of the Phytopathological Society of Japan, v. 60, p. 162-166, 1994 b.

SAVILlE, A. C.; MARTIN, M. D.; RISTAINO, J. B. (2016) Historic Late Blight Outbreaks Caused by a Widespread Dominant Lineage of Phytophthora infestans (Mont.) de Bary. Plos One, San Francisco, v. 11, n. 12, p. 1-22, 2016. Disponível

em: https://journals.plos.org/plosone/article?id=10.1371/journal.pone.0168381 . DOI: 10.1371/journal.pone.0168381. Acesso em: $04 \mathrm{dez} 2018$.

SAVILLE, A. et al. Fungicide sensitivity of US genotypes of Phytophthora infestans (Mont.) de Bary to six oomycete-targeted compounds. Plant Disease, Saint Paul, v. 99, n. 05, p. 659-666, 2015.

SCHUMANN, G. L. The Irish potato famine and the birth of plant pathology. In: Plant Diseases: Their Biology and Social Impact. Minnesota: American Phytopathological Society, 1991. 397 p.

SCHMITZ, A.; RIESNER, D. Purification of nucleic acids by seletive precipitation with polyethylene glycol 6000. Analytical Biochemistry, v.354, n. 02, p.311-313, 2006.

SCHUMANN, G. L.; D'ARCY, C. J. Requeima da batateira e tomateiro. 2000. Disponível em: http://www.apsnet.org/edcenter/intropp/lessons/fungi/Oomycetes/ Pages/ LateBlightPort.aspx. Acesso em: 01/10/2013.

SECRETARIA DE ESTADO DA AGRICULTURA E DO ABASTECIMENTO (SEAB) - DEPARTAMENTO DE ECONOMIA RURAL (DERAL) - SEABDERAL. Batata: aspectos economicos. Curitiba: SEAB-DERAL, 1998. 40 p.

SHARVELlE, E. G. The nature and uses of modern fungicides. Minneapolis: Burgess Publishing Company, 1961. 308 p. 
SOUZA DIAS, J. A. C.; IAMAUTI, M. T.; FISCHER, I.H. Doenças da batateira. In: AMORIN, L.; REZENDE, J. A. M.; BERGAMIN FILHO, A.; CAMARGO, L. E. A. (Ed.). Manual de fitopatologia Vol 2: Doenças de plantas cultivadas. 5.ed. Ouro Fino-MG: Ceres, 2016. p. 125-147.

SOUZA, J. R. Potencialidade de Fungicidas e Agente Biológico no Controle de Requeima do Tomateiro. 2013. 63f. Dissertação (Mestrado). Universidade Estadual do Sudoeste da Bahia, Vitória da Conquista, BA, 2013.

STAMMLER, G.; BENZINGER, G.; SPEAKMAN, J. A rapid and reliable method for monitoring the sensitivity of Sclerotinia sclerotiorum to boscalid. Journal of Phytopathology, v. 155, n. 11-12, p. 746-748, 2007.

STEVENSON, R.; LORIA, R.; FRANC, G. D.; WEINGARTNER, D. P. Compendium of potato diseases. Saint. Paul: APS, 2001. 134 p.

STEVENSON, W. R. An integrated program for managing potato late blight. Plant Disease, Saint Paul, v. 67, p. 1047-1048, 1983.

STEVENSON, W.; KIRK, W.; ATALLAH, Z. K. Managing foliar disease: early blight, late blight and white mold. In: JOHNSON, D. A. (Ed.). Potato health management. APS: Saint Paul, 2008. p. 209-222.

SUASSUNA, N.D., MAFFIA, L.A.; MIZUBUTI, E.S.G. Epidemiological components related to fitness contribute to the host specificity of Phytophthora infestans populations in Brazil. Phytopathology, v. 91, 2001.

SUASSUNA, N. D.; MAFFIA, L. A.; MIZUBUTI, E. S. G. Aggressiveness and host specificity of Brazilian isolates of Phytophthora infestans. Plant Pathology, v. 53, n. 04, p. 405-413. 2004.

SUGITA, T. et al. Analysis for Resistance to Phytophthora Blight (Phytophthora capsici Leon.) Using an Intraspecific Doubled-Haploid Population of Capsicum annuum”. Breeding Science, v. 56, n. 02, p. 137-145, 2006.

SUJKOWSKI, L.S. The influence of temperature on Phytophthora infestans (Mont.) de Bary. Journal of Phytopathology, v. 120, n. 03, p. 271-275, 1987.

TAFFOREAU, S. et al. Consento: New experiences on the control of late blight 20072008. A summary of recent data with Consento in Europe. PPO-Special Report, v.13, p.135-142, 2009. 
TAFFOREAU, S. et al. Infinito: Profile of a novel potato late blight fungicides. Summary of three years of development trials in Europe. PPO-Special Report, v.11, p.77-88, 2006.

TANTIUS, P. H. et al. Occurrence of the A2 mating type and self-fertile isolates of Phytophthora infestans in England and Wales. Plant Pathology, v. 35, n. 04, p. 578-581, 1986.

TAYLOR, M. C. et al. Relative performance of five forecasting schemes for potato late blight (Phytophthora infestans) I. Accuracy of infection warnings and reduction of unnecessary, theoretical, fungicide applications. Crop Protection, v. 22, n. 02, p. 275-283, 2003.

TENZER, I. et al. Identification of microsatellite markers and their application to population genetics of Venturia inaequalis. Phytopathology, Saint Paul, v. 89, n. 09, p. 748-753, 1999.

TÖFOLI, J. G. Ação de fungicidas e indutores de resistência no controle da requeima e pinta preta na cultura da batata. 2011. 176f. Tese (Doutorado). Universidade de São Paulo, Piracicaba, SP, 2011.

TÖFOLI, J. G. et al. Ametoctradin: a new fungicide for potato late blight control. Arquivos do Instituto Biológico, São Paulo, v. 83, p. 1-6, 2016.

TOFOLI, J. G.; MELO, P. C. T.; DOMINGUES, R. J. Ação protetora, residual, curativa e anti esporulante de fungicidas no controle da requeima e da pinta preta da batata em condições controladas. Biológico, v. 79, n. 2, p. 209-221, 2012.

TOFOLI, J. G.; MELO, P. C. T.; DOMINGUES, R. J.; FERRARI, J. T. Requeima e pinta preta na cultura da batata: importância, características e manejo sustentável. Biológico, São Paulo, v. 75, n. 1, p. 33-40, 2013.

TÖFOLI, J.G.; DOMINGUES, R.J.; ZANOTTA, S. Doenças fúngicas da batata. In: SALAS, F.J.S.; TOFOLI J.G. (Eds.). Cultura da batata: pragas e doenças. 1. ed. Instituto Biológico: São Paulo, 2017. 222 p.

THOMPSON J. M.; COOKE, L. R. The effect of mandipropamid on infection of potato leaves by Phytophthora infestans: an SEM study. PPO-Special Report, v.13, p.229- 236, 2009. 
TOKESHI, H.; CARVALHO, P.C.T. Doenças do tomateiro - Lycopersicon esculentum Mill. IN: GALLI, F. Manual de Fitopatologia - Doenças das Plantas Cultivadas. São Paulo: Ceres, 1980. 706 p.

TOOLEY, P. W.; FRY, W. E.; VILLAREAL GONZALEZ, M. J. Isozyme characterization of sexual and asexual Phytophthora infestans populations. Journal of Heredity, v. 76, n. 06, p. 431-435, 1985.

TORGESON, D. C. Determination and Measurenment of Fungitoxicity. In: TORGESON, D. C. Fungicides: An Advanced Treatise, New York: Academic Press, v. 1, 1967. 742 p.

TRIGIANO, R. N.; AMENT, M. H.; LAMOUR, K. H. Oomycota Organismos Similares a Fungos. In: TRIGIANO, R. N.; WINDHAM, M. T.; WINDHAM, A. S. (Ed.). Fitopatologia conceitos e exercícios de laboratório. 2.ed. Porto Alegre: Editora Artmed, 2010, p. 215-225.

TRENTIN, G. Avaliação de sistemas de previsão de ocorrência de Phytophthora infestans em batata. 2006. 100 f. Dissertação (Mestrado em Agronomia) Universidade Federal de Santa Maria, Santa Maria.

TURNER, R.S. After the famine: Plant pathology, Phytophthora infestans, and the late blight of potatoes, 1845-1960. Historical Studies in the Physical and Biological Sciences, v. 35, n. 02, p. 341-70, 2005.

USABLIGHT, 2017. Disponível em: https://usablight.org/. Acesso em: 22 de novembro de 2017.

VALENCIO, S. A. X. Microtitulação colorimétrica para avaliar a sensibilidade de Corynespora cassiicola e Colletotrichum spp. a fungicidas e caracterização de isolados de Colletotrichum spp. 2017. 101f. Tese (Doutorado em Agronomia) Centro de Ciências Agrárias, Universidade Estadual de Londrina, Londrina, 2017.

VARGAS, A. et al. Characterization of Phytophthora infestans populations in Colombia: First report of the A2 mating type. Phytopathology, Saint Paul, v. 99, n. 01, p. 82-88, 2009.

VARTANIAN, V.G.; ENDO, R. M. Survival of Phytophthora infestans in seeds extracted from infected tomato fruits. Phytopathology, Saint Paul, v. 75, n. 03, p. 375-378, 1985. 
VEGA, B. et al. A rapid resazurin-based microtiter assay to evaluate Qoi sensitivity for alternaria alternata isolates and their molecular characterization. Plant Disease, Saint Paul, v. 96, n. 09, p. 1262-1270, 2012.

VEGA-SANCHEZ, M. E. et al. Host adaptation to potato and tomato within the US-1 clonal lineage of Phytophthora infestans in Uganda and Kenya. Plant Pathology, v. 49, n. 05, p. 531- 539, 2000.

VIGNA, B.B.Z. et al. New microsatellite markers developed from Urochloa humidicola (Poaceae) and cross amplification in different Urochloa species. BMC Research Notes, v. 4, p. 523, 2011.

WALE, S.; PLATT, H. W.; CATTLIN, N. Disease pests and disorders of potatoes. A Color Handbook. Amsterdam: Elsevier, 2008. 179 p.

WANG, J. et al. High levels of diversity and population structure in the potato late blight pathogen at the Mexico centre of origin. Molecular Ecology, v. 26, n. 04, p. 1091-1107, 2017.

WANG, Z. et al. Development of an improved isolation approach and simple sequence repeat markers to characterize Phytophtora capsici populations in irrigation ponds in Southern Georgia. Applied Environmental Microbiology, v. 75, n. 17, p. 5467-5473, 2009.

WANG, X. W.; HAN, M.; GUO, L. Y. Comparison of molecular markers in mating type determination of Phytophthora infestans. Mycosystema, Beijing, v. 35, n. 12, p. 1535-1546, 2016.

WATANABE, E. Y. Produtividade de um clone de batata submetido às adubações mineral e orgânica. 73 p. Dissertação (Mestrado em Ciências, Área de concentração: Fitotecnia) - Escola Superior de Agricultura "Luiz de Queiroz", Piracicaba, 2013.

WERE, H. K. et al. Occurrence and distribution of potato pests and diseases in Kenya. Potato Research, v. 56, n. 04, p. 325-42, 2013.

WERNER, S. et al. Chitin synthesis during in planta growth and asexual propagation of the cellulosic oomycete and obligate biotrophic grapevine pathogen Plasmopara viticola. FEMS Microbiology Letters, United Kingdom, v. 208, n. 2, p. 169-173, 2002. 
WIDMARK, A. K. et al. Phythophthora infestans in a single field in southwest Sweden early in spring: symptoms, spatial distribution on genotypic variation. Plant Pathology, v. 56, n. 04, p. 573-579, 2007.

YOSHIDA, K. et al. 2013. The rise and fall of the Phytophthora infestans lineage that triggered the Irish potato famine. eLife, Cambridge, 2013. doi: 10.7554/eLife.00731.

ZHANG, X. et al. An integrated BAC and genome sequence physical map of Phytophthora sojae. Molecular Plant-Microbe Interactions, v. 19, n. 12, p. 1302-1310, 2006.

ZHU, W. et al. Increased frequency of self-fertile isolates in Phytophthora infestans may attribute to their higher fitness relative to the A1 isolates. Scientific Reports, v. 6, n. 29428, p. 1-10, 2016. 
8. ANEXOS 
Anexo 1. Lista de alelos e tamanhos de produtos dos 12 marcadores usados pelo para o estudo molecular por microssatélite (SSR) de acordo com o consórcio EuroBlight.

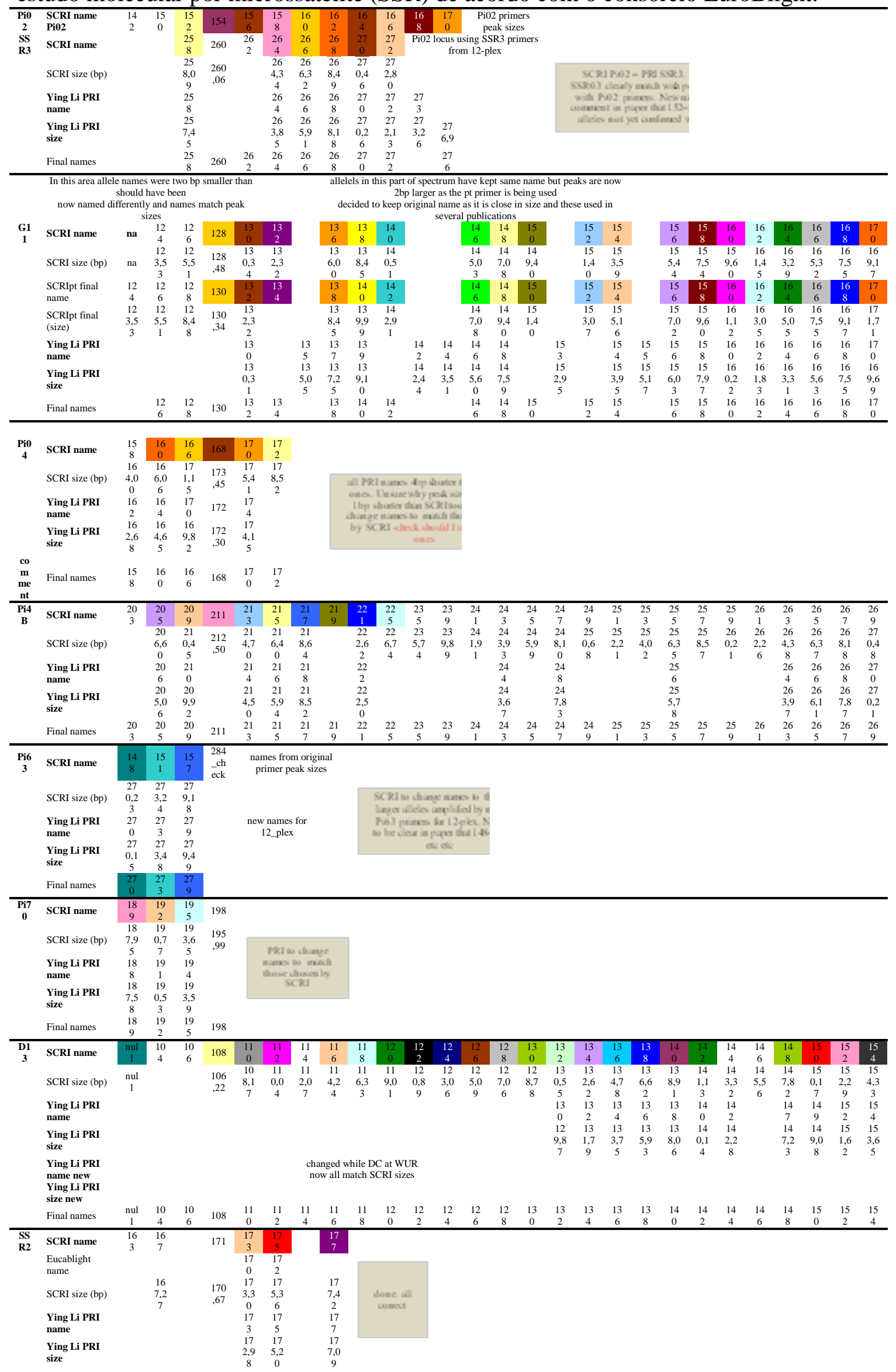




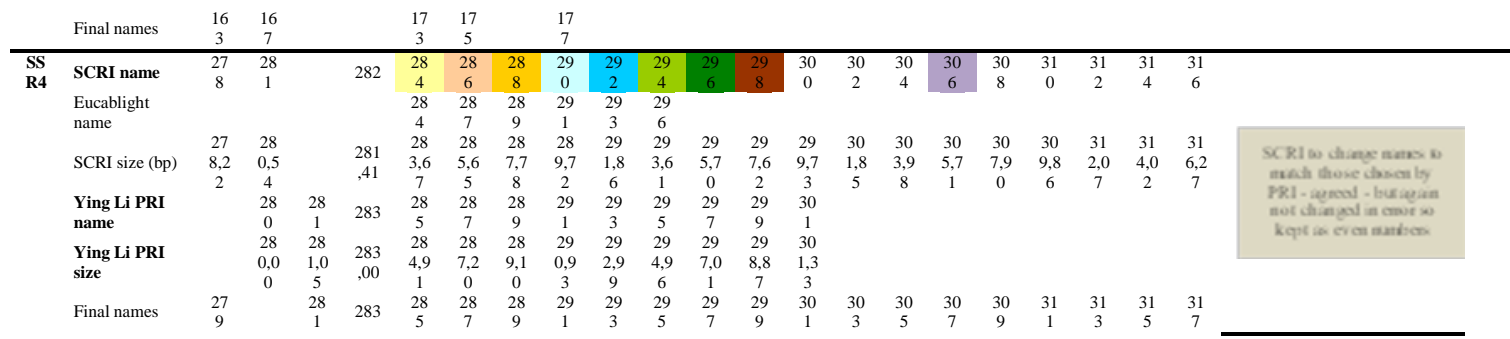




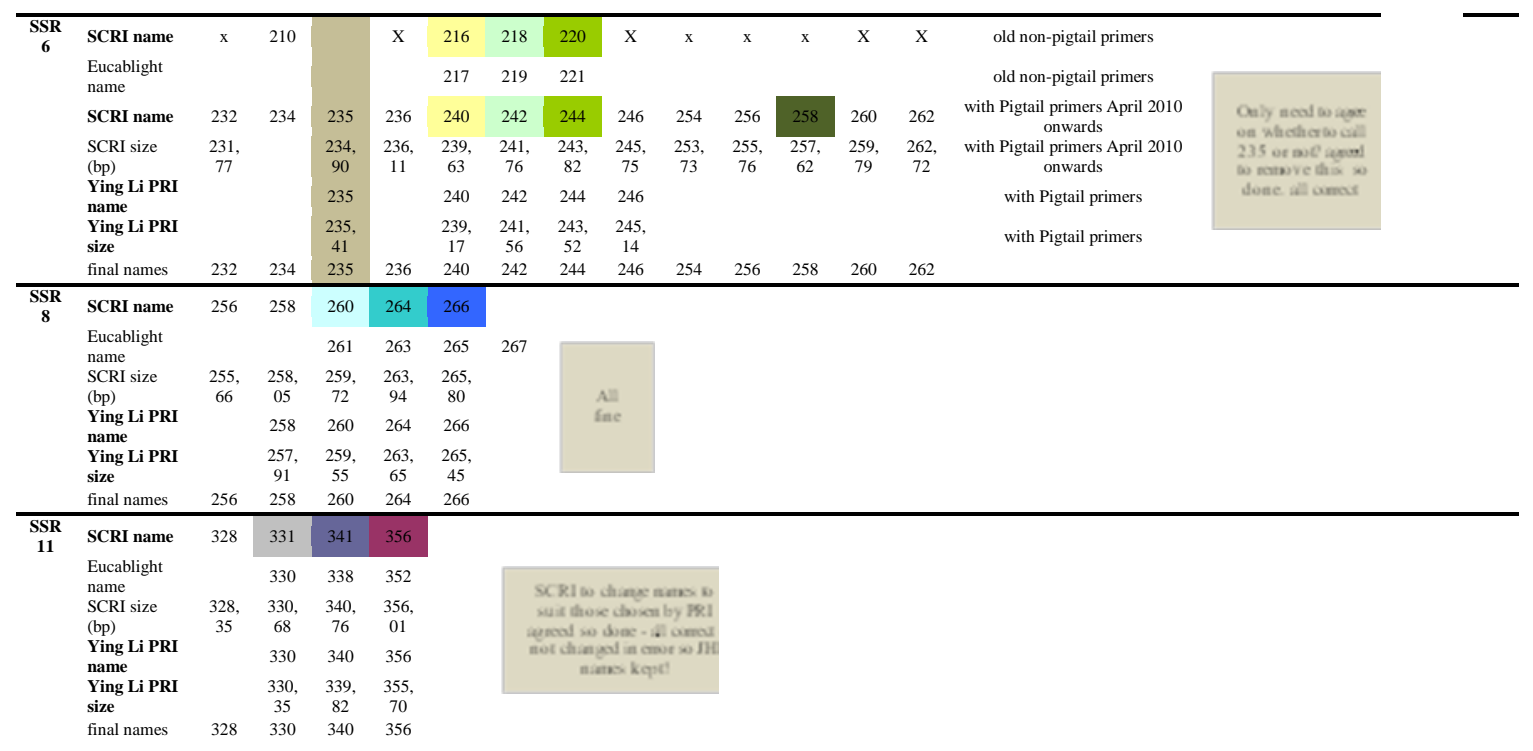


Anexo 2. Continuação da lista de alelos e tamanhos de produtos dos 12 marcadores usados pelo para o estudo molecular por microssatélite (SSR)

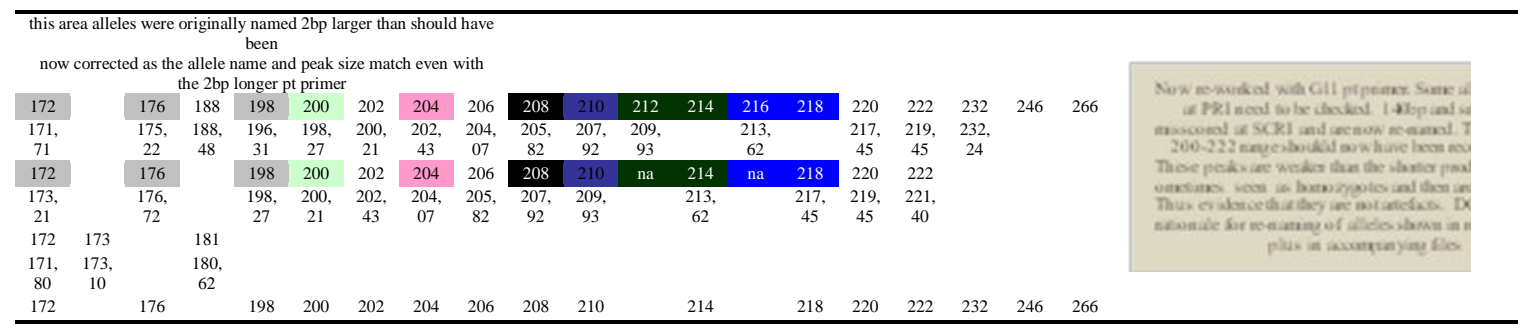

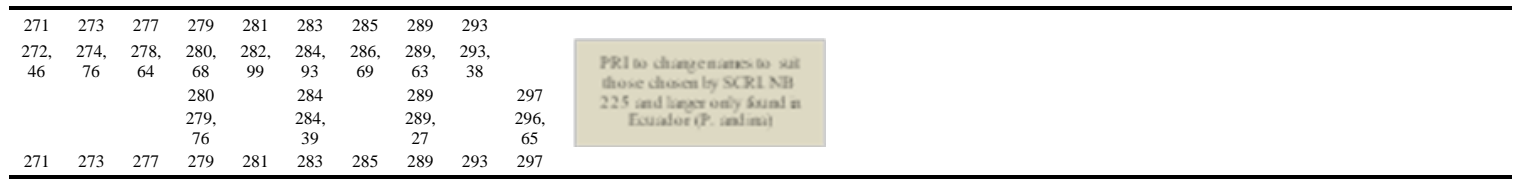

\begin{tabular}{|c|c|c|c|c|c|c|c|c|c|c|c|c|c|c|c|c|c|c|c|c|}
\hline 156 & 158 & 160 & 162 & 164 & 166 & 168 & 170 & 172 & 174 & 176 & 184 & 188 & 190 & 206 & 208 & 210 & 212 & 214 & 216 & \\
\hline $\begin{array}{c}156, \\
43 \\
156 \\
155, \\
91\end{array}$ & $\begin{array}{c}158, \\
64 \\
158 \\
157, \\
80\end{array}$ & $\begin{array}{c}160, \\
59\end{array}$ & $\begin{array}{c}162, \\
37\end{array}$ & $\begin{array}{l}164, \\
41\end{array}$ & $\begin{array}{c}166, \\
57\end{array}$ & $\begin{array}{c}168, \\
36\end{array}$ & $\begin{array}{c}170, \\
41\end{array}$ & $\begin{array}{c}172, \\
46\end{array}$ & $\begin{array}{c}174, \\
41\end{array}$ & $\begin{array}{c}176 \\
58\end{array}$ & $\begin{array}{c}185, \\
11\end{array}$ & $\begin{array}{c}188, \\
85\end{array}$ & $\begin{array}{c}190, \\
80\end{array}$ & $\begin{array}{c}206, \\
65\end{array}$ & $\begin{array}{c}208, \\
69\end{array}$ & $\begin{array}{c}210, \\
78\end{array}$ & $\begin{array}{c}212, \\
71\end{array}$ & $\begin{array}{c}214 \\
73\end{array}$ & $\begin{array}{c}217, \\
00\end{array}$ & 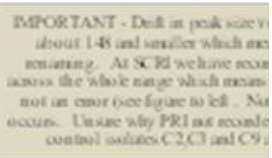 \\
\hline 156 & 158 & 160 & 162 & 164 & 166 & 168 & 170 & 172 & 174 & 176 & 184 & 188 & 190 & 206 & 208 & 210 & & & 216 & \\
\hline
\end{tabular}

